Strategic Environmental Research and Development Program

\title{
Quick Prediction of Future Training/Testing Opportunities Using mLEAM
}

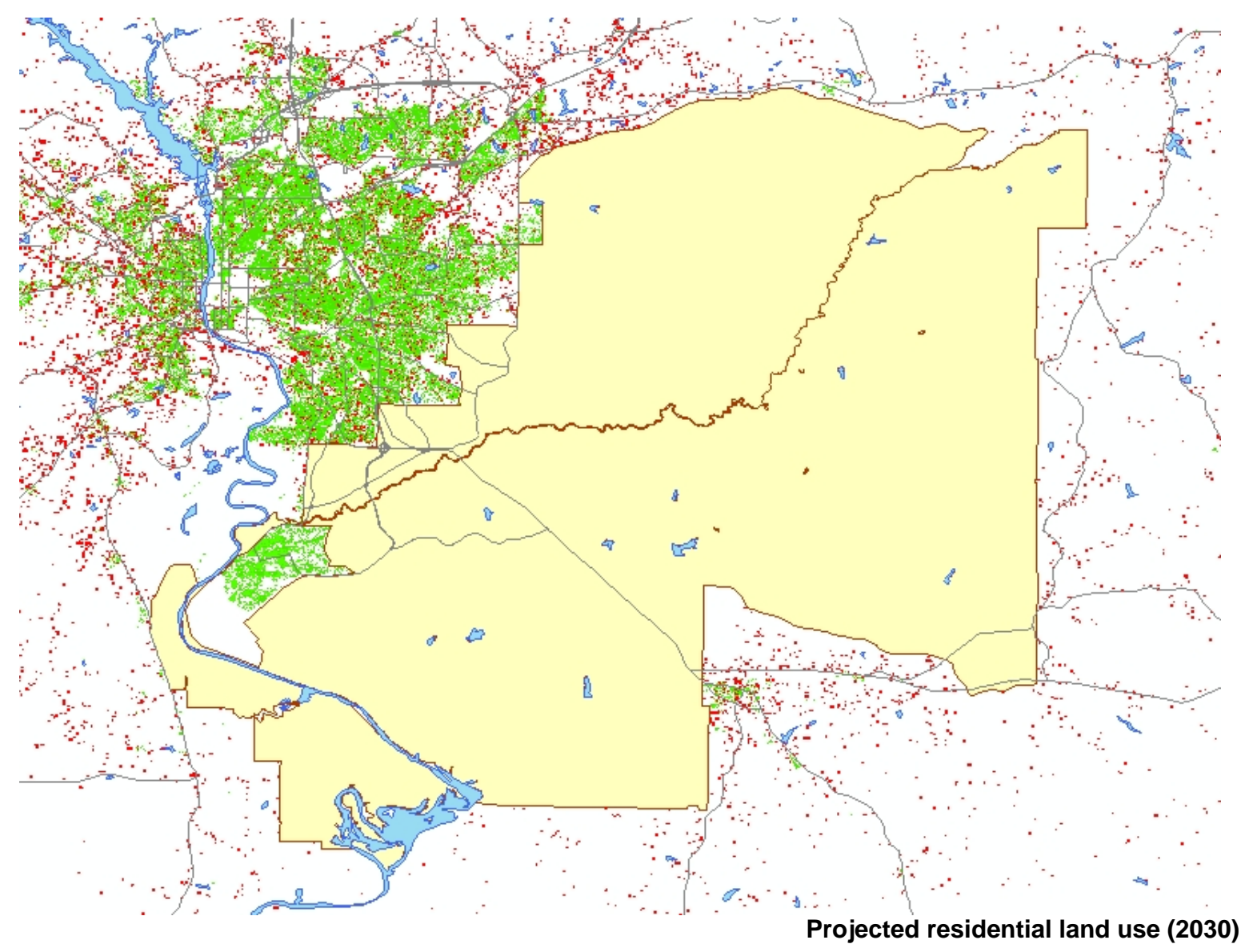





\section{Quick Prediction of Future Training/Testing Opportunities Using mLEAM}

James Westervelt and Bruce MacAllister

Construction Engineering Research Laboratory (CERL)

U.S. Army Engineer Research and Development Center

2902 Newmark Dr.

Champaign, IL 61824

Final Report

Approved for public release; distribution is unlimited.

Prepared for U.S. Army Corps of Engineers

Washington, DC 20314-1000 


\begin{abstract}
Urban development around many installations threatens the ability to provide realistic military training to the soldiers of the U.S. Army and adequate testing for future weapon systems. Regional planning can alter the patterns of future development around installations. The Engineer Research and Development Center, Construction Engineering Research Laboratory (ERDC-CERL) has developed the military Landuse Evolution Assessment Model (mLEAM) suite of software tools to allow for the rapid and inexpensive testing of the impact of alternative regional plans on the future training and testing opportunities of nearby installations. This report describes the mLEAM approach and documents the application of mLEAM to the counties surrounding Fort Benning, GA to provide Fort Benning with options to proactively mitigate conflicts between the Army and the growing civilian community surrounding the installation.
\end{abstract}

DISCLAIMER: The contents of this report are not to be used for advertising, publication, or promotional purposes. Citation of trade names does not constitute an official endorsement or approval of the use of such commercial products. All product names and trademarks cited are the property of their respective owners. The findings of this report are not to be construed as an official Department of the Army position unless so designated by other authorized documents. 


\section{Contents}

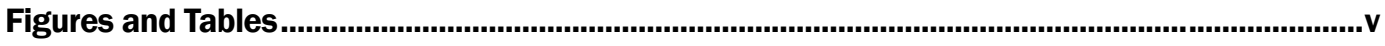

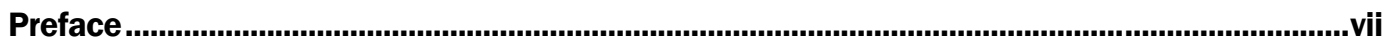

Unit Conversion Factors.........................................................................................................

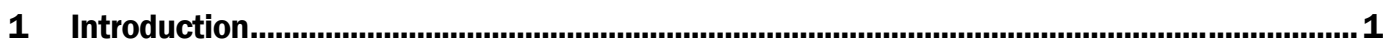

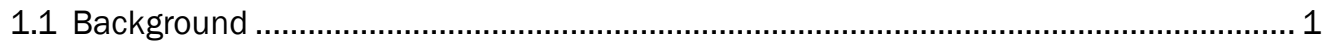

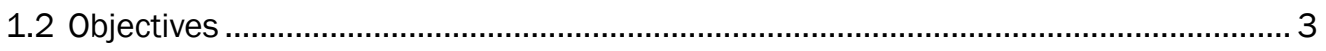

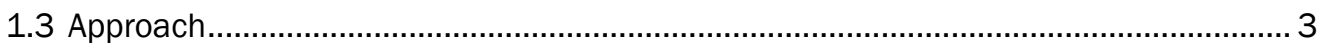

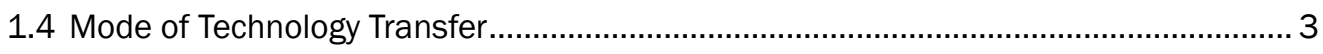

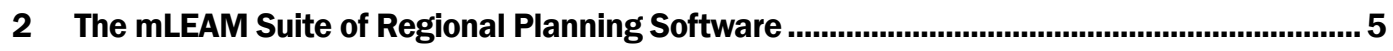

2.1 LEAMram - Residential Attractiveness Model ........................................................... 8

2.1.1 NLCD Datasets 9

$\begin{array}{ll}2.1 .2 & \text { Approach } \\ 2.1 .3 & 10\end{array}$

$\begin{array}{ll}2.1 .3 & \text { Implementation and Demonstration } \\ & 17\end{array}$

2.1.4 Caveats 22

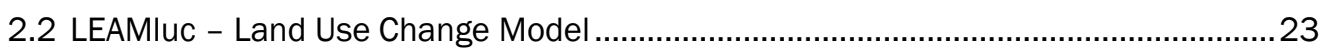

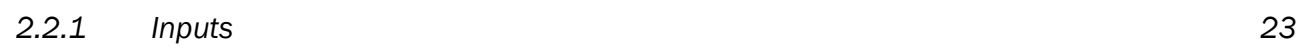

$\begin{array}{lll}\text { 2.2.2 Outputs } & 23\end{array}$

$\begin{array}{lll}2.2 .3 & \text { Approach } & 24\end{array}$

2.2.4 Comparison with LEAM $\quad 24$

2.2.5 Caveats 25

2.3 LEAMtom - Training Opportunities Models .............................................................26

2.3.1 Approach 26

2.3.2 Comparison with Other Models $\quad 27$

$\begin{array}{lll}2.3 .3 & \text { Caveats } & 28\end{array}$

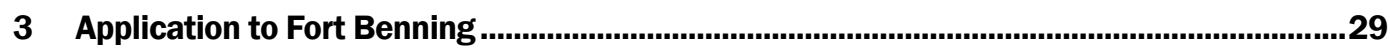

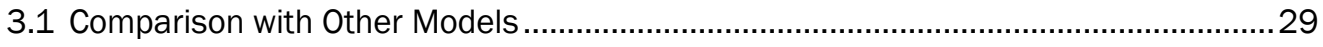

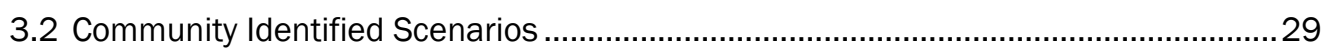

3.2.1 Interstate 14 around Fort Benning Scenario $\quad 30$

3.2.2 Interstate 14 through Fort Benning Scenario 31

3.2.3 Expansion of US431 Scenario 31

3.2.4 US431, State Highway 165 Connector Scenario 31

3.2.5 No-Development Buffer Scenario 33

3.2.6 New Sewer and Water Utility Lines Scenario $\quad 34$

3.2.7 New Tourism and Industry Scenario $\quad 34$

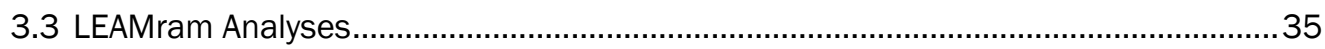

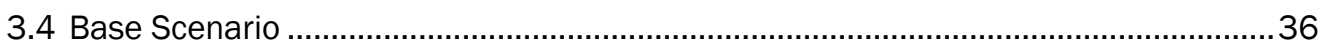

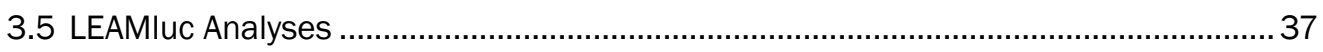

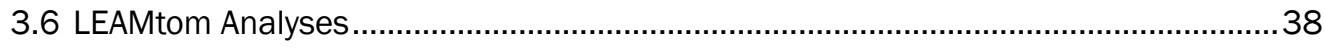

3.7 Analysis of the Scenarios................................................................................ 44 
3.8 Discussion of Annoyance Tolerance Contours...........................................................48

3.9 Internet Presentation of Results ........................................................................ 49

4 Conclusions and Recommendations ..............................................................................53

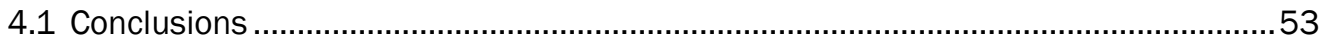

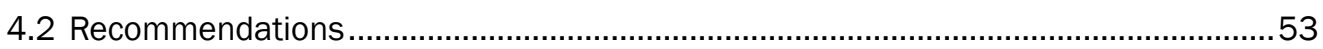

References.................................................................................................................................54

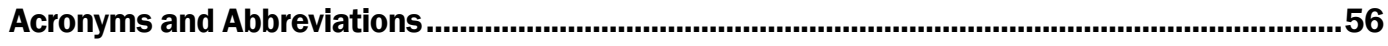

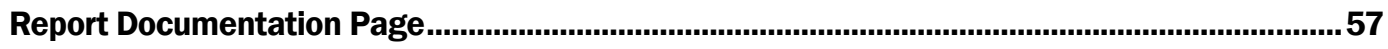




\section{Figures and Tables}

\section{Figures}

1 Past trends are not necessarily good at predicting the future........................................ 7

2 Example map for land uses, as presented in the 1992 NLCD ...................................10

3 Gross steps for generating a regional residential attractiveness map ..........................12

4 Sample urban pattern map .......................................................................................14

5 Results of passing the urban pattern map through a distance-weighted

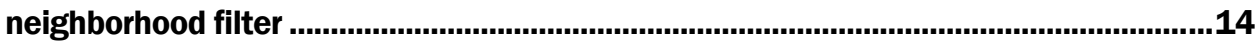

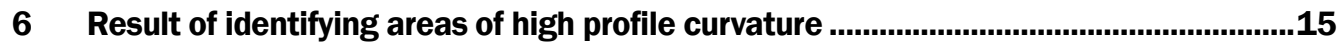

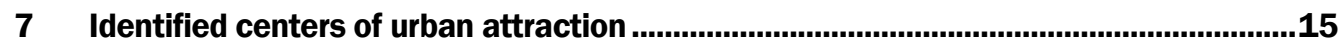

8 Result of automated location of residential centers..................................................18

9 Automatic identification of interstate ramps and generation of driving time to ramps.............................................................................................................................18

10 Relationship between driving time to ramps and percent residential .........................19

11 Probability of residential based on driving time to ramps ......................................19

12 Relationship of residential attractiveness to percent residential...................................21

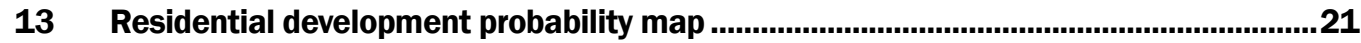

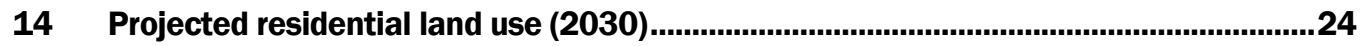

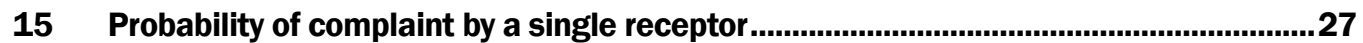

16 I14_around scenario showing Interstate 14 as it may look in the future

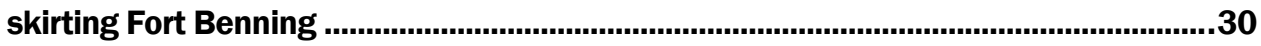

17 114_thru scenario shows Interstate 14 running through the installation ....................31

18 US431 scenario models effects from improvement of this U.S. highway.....................32

19 US431_SR165 scenario examines effects of a connector between these two

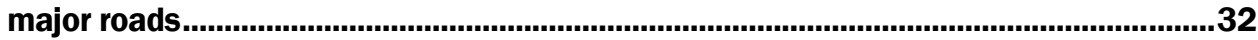

20 No-development buffer scenario looks at fictitious no-growth areas...........................33

21 new_utilities scenario; Blue areas indicate where water and sewer lines have been laid in anticipation of growth south and east of Fort Benning ..........................34

22 New industry scenario models effects of new industrial and tourism areas

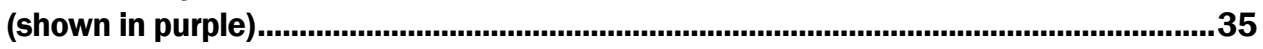

23 Residential Attractiveness map for Base Scenario ........................................................36

24 Projected urban residential growth near Fort Benning (before to left; after to right)

25 Detail of projected urban residential growth near north edge of Fort Benning (before at top; after at bottom)

26 Potential noise complaints from artillery training 
27 Potential complaints from tracked vehicle training ....................................................41

28 Potential complaints from C-130 aircraft...................................................................42

29 Potential complaints from a helicopter training exercise ..........................................42

30 Potential noise complaints from an F-22 training above Fort Benning .......................42

31 Potential number of dust complaints from tracked vehicles .........................................44

32 Night training opportunities; black cells are areas of low light pollution compatible with Army night vision goggle training ...................................................44

33 Comparison of 2030 maps for all modeled scenarios ...................................................45

34 Introduction page to mLEAM results..........................................................................50

35 Benning “scenarioBase" results..........................................................................50

\section{Tables}

1 Correlation of attractors to residential ...................................................................20

2 Analysis of training land available by training disturbance and scenario ....................46

3 Analysis of potential losses of training lands on Fort Benning by 2030....................47

4 Temporary maps that can be useful for further analysis..............................................51 


\section{Preface}

This study was conducted for the Strategic Environmental Research and Development Program (SERDP) under Sustainable Installations Projects (Natural Resource Management/Land management and Watershed protection) as Project SI-1257, "The Evolving Urban Community and Military Installations: A Dynamic Spatial Decision Support System for Sustainable Military Communities." The technical monitor was John Hall, SERDP.

The work was performed jointly by the Ecological Processes Branch (CN$\mathrm{N})$ of the Installations Division (CN), Construction Engineering Research Laboratory (CERL). The CERL Principal Investigator was Dr. James Westervelt. Alan B. Anderson is Chief, CEERD-CN-N, and Dr. John T. Bandy is Chief, CEERD-CN. The Director of ERDC-CERL is Dr. Ilker R. Adiguzel.

CERL is an element of the U.S. Army Engineer Research and Development Center (ERDC), U.S. Army Corps of Engineers. The Commander and Executive Director of ERDC is COL Richard B. Jenkins, and the Director of ERDC is Dr. James R. Houston. 


\section{Unit Conversion Factors}

\begin{tabular}{|c|c|c|}
\hline Multiply & By & To Obtain \\
\hline acres & $4,046.873$ & square meters \\
\hline cubic feet & 0.02831685 & cubic meters \\
\hline cubic inches & 1.6387064 E-05 & cubic meters \\
\hline cubic yards & 0.7645549 & cubic meters \\
\hline degrees (angle) & 0.01745329 & radians \\
\hline degrees Fahrenheit & $(F-32) / 1.8$ & degrees Celsius \\
\hline feet & 0.3048 & meters \\
\hline gallons (U.S. liquid) & 3.785412 E-03 & cubic meters \\
\hline horsepower (550 foot-pounds force per second) & 745.6999 & watts \\
\hline inches & 0.0254 & meters \\
\hline inch-pounds (force) & 0.1129848 & Newton meters \\
\hline ounces (mass) & 0.02834952 & kilograms \\
\hline ounces (U.S. fluid) & $2.957353 \mathrm{E}-05$ & cubic meters \\
\hline pints (U.S. liquid) & 4.73176 E-04 & cubic meters \\
\hline pints (U.S. liquid) & 0.473176 & liters \\
\hline quarts (U.S. liquid) & $9.463529 \mathrm{E}-04$ & cubic meters \\
\hline square feet & 0.09290304 & square meters \\
\hline square inches & 6.4516 E-04 & square meters \\
\hline square miles & $2.589998 \mathrm{E}+06$ & square meters \\
\hline square yards & 0.8361274 & square meters \\
\hline tons (long) per cubic yard & $1,328.939$ & kilograms per cubic meter \\
\hline yards & 0.9144 & meters \\
\hline
\end{tabular}




\section{Introduction}

\subsection{Background}

The creation and development of military installations and their associated training and testing facilities represents a substantial national investment. It is important - cost effective- to maintain this investment so the society can enjoy its benefits far into the future. However, a growing number of military installations face constraints on mission activities due to land use changes near their boundaries. Growing patterns of development surrounding military installations can slowly erode the installations' ability to perform their current and future training/testing missions. Changes such as urbanization can create problems between civilian and military interests. Civilian community commonly voice concerns about limiting noise, dust, and traffic associated with military activities. Military trainers, on the other hand, express concerns about civilian activities that affect their mission, e.g., radio interference, light interference with night training, and other issues.

Such concerns, sometimes termed "encroachment," can cause installation trainers to decrease military mission activities. The Defense Senior Readiness Oversight Committee defines "encroachment" as "any outside activity, law or pressure that affects the ability of military forces to perform the mission assigned to the installations." Military installations are increasingly asked to alter activities within their boundaries to alleviate conflicts between military activities and activities "outside the fence." Flight routes may be restricted, firing operations limited, firing ranges eliminated, etc. Such operational restrictions can limit installations' abilities to meet vital mission requirements.

Fort Benning, GA is one such installation facing constraints on missionrelated activities due to urban encroachment around its boarders. The growing presence of civilian concerns increases pressure on the installation trainers to modify military mission activities within the installation boundaries. Since Fort Benning is being increasingly pressured to alter training activities, it has become clear there is a need to better define the trend of development, project that trend to the immediate future and identify key opportunities for preserving those lands currently available to train and test the soldiers of the future. These efforts will most effectively minimize future impacts on its training and readiness mission. 
Military and civilian planners can cooperate in anticipating (and planning) future land use patterns and in devising appropriate mitigation strategies to avoid or otherwise deal with potential conflicts before they occur. In planning, problem avoidance is usually much less expensive and more effective than mitigation after the fact. There is a critical need to develop regional plans that identify and consider the future of installation training and testing activities, and anticipate restrictions to those activities that may result from nearby urban growth.

Fort Benning's training and testing missions can be evaluated from the perspective of:

- blast noise and small arms noise

- training/testing generation of smoke and dust

- generation of Radio Frequency (RF) interference to commercial television and radio

- urban night lights impacting night training exercises.

To deal with these issues effectively, installation planners must establish three "trajectories of change":

1. Clearly identify regional planning options and opportunities in areas surrounding the military reservation

2. For those option, project future growth and change

3. From those projections, identify where on the installation trainers will be able to conduct training exercises with minimal risk of disturbing the civilian population beyond the installation boundary.

The U.S. Army Engineer Research and Development Center, Construction Engineering Research Laboratory (ERDC-CERL), Champaign, IL has engaged in several research projects to develop and apply tools for land-use risk assessment, and has developed an approach that illustrates future changes in land use around an installation. This approach uses the military Land Evolution and Assessment Model (mLEAM $\left.{ }^{\mathrm{TM}}\right)$ to help evaluate how alternative regional policies and land ownership patterns affect future land development and military training and testing opportunities. The mLEAM $^{\mathrm{TM}}$ software is a powerful tool that projects changing conditions around installations, rapidly and cost-effectively providing a visual (mapbased) presentation that clearly conveys the potential for land-use conflicts as the separation between military lands and the neighboring community disappears. 


\subsection{Objectives}

The overall objectives of this work were to help minimize future impacts of civilian urban development on the training and readiness mission of Fort Benning. Specific objectives were to develop a tool that can quickly and cost-effectively:

1. Define the present state of development surrounding Fort Benning

2. Project that trend to the immediate future

3. Identify areas within the installation boundary with a potential to receive an increased number complaints about military training activities at that future point in time.

\subsection{Approach}

This work obtained and examined current land use information and used that information to model future trends in development around Fort Benning. (National Land Cover Data land use maps, current and future highway system plans, and municipal zoning information all contributed to forecasting residential and commercial development.) The data resulting from this modeling effort was then used to predict the best areas to train on Fort Benning that will minimize the risk of complaint from civilian communities outside the installation boundary, in the following steps:

1. GIS (geographic information system) map layers were used to analyze land use and growth in the region.

2. These GIS layers were used as input to the mLEAM residential attractiveness model (LEAMram).

3. The output from LEAMram was then used as input for the LEAM land use change (LEAMluc) model to project urban growth around Fort Benning into the future.

4. These consolidated results were then analyzed to identify remaining suitable lands for training/testing using the LEAM training opportunities model (LEAMtom).

\subsection{Mode of Technology Transfer}

The results of this study will be made available to project sponsors and may be leveraged with other appropriate simulation technologies, as well as assessment and planning environments to aid Directorate of Base Operation Support (DBOS), trainers and installation commanders in the decisionmaking process. 
Future projections in the form of maps of urban development surrounding Fort Benning have been created by the LEAMluc model and are accessible online at http://earth.cecer.army.mil/FF

This report will also be made accessible through the World Wide Web (WWW) at URL: http://www.cecer.army.mil 


\section{The mLEAM Suite of Regional Planning Software}

The military Land Evolution and Assessment Model (mLEAM ${ }^{\mathrm{TM}}$ ) is comprised of a suite of related models to help evaluate how alternative regional policies and land ownership patterns affect future land development and military training and testing opportunities. The software is designed help minimize future land use conflicts between military installations and nearby residential/business areas that result from urban development near military training and testing activities.

Previous efforts have taken approaches that are enhanced by technology, but rely largely on paper maps (Timlin 2002). Several advances have occurred that now make possible a more defensible illustration of developmental growth. Significantly, data are much more standardized, and may be shared and manipulated more easily.

To assess potential future impacts on military readiness, we turned to one primary data source: the National Land Cover Data (NLCD), which became the backbone of the mLEAM simulations. We were interested in those land use types that have the potential to affect military missions; specifically, residential land uses, as these most often generate incompatibilities with military operations (most often due to the generation of noise, fugitive dust and light trespass from within the boundaries of the installation).

Installations like Fort Benning routinely produce high intensity noise levels by firing artillery and small arms, conducting armor training, flying fixed and rotary wing aircraft, and detonating high explosives. These sound levels are intrinsic to the operation of the weapons systems vital to Fort Benning's national defense mission, and a necessary component of the training received by soldiers, who must learn to function in environments similar those they may encounter in actual combat situations. Unfortunately, these high noise levels reach beyond the installation with the potential to disturb civilians not participating in these training activities and set up a situation of incompatible land use between the Army and its neighbors. 
Various techniques have been developed to predict the future patterns of these incompatible land uses around military installations, ranging from simple questionnaires answered by installation personnel to the development of complex spatially explicit dynamic simulation models. Perhaps the most common approach for predicting the potential for future incompatible land use involves a technique similar to that constituting phase one of this project, i.e., using current and historic digital land use maps to determine how the trend is likely to proceed in the future. By counting the cells deemed to be "urban" in these areas over the time-series of maps, one can create a simple graph of time vs. total amount of urbanized area (Lozar 2005).

These simple trends can be very useful and are often sufficient to predict future trends. The extrapolation of past trends can be misleading, however (Figure 1). Growth might continue to accelerate in situations where there is still plenty of land available for development and where the fringe of a major urbanized area is entering the area of interest. Growth may be moderate if an urbanized center is already in the area and growing along the edge of an installation. It might decelerate if the there is little or no more land available to develop or for unforeseen economic reasons. To better account for such uncertainties, a more careful analysis of the spatial relationships of growing urban centers, available land, natural (e.g., rivers) or man-made barriers (e.g., limited access highways), and zoning can help predict future potentials for incompatible land use situations.

Many land use change models have been developed and are being used to test alternative land use policies with respect to their impact on future land patterns in and around cities and towns (EPA 2000). The Corps of Engineers is adopting the Land Evolution and Assessment Model (LEAM) to help evaluate how alternative regional policies and land ownership patterns affect future land development. The primary interest is to help minimize future land use conflict resulting from the development of new uses in areas that are and will be impacted by military training and testing activities. All of these good models tend to be expensive to develop and run; consulting firms may charge $\$ 500 \mathrm{~K}$ or more to develop, test, and apply a regional model that generates future land use scenarios in response to proposed regional plans. 


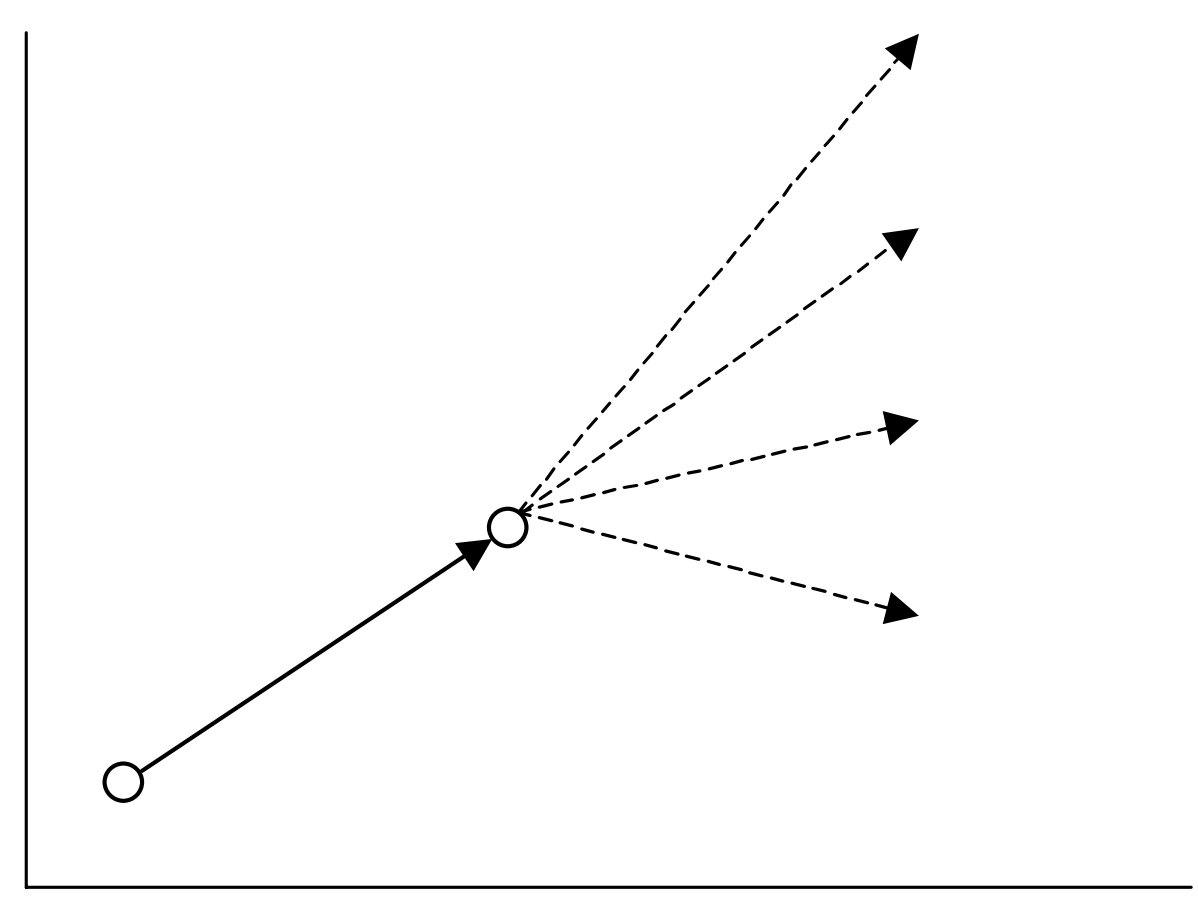

Figure 1. Past trends are not necessarily good at predicting the future.

The mLEAM approach described here to predict future development around Fort Benning represents a compromise between expensive, "data hungry" dynamic simulation models and the simplistic linear progression that relies solely on historic trends. This effort is part of the larger LEAM effort that includes the development of a simulation model to project future landscape settlement patterns. Components of mLEAM include the residential attractiveness model (LEAMram), the LEAM land use change (LEAMluc) model, and the LEAM training opportunities model (LEAMtom). The use of these models offers a somewhat crude, but useful, predictor of the impact of proposed regional plans on future training and testing opportunities. The suite of models does not allow us to predict where growth will occur, but can help identify where growth is likely to occur.

The Landuse Evolution and impact Analysis Model, initially developed at the University of Illinois, Urbana-Champaign (Deal 2005), was further developed under the Strategic Environmental Research and Development Program (SERDP) project 1257. The LEAM approach involves running a series of meetings and charrettes that involve regional planning stakeholders across a set of counties, cities, and towns to develop a localized model of the regional urban growth that projects land use changes from undeveloped to developed residential, commercial, and urban park land. A location specific model is developed and calibrated that captures local con- 
cerns, situations, and drivers of urban development. The full application of LEAM can require many months of effort.

A military version of LEAM was required that would allow the development of initial analyses of the impact of regional plans on future training/testing opportunities - often within the course of a day's effort. This report demonstrates the capabilities of the resulting suite of software called the military LEAM (mLEAM). This software allows a regional planning analyst to generate the impacts of a proposed set of regional plans on the opportunity of an installation to support training 30-50 years into the future-often within a day. The process involves primary steps:

1. Acquire and prepare nationally available data

2. Run the mLEAM software to generate "base" scenario results

3. Prepare maps for alternative regional planning scenarios and rerun mLEAM for each.

The acquisition and preparation of data involves Internet downloads of national land cover data (NLCD) from the United States Geological Survey (USGS), digital elevation models from various sources, roads and highways from the Census Bureau, and location of government lands (Westervelt, et al. 2004; Westervelt and Rank 2006). The process typically requires several hours for a trained GIS technician. The data is then loaded into the GRASS GIS software and it is processed in three phases to identify future training/testing restrictions. The first step, LEAMram (residential attractiveness model), identifies the relative attractiveness of land in the area for urban residential development (Westervelt and Rank 2006). This result is then fed to LEAMluc, the land use change model, which generates future land use patterns. Urban residential development evolves over a series of 50 steps in which the population grows at the rate of 1 percent of the original population in the region. This final result is then processed with the LEAMtom (training opportunities model) (Westervelt et al. 2006). These steps are explained in more detail through their application to Fort Benning.

\subsection{LEAMram - Residential Attractiveness Model}

LEAMram is the first step used for testing a regional plan for its long-term impacts on training and testing opportunities. Using readily available national GIS map data, LEAMram generates a map showing the apparent attractiveness of land for conversion to urban residential areas based on analyses of current local patterns. The key landuse map is the national 
land cover data (NLCD), but is supported with road/highway maps, digital elevation models, and maps identifying no-growth areas such as government lands. The LEAMram final result is a map of attractiveness to urban growth, which is then used to evolve the NLCD map to project future urban residential patterns.

\subsubsection{NLCD Datasets}

The NLCD project came about due to the high cost of acquiring satellite images. In 1992, several Federal agencies agreed to operate as a consortium to appropriate satellite-based, remotely sensed data for their environmental monitoring programs. This group of agencies became known as the Multi-Resolution Land Characteristics Consortium (MRLC), which was responsible for the production of the NLCD dataset, data derived from images acquired by the Landsat Thematic Mapper ${ }^{\mathrm{TM}}$ sensors, as well as a number of ancillary data sources. Original members of the MRLC were the USGS, U.S. Environmental Protection Agency (USEPA), National Oceanic and Atmospheric Administration (NOAA), and the U.S. Forest Service (USFS). Later, the National Aeronautics and Space Administration (NASA) and the Bureau of Land Management (BLM) joined the consortium.

The NLCD includes the source images, and corresponding classifications of land-cover data for specific acquisition dates. This was the first national land-cover data set produced since the early 1970 s, effectively replacing older data sets, and has a finer resolution than the North American Landscape Characterization (NALC), at 30 meters. Data for the contiguous United States circa 1992, derived from Landsat-5 Thermal Mapper ${ }^{\mathrm{TM}}$ images (Figure 2), are complete for the entire country and are available for download via the World Wide Web (Kelly and White 1993; Cowardin et al. 1979; Vogelmann et al. 1998a, and b) through URL:

\section{http://landcover.usgs.gov/natllandcover.html}

The USGS is currently in the process of updating the National Land Cover Data using newly available satellite imagery. This project is ongoing, only certain portions of the United States are currently available. Unfortunately, the entire states of Georgia and Alabama have not been completed. Certain sections of the Fort Benning region have not yet been made available for download from the USGS. 


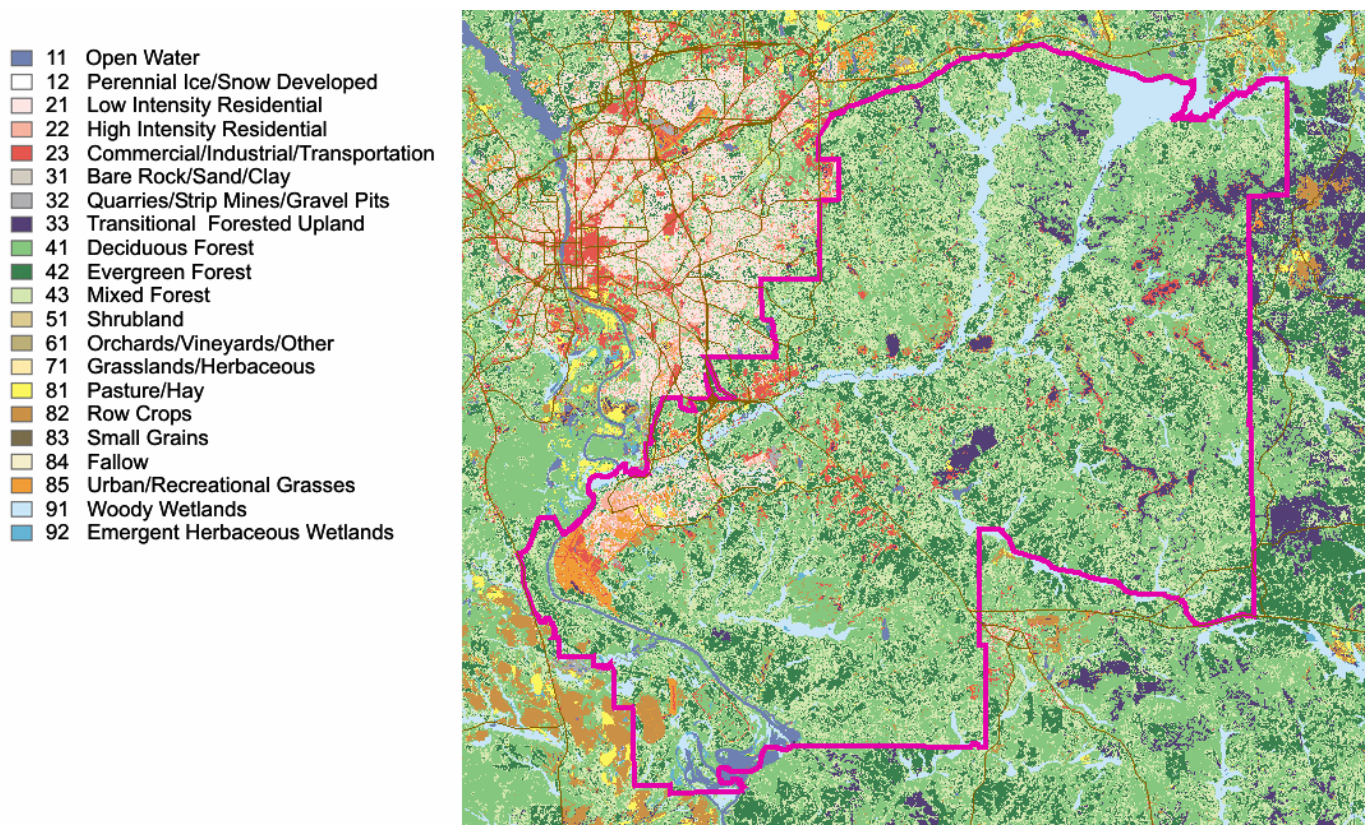

Figure 2. Example map for land uses, as presented in the 1992 NLCD.

\subsubsection{Approach}

The LEAMram goal is to generate residential attractiveness maps with as little human intervention and operation as possible using readily available national data sets. The fundamental approach is to employ hedonic modeling to establish relative attractiveness values for all locations within a study area. Hedonic modeling is essentially a regression approach (Equation 1) that identifies the relative importance of a list of independent variables considered important in setting the price or value of a property (Haas 1922; Wallace 1926; Court 1939).

$A=\sum_{i=1}^{n} C_{i} A_{i}$

where:

A - Overall attractiveness of a parcel to development

$\mathrm{Ai}$ - Attractiveness index of attractor $\mathrm{i}$

$\mathrm{Ci}$ - Coefficient for attractor i.

Hedonic modeling is often used in the real estate industry to identify the value of a house based on how the individual factors making up the interior of the house and its location contribute to its value (Sirmans, Macpherson, et al. 2005). Each aspect of a home and its surroundings imbue some level of pleasure (hedonism), which provides a common currency that allows for the summation of all of the characteristics. Translat- 
ing this into a willingness to pay yields a monetary value of the property. For this study the value of a house structure is ignored allowing a focus on the fundamental value or attractiveness of the land for urban residential development.

The number of characteristics of land parcels to consider can be large, but focusing on a relatively small number allows for efficiencies in evaluation. For this analysis, considerations include density of the surrounding neighborhood, distance to neighborhood forest and water, and driving times to commercial centers, interstates, intersections, state roads, and county roads.

There are two main steps in the analysis process:

1. Acquire nationally available data and resample into a common coordinate system

2. Process the data with GIS scripts to generate a residential development attractiveness map.

The first is accomplished with standard GIS technician skills, typically in less than a day's worth of work. The automated processing involves the development and analysis of various maps that identify the level of the various chosen hedonic attractors. The particular application of the process can involve as many attractors as desired, but the basic process is accomplished with the steps shown in Figure 3 .

All attractiveness maps are based on a single land cover map, typically the consistent set of 1993 NLCD. This analysis assumes that the displayed pattern of growth reflects the current attractiveness to urban development (as opposed to the LEAM approach, which requires identification of recent land use changes). The procedure begins by developing and processing a series of chosen attractor maps. These maps include driving or travel time to attractors such as businesses, roads, highways, intersections, interstates, water, and forest. The values are factual and must be converted into levels of attractiveness. That is, we want to identify how attractive a driving time of 10 minutes to work is compared with a 20 minute commute, a 30 minute commute, and so on.

Because human responses to the environment are often logarithmic in nature, as described by the Weber-Fechner law, the log of the attractor is calculated. A graph is then created relating the log of the attractor to the percent of the developable land already in residential development. 


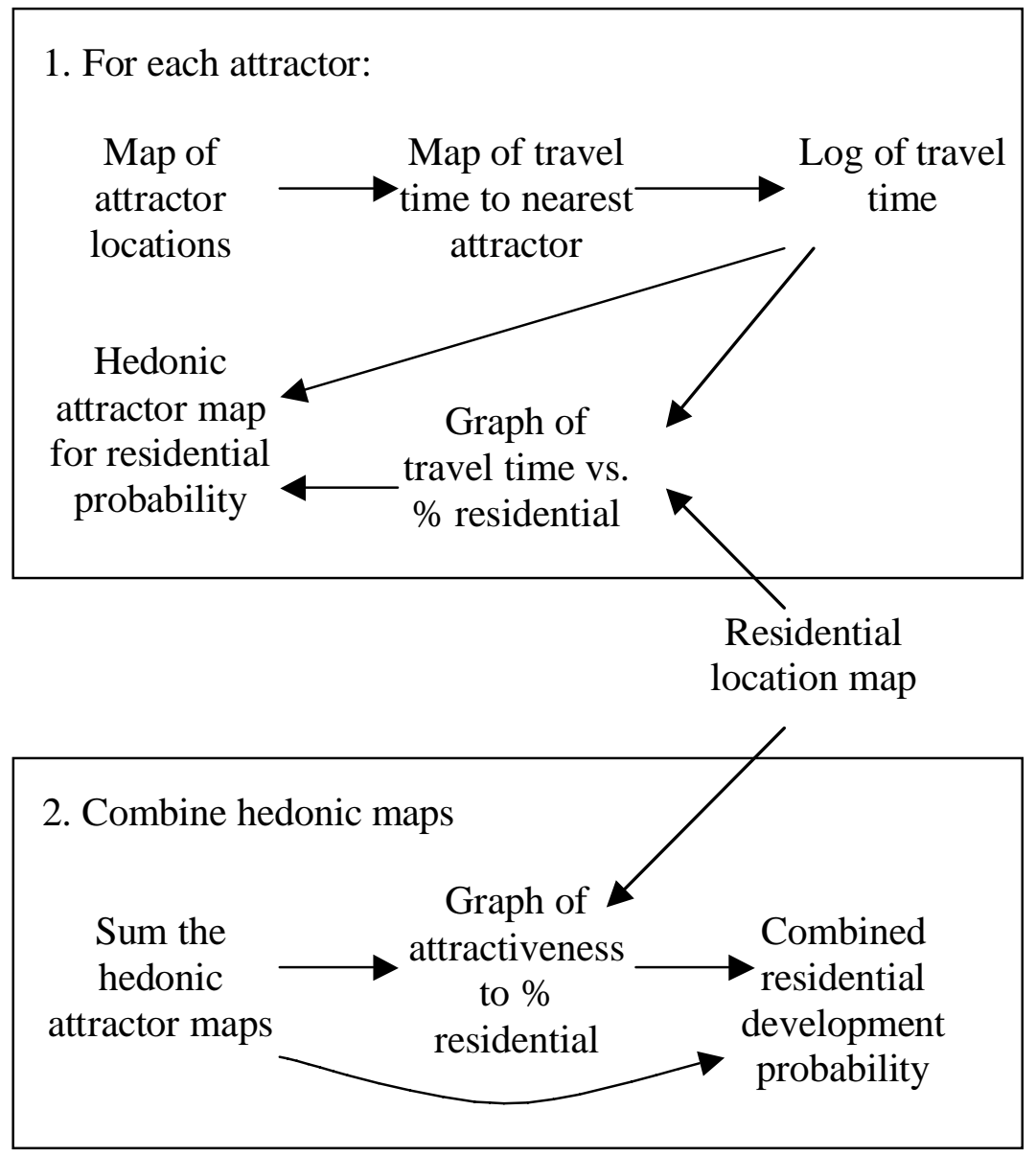

Figure 3. Gross steps for generating a regional residential attractiveness map.

This is accomplished by dividing the attractor log map range into 20 bins to create a clumped attractor map. A cross-tabulation of this and the residential location map is then made, which identifies what percent of developable areas are developed in each bin. The series of these values across the bins results in a graph (using the percent developed values and the midpoint of each attractor bin). This graph, linearly interpolated, is then applied to the map of attractor values to yield a map of the probability of development for every location. This process is repeated for each of the chosen attractors, which completes the top half of Figure 3.

Most of the attractors are readily derived from the raw data. These include roads, intersections, highway ramps, forest, and water. One of the most important attractors includes job and shopping locations. Ideally, the attractiveness value of every parcel should have a calculated effect on every other parcel, but the computational power necessary to accommodate such a calculation is prohibitive. Consider a raster GIS map of 1000 by 1000 cells. Such an area would require the generation and summing of one mil- 
lion maps - each identifying the attractiveness of one cell to all surrounding areas. Instead, a procedure is used to first rapidly identify locations representing centers of attractiveness, sort the center of those locations into four levels of attractiveness, and only compute the effect of these over the study area.

Our approach follows the following steps. In the first step we generate a map based on the NLCD map that gives low-density residential locations a value of 1 and high-density a value of 2 . Figure 4 shows residential areas of an area in our study site (northern part of Columbus, GA). This map is passed through an inverse-distance weighting neighborhood filter to generate a map showing the level of co-location of every location with surrounding urbanized areas (Figure 5). Running a profile curvature analysis identifies the peaks in this map. Concave areas are assigned positive values, whereas convex areas are assigned negative values. Those locations with a value above 0.01 are selected and capture the peaks in the map (black areas highlighted by white rings in Figure 6).

Each contiguous patch is given a distinct value and its centroid is identified. The location of the centroid is associated with the value of the inverse-distance weighted result and a raster GIS map is generated where this value is assigned to all cells within 90 meters of the centroid. This buffering helps ensure that the patch is co-located with a road, which provides the primary accessway to the site. These locations are divided into five value levels. The highest values are considered to be the highest set of city attractors and the lowest are discarded. The result is shown in Figure 7. The expanded centroids are circled with white rings for easier identification. The map is scaled so that the lighter areas are less attractive than those that are darker. The areas in black are the most attractive. These are then overlaid on the neighborhood density image to show that the results indeed capture the peaks in that map.

Driving times are then calculated, based on each of the four sets of attractor locations, for every location (grid cell) to the nearest attractor. The result is four maps giving driving times to the nearest location - one map for each set of attractors. These maps are then combined into one cityattractor map giving increasingly weighted preference from the set of low to high attractor maps. 


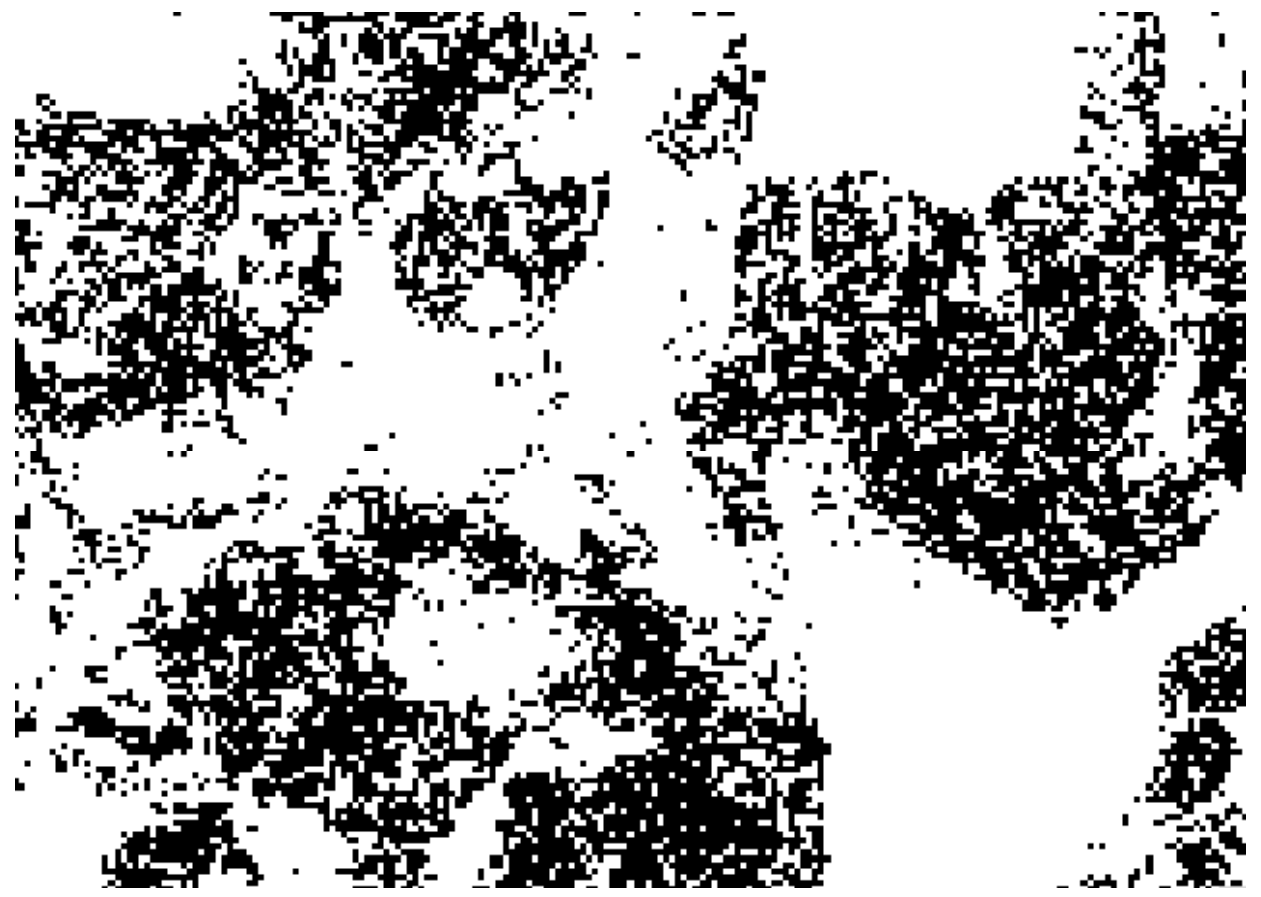

Figure 4. Sample urban pattern map.

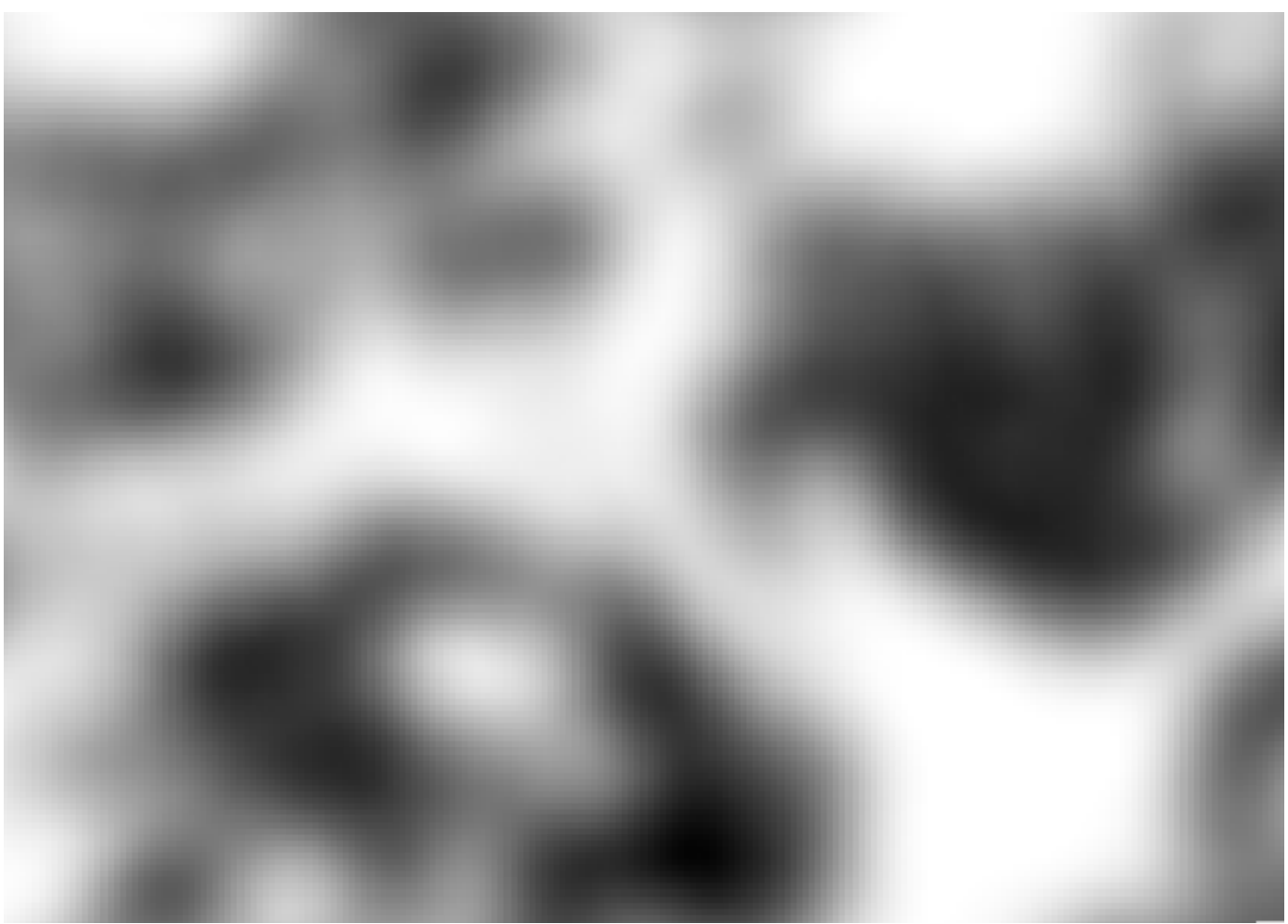

Figure 5. Results of passing the urban pattern map through a distanceweighted neighborhood filter. 


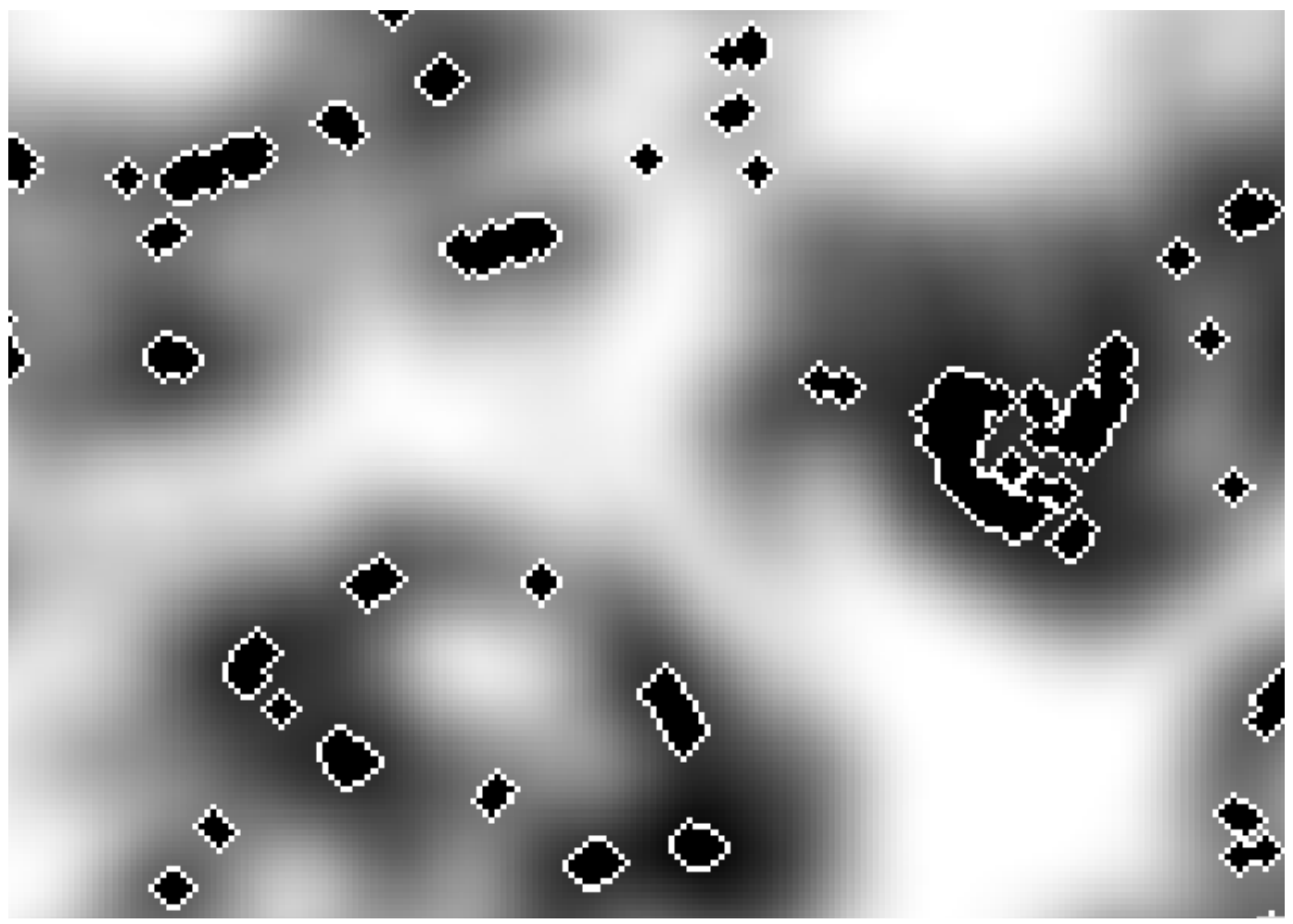

Figure 6. Result of identifying areas of high profile curvature.

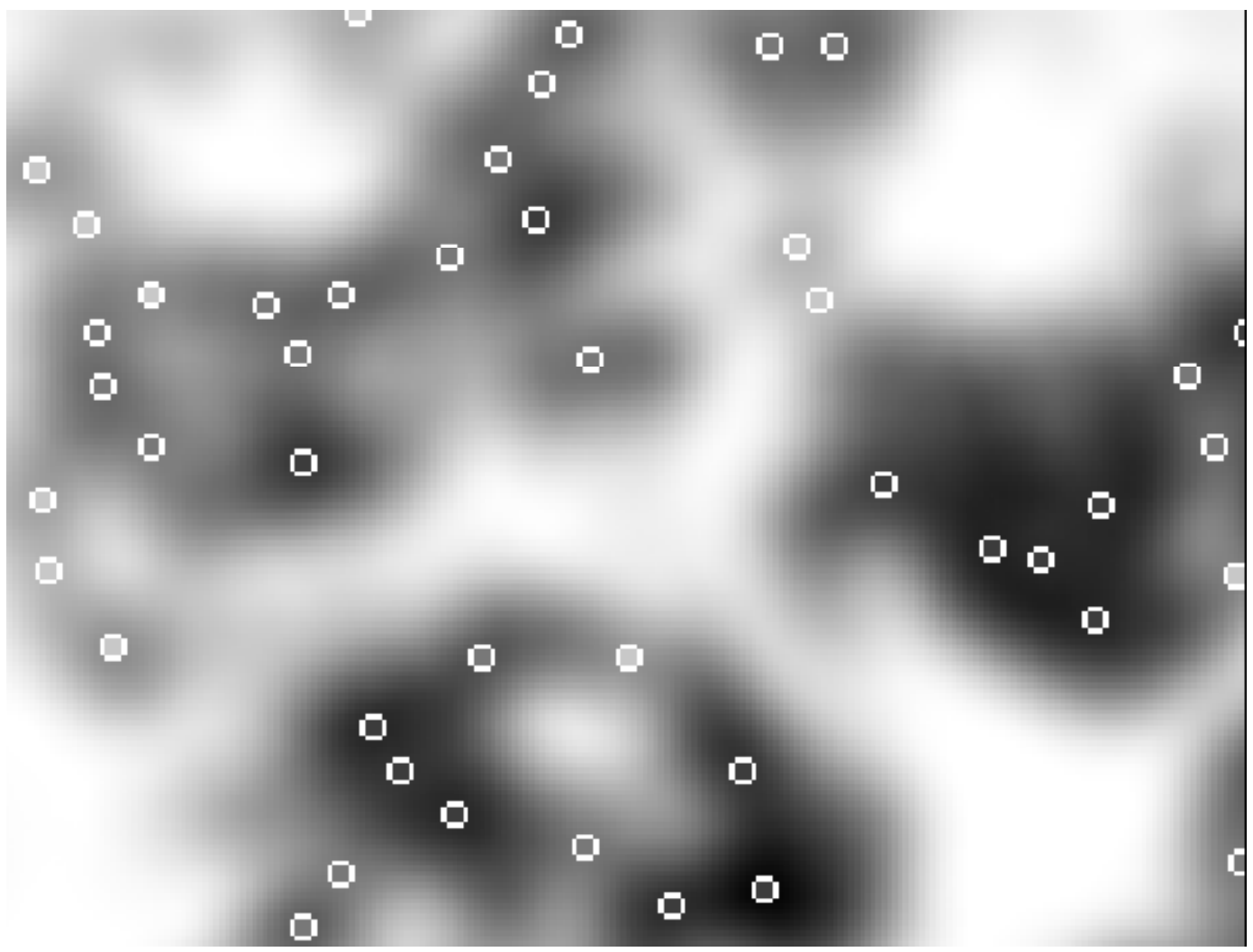

Figure 7. Identified centers of urban attraction. 
At this point a full set of hedonic attractor maps has been generated. These are then combined to create an overall attractor map for development. Equation 1 calls for coefficients for each attractor. One approach is to interview local people to acquire trade-off decisions that can be applied to collectively rate a set of attractors using approaches such as MultiAttribute Utility Theory (Schkade and Payne 1993), the Analytic Hierarchy Process (Saaty 1996), or the Contingent Valuation Method. These are intensive processes, requiring significant investments of time and money. Therefore, they do not satisfy our need for a quick and inexpensive approach. Another approach is to use a regression analysis to establish an equation with coefficients associated with each attractor that reflect the weight or importance of each attractor (Hosmer and Lemeshow 1989). This often begins by normalizing each attractor to a full range of 0-1. Attractors can be multiplied by one another in all combinations to generate further values for which weights can be generated, and this process can pick up the importance of attractors in combination. Unfortunately, it also requires the integration of the GIS with a statistics package and a technician's skills with both.

This approach begins not with normalizing the attractors, but instead by using the attractor values directly (Equation 2). The importance of each attractor is already captured in the map value variances. For example, an area that has lots of forest may not show that forest is a significant attractor to development; the probability of finding development at all distances from a forest will be about the same across the map. Such attractiveness values, when summed with other values affect the final sum less than more variable attractor values. The sum of all attractiveness values provides an overall attractiveness for each location. The result is a map of overall attractiveness for all locations.

$$
A=\sum_{i=1}^{n} A_{i}
$$

Eq. 2

where:

A - Overall attractiveness of a parcel to development $\mathrm{Ai}$ - Attractiveness index of attractor $\mathrm{i}$.

The resulting combined attractiveness maps are then evaluated in the same manner as each of the original individual attractiveness maps. That is, the combined map values are divided into 20 sub-ranges and then compared with the initial residential land use map (derived from the 
NLCD) by cross-tabulating the occurrence of each bin with developed and developable land. The developed values are divided by the developable (plus developed) totals to generate a graph relating attractiveness to percent-developed. This graph is then applied to the combined attractiveness map to generate the final percent-developed map, which in turn is used as a development probability map.

\subsubsection{Implementation and Demonstration}

Land cover, digital elevation, and road network files are downloaded from USGS and Census Bureau data sites for the sample study area, Fort Benning. Using ArcGIS these maps are re-projected into a common equal-area projection. The maps are then saved as ESRI Shape files and moved to a computer running Red Hat LINUX and GRASS 5.3 (Geographic Resources Analysis Support System version 5.3), an open source geographic information system software. A script capturing the steps described at the end of the Approach section is run to create the very high, high, and medium density centers to be used as city attractors. These centers are called small, medium, large, and extra large (xl) cities. Figure 8 shows the result of running this script on the 1993 NLCD map for the study area. The largest black spot is the xl_city, with increasingly smaller dots representing large, medium, and small cities (residential centers) respectively. Very small towns can be found near the large city of Columbus, GA, as well as different sized and density neighborhoods within the city itself.

Attractor points for ramps, intersections, state highways, and county roads are generated through raster analysis of the road maps. Driving time maps are then generated to provide the shortest driving time to these and the city attractors. We next created the attractor maps by running a modified version of the GRASS cumulative cost analysis program, "r.cost," using the starting points and a map providing the required time to cross each $30-$ meter square grid cell. The travel time map is created using estimated travel speeds across all roads and all land cover types. The GRASS r.cost program is modified to accommodate the situations where two roads cross, but do not intersect, such as a county road crossing an interstate highway. This version may be available as part of a future release of the GRASS software.

Consider the calculation of the driving times to interstate highway ramps. After identifying ramp locations, the r.cost program is run to generate the driving time to the nearest ramp from every cell (Figure 9). Driving time increases from black areas (closest) to white area (farthest) on the map. 


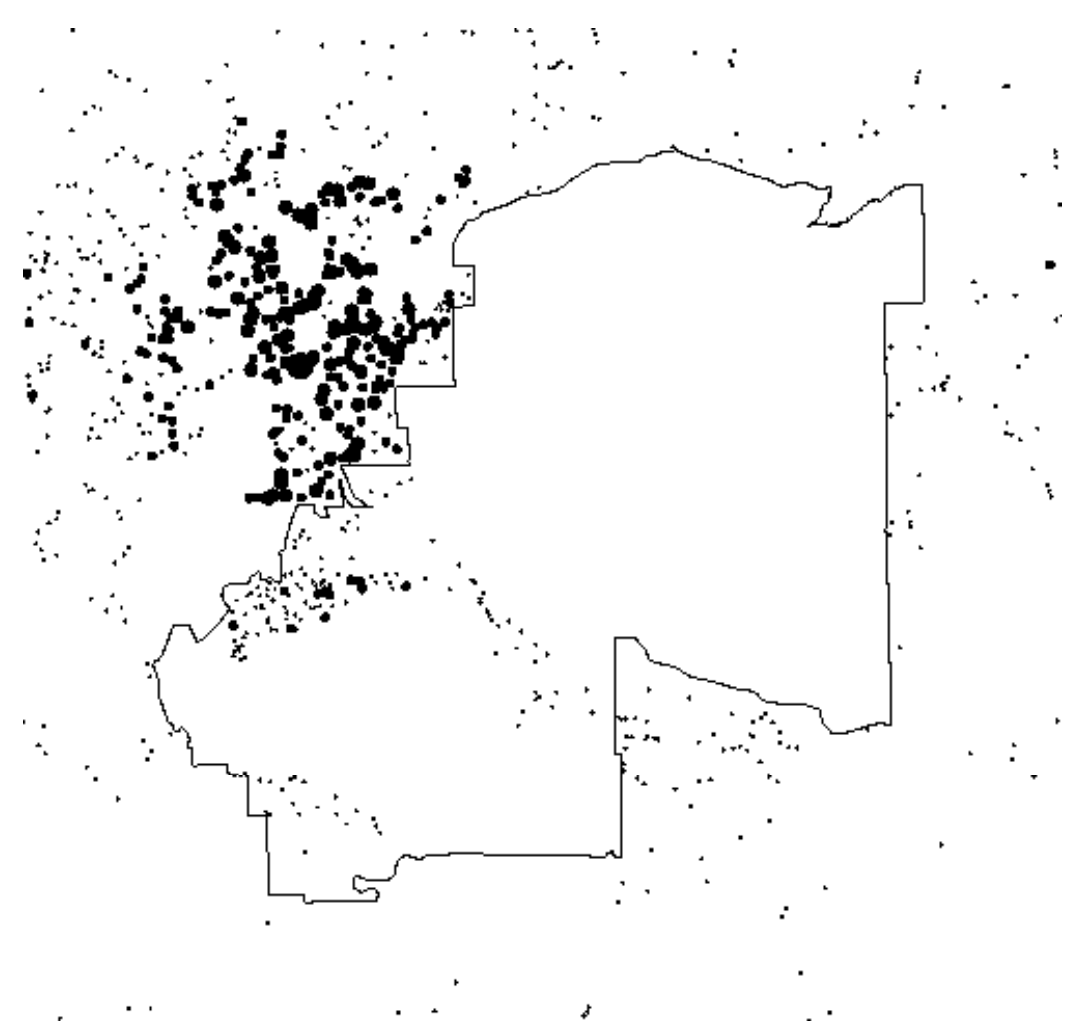

Figure 8. Result of automated location of residential centers.

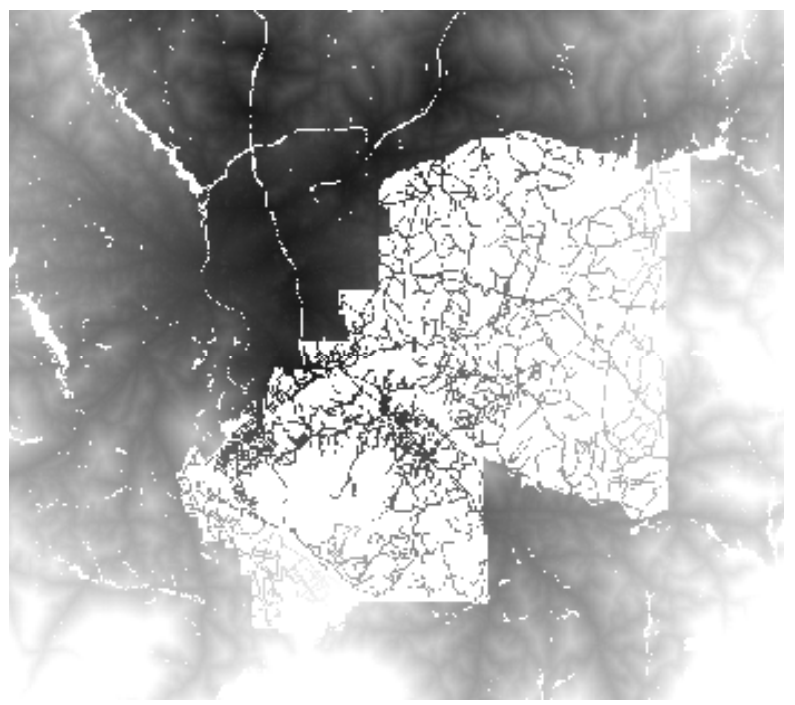

Figure 9. Automatic identification of interstate ramps and generation of driving time to ramps.

This driving time map is then log-transformed, and the results are divided into 20 sub-ranges (bins) and cross-tabulated with a map of residential and potentially residential areas (derived from the NLCD map). This generated the relationship shown in Figure 10. Finally, every grid cell is classified with respect to the percent residential value associated with its driving time to generate the map in Figure 11. 


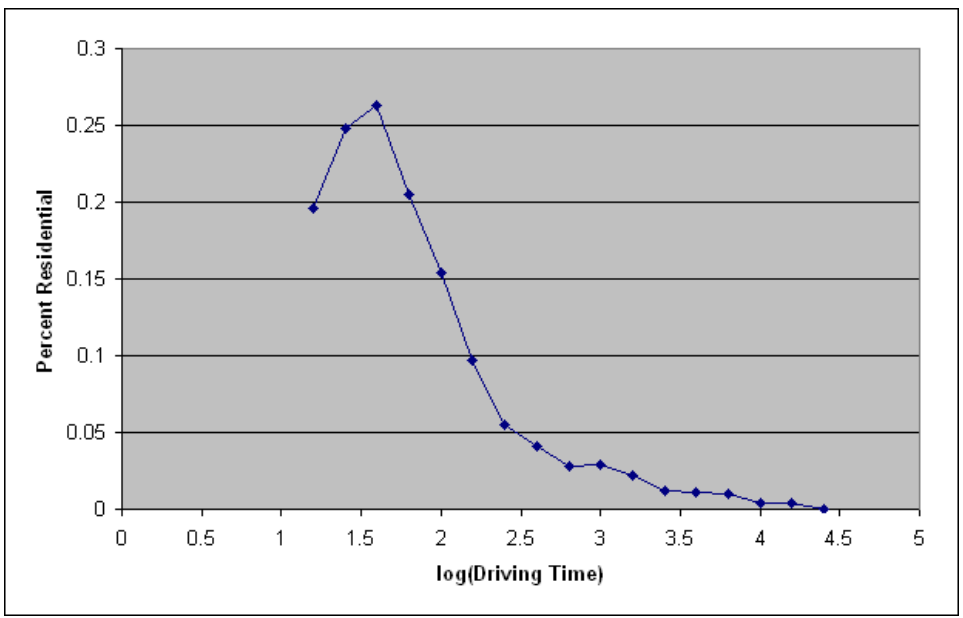

Figure 10. Relationship between driving time to ramps and percent residential.

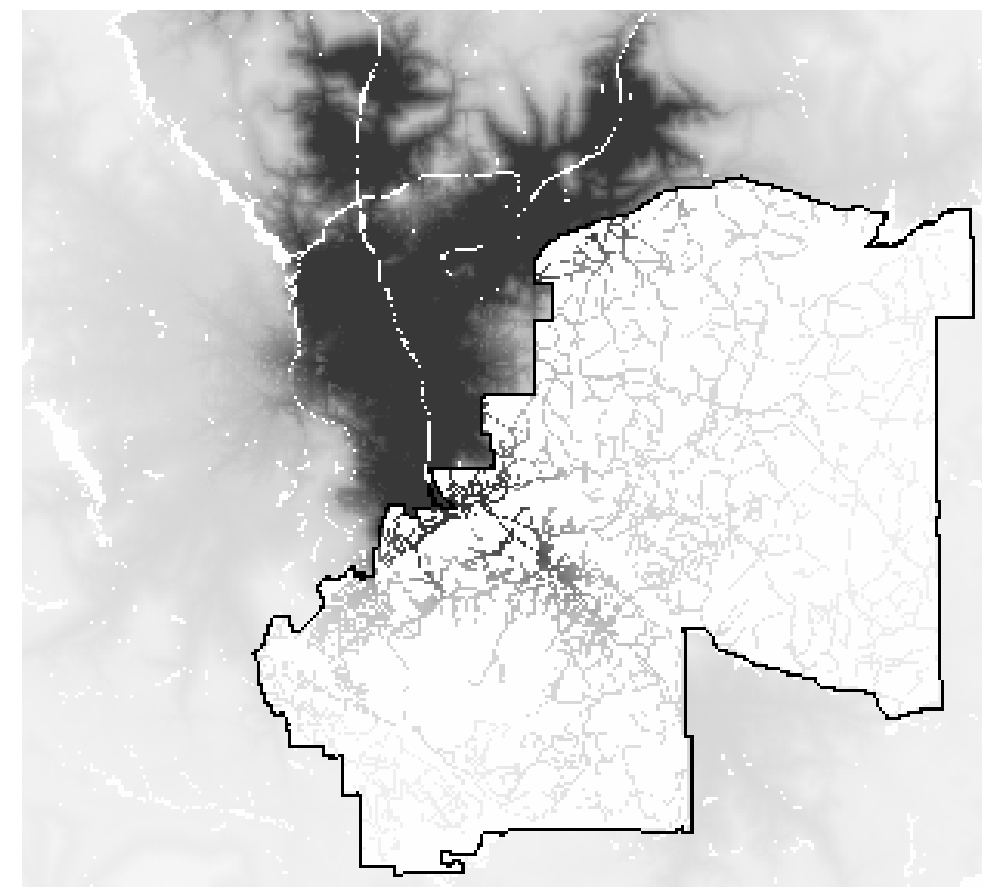

\section{Figure 11. Probability of residential based on driving time to ramps.}

A series of eight such maps is generated based on the road, highway, ramp, intersection, and city maps. The city maps, generated separately for the four attractor sizes, are first combined by dividing the travel times by values proportional to the relative size of the attractor. The log of this result is then divided into the 20 sub-ranges and compared with the residential and potential residential areas as described above. 
Forest and water attractor maps are developed to capture the notion that immediate access to these features in a neighborhood can be a significant attractor - especially in areas where either is scarce. Instead of driving times, straight-line distances are used out to 150 meters; beyond this point all areas are treated as equal.

After conversion of all attractors to full-coverage attractor maps and then to a map of residential probability, we observed that the correlation between residential development and the attractor varied in strength. Table 1 lists the nine residential probability maps associated with the different attractors. These are listed in order of the strength of the correlation reflected in the value range. These values are simply averaged for each cell location in the study area to generate a summary attractiveness value. The strength of influence of each attractor on the prediction of residential development lies in the size of its correlation range.

The averaged value map can be viewed as a grouping of locations with similar overall attractiveness to residential development. One more step is performed to identify the probability of development associated with each attractiveness level. As before, the summary attractiveness is divided into 20 sub-ranges that are cross-tabulated with the residential and potential residential areas (combined to give a residential probability level). Figure 12 shows the resulting relationship of the summary of attractiveness and residential probability. Finally, this relationship is applied to the summary attractiveness map to generate the residential probability map, which is used to identify where future development is likely to occur (Figure 13).

Table 1. Correlation of attractors to residential.

\begin{tabular}{|l|c|c|c|}
\hline Probability map & Minimum & Maximum & Range \\
\hline Cities (res. centers) & 0.002 & 0.804 & 0.802 \\
\hline Neighborhood & 0.052 & 0.937 & 0.885 \\
\hline Ramp (Interstates) & 0.000 & 0.156 & 0.156 \\
\hline Intersections & 0.000 & 0.054 & 0.054 \\
\hline State Highways & 0.000 & 0.036 & 0.036 \\
\hline Roads & 0.000 & 0.012 & 0.012 \\
\hline Slope & 0.000 & 0.028 & 0.028 \\
\hline Water & 0.014 & 0.022 & 0.008 \\
\hline Forest & 0.034 & 0.200 & 0.166 \\
\hline
\end{tabular}




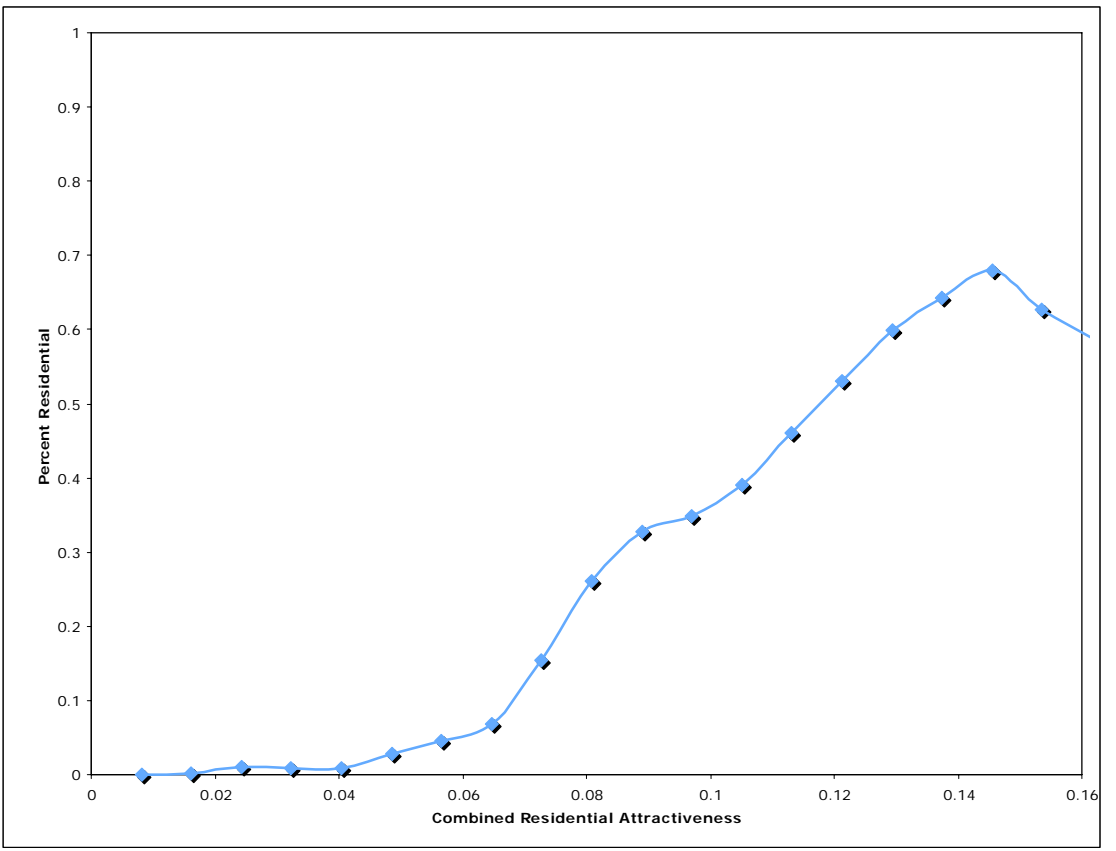

Figure 12. Relationship of residential attractiveness to percent residential.

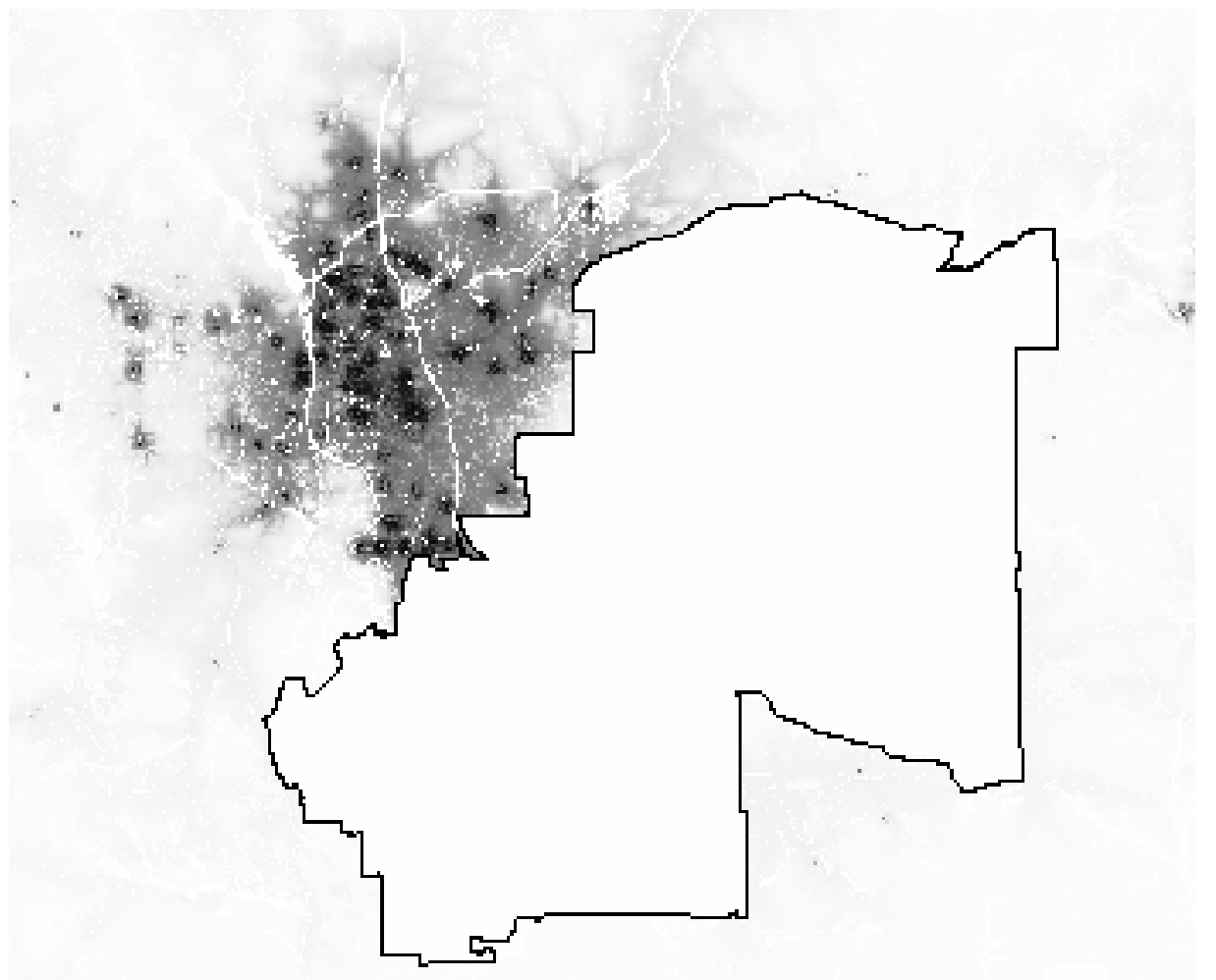

Figure 13. Residential development probability map. 


\subsubsection{Caveats}

The application of LEAMram results in the development of a map of the attractiveness to urban growth based on the actual settlement patterns in the area. These patterns developed in response to population, employment centers, transportation networks and apparent preferences, but there are several assumptions and caveats that need to be recognized at the outset:

- Other potential attraction considerations could be added to this list, and some on the list could be dropped for any particular location. Note, for example, that drinking water availability is not considered and can be critical from a legal standpoint (e.g., western water rights) or from a geologic perspective. Some areas offer more water well opportunities than others.

- This analysis generally assumes no new investments in roads or in the development of new neighborhoods, but can be rerun with such developments provided as inputs. It also does not recognize the affect of development affecting travel times on roads.

- Travel times are assumed to be optimal for each type of road. Hence, the resulting map provides a snapshot in time of the attraction to new growth, but does not consider the impact of new growth on the overall attraction.

- The analysis identifies attractiveness to new development on a $30 x 30$ meter cell-by-cell basis - parcels approximately the size of city lots. While some growth happens this way, much development occurs as part of new neighborhood development sites that can be roughly 800 meters square.

- Parcel size and ownership is not considered. Developers looking to build a new neighborhood are more likely to purchase a single large parcel rather than piece together many smaller contiguous parcels making urban development less likely.

- Negative attractors are not considered in this analysis. Urban development tends to avoid being co-located with industrial sites.

- The attractiveness to urban growth can be outweighed by attractiveness to other land uses such as parks and industrial areas. This competition is not identified here.

- The attractiveness to cities map must be developed in close consultation with local planners to best capture understandings of the location and attractiveness of local population, employment, and shopping centers. 


\subsection{LEAMluc - Land Use Change Model}

Once we have established which areas are attractive for growth, the next step is to determine how those attractors might influence future growth within the region. The maps of attractors resulting from LEAMram are used as inputs to the LEAMluc, the LEAM land use change model. This model uses those maps to predict expansions in urban development patterns, given the relative attractiveness of each plot of land. It then produces a land use map, similar to the NLCD data set, which shows the predicted future land uses across the study area. LEAMram and LEAMluc are best used to test and compare alternative regional plans that include zoning, property purchases, highway and access ramp construction, and development incentives.

LEAMram generates a map of the attractiveness of land to residential development, which is an important ingredient for predicting future land use change. With other inputs, the LEAM land use change (LEAMluc) model is used to project future patterns of residential development. LEAMluc is adapted from the generic version of the generic LEAM model (Deal 2005).

\subsubsection{Inputs}

The primary input to LEAMluc is the LEAMram generated residential attractiveness map. This raster map provides values in the range of o to 1.0 that indicate the probability of each cell being residential at the time of the base NLCD map was developed. LEAMram grouped cells together into sets of similar overall attractiveness and then assigned these potential development values based on the percent of similar cells already developed. The second input is the percent overall residential growth that will be accommodated each growth-step (not time-step) and the number of steps. The percent growth per step is typically 1 percent; the number of steps is 50 .

\subsubsection{Outputs}

The output is provided in two raster maps. The first is the projected NLCD map at the end of the simulation; the second is the growth-step at which each changed cell changed. With this information an NLCD map at any time step can be recreated with simple GIS commands. Figure 14 shows the projected location of residences in the region surrounding Fort Benning over the next 30 years based on population projections and changing attractiveness to urban growth. Current residential areas are shown in green. Red areas indicate predicted growth. 


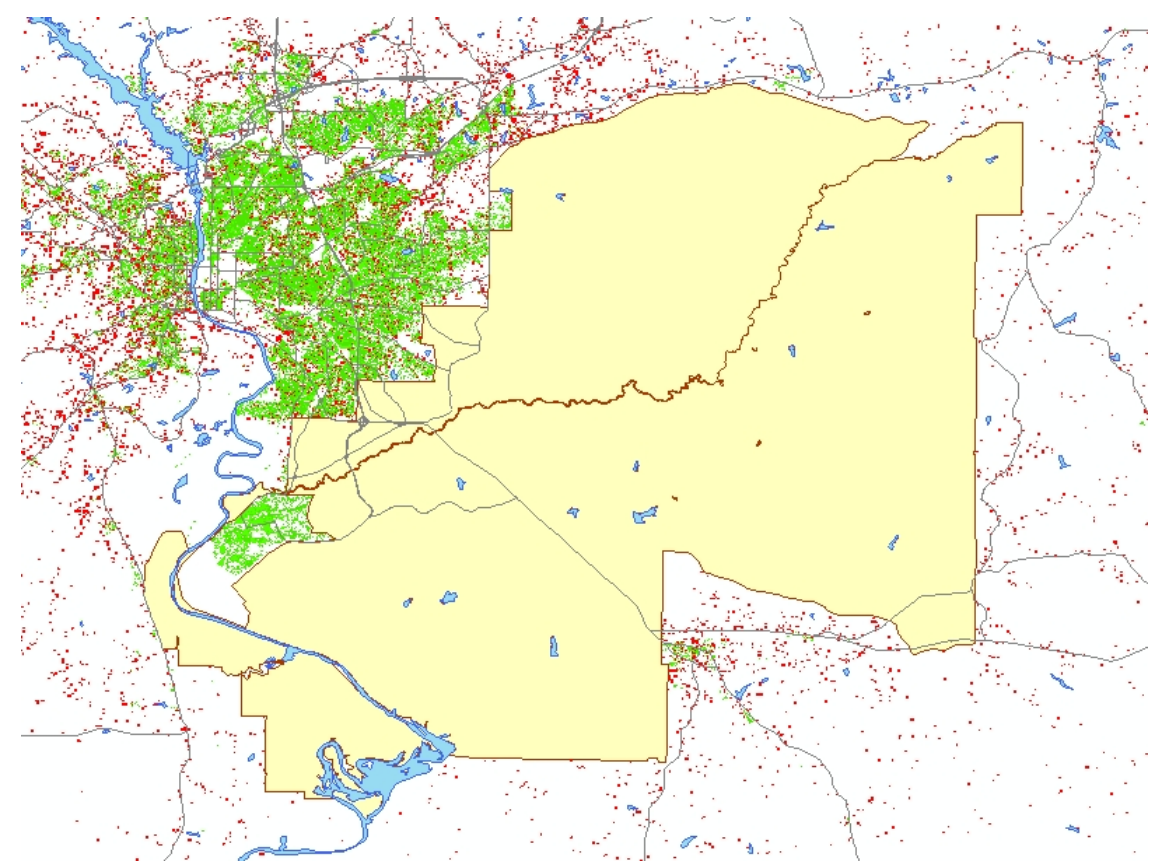

Figure 14. Projected residential land use (2030).

\subsubsection{Approach}

At each growth-step, LEAMluc must allocate enough new residential landuse cells to accommodate the input growth desired. This is a stochastic process mediated by the generation of a random number between 0 and 1 . If that number is lower than the attractiveness value of the cell a second random number is generated. If that number is greater than a given number, then the cell is converted to urban residential. That given number is calculated within the program to ensure that the desired overall growth rate is achieved. The attractiveness values are then modified to reflect the fact that newly developed areas will attract more development. In reality, when utilities are put in place to support one new developed cell, they can easily be extended to support development in neighboring cells - resulting in the creation of new developments or subdivisions. This overall process is repeated for each desired growth step with internal maps updated and written out as final maps.

\subsubsection{Comparison with LEAM}

LEAM essentially converts a given land use pattern of urban areas to future patterns where undeveloped (but developable) land is converted to urban residential, urban commercial, and urban open space land. mLEAM only converts land to residential as it is the residential development that can result in the greatest incompatibilities with military training and testing. Typically, the generic LEAM model is modified to capture specific ur- 
ban development drivers and conditions for a particular location, resulting in a unique urban growth model for the target area. mLEAM models are calibrated through the LEAMram process based on the overall residential land use pattern. That is, mLEAM assumes that, if the urban areas would develop today from nothing in the area, the pattern would match the current visible pattern.

The application of LEAM accommodates the notion that development patterns and attractiveness to growth are significantly based on available transportation technologies and costs and the wealth of the community. When transportation is relatively inexpensive, urban patterns tend to be more disperse. For example, wealthier neighborhoods often accommodate fewer people per unit area. Similarly, when transportation is less important, urban patterns are less dense. Transportation can be less important in areas where people live close to work, social networks, shopping, and entertainment. It can also be less important as communication technologies allow people to work remotely from central business offices. LEAM accommodates these challenges by identifying urban attractiveness based on recent development rather than on overall development patterns. This essentially requires two historic NLCD (or equivalent) maps and the difference between those maps is used to generate the attractiveness maps. In the absence of an NLCD pair, census data, records of new housing starts, and satellite imagery have been used. While LEAMluc, within mLEAM, generates future residential patterns only, LEAM also generates patterns that consider future urban commercial and urban open area (e.g., parks). In summary the main differences is that LEAMluc is run autonomously giving quick results that project future residential patterns only. The LEAM calibrations require two historic (and consistent) maps that are not nationally available and therefore must be developed and processed by skilled GIS technicians. Attractiveness maps are developed for residential, commercial, and open space, with which LEAM generates future patterns that accommodate the competition of these spaces.

\subsubsection{Caveats}

LEAMluc is a regional urban growth model, not a city growth model. The purpose here is to identify future constraints to military training and testing and the most important need is to identify potential new urban areas that may conflict with future training/testing.

The key input to LEAMluc is the land cover map, typically from the archive of national land cover data (NLCD). The 1993-generation of these maps is 
consistent, but often lacks local detail. Urban pixels in NLCD images appear inaccurately-especially along highways. Local users are typically interested in having more accurate land use maps used in the analyses.

LEAMluc forecasts general residential development and does not distinguish between different housing types, costs, and densities. However, the attractiveness of land to residential development is locally calibrated using the local residential land use patterns.

\subsection{LEAMtom - Training Opportunities Models}

The long-term viability and sustainability of a military installation and its associated training and testing areas is based not only on its ability to sustain its current mission, but to accommodate unknown future missions as well. It is desirable to use the LEAMluc future residential landuse pattern predictions to identify where training and testing opportunities are affected. The LEAM training opportunities models turn maps of urban residential patterns into maps of relative suitability for training and testing. The general need is to identify where training and testing can occur without generating noise, dust, and smoke-related complaints from the residential areas.

\subsubsection{Approach}

The objective of this work is to create a raster map showing where an activity associated with an annoyance radiating away from that activity could be located to minimize the potential of complaint from receptors of that annoyance (residential neighborhoods) when the locations of receptors are known or given. Consider first the location of a noise-generating activity with respect to a single receptor; perhaps a single-family residential house. Assume that we are given the fact of a known decibel level at a known distance for the training or testing activity. Assuming that sound radiating equally in all directions decays with the square of the distance, it is possible to identify the sound level of a given noise-generating activity across the landscape. Published measurements of sound annoyance associated with sound level allows for the identification of the probability of high annoyance by the single receptor. In the left map in Figure 15, a single receptor sits in the center and a potential noise source has been simulated at every location (cell) in the map, one cell at a time. The probability of complaint by the receptor for the noise source has been calculated for every potential placement of the noise source. 


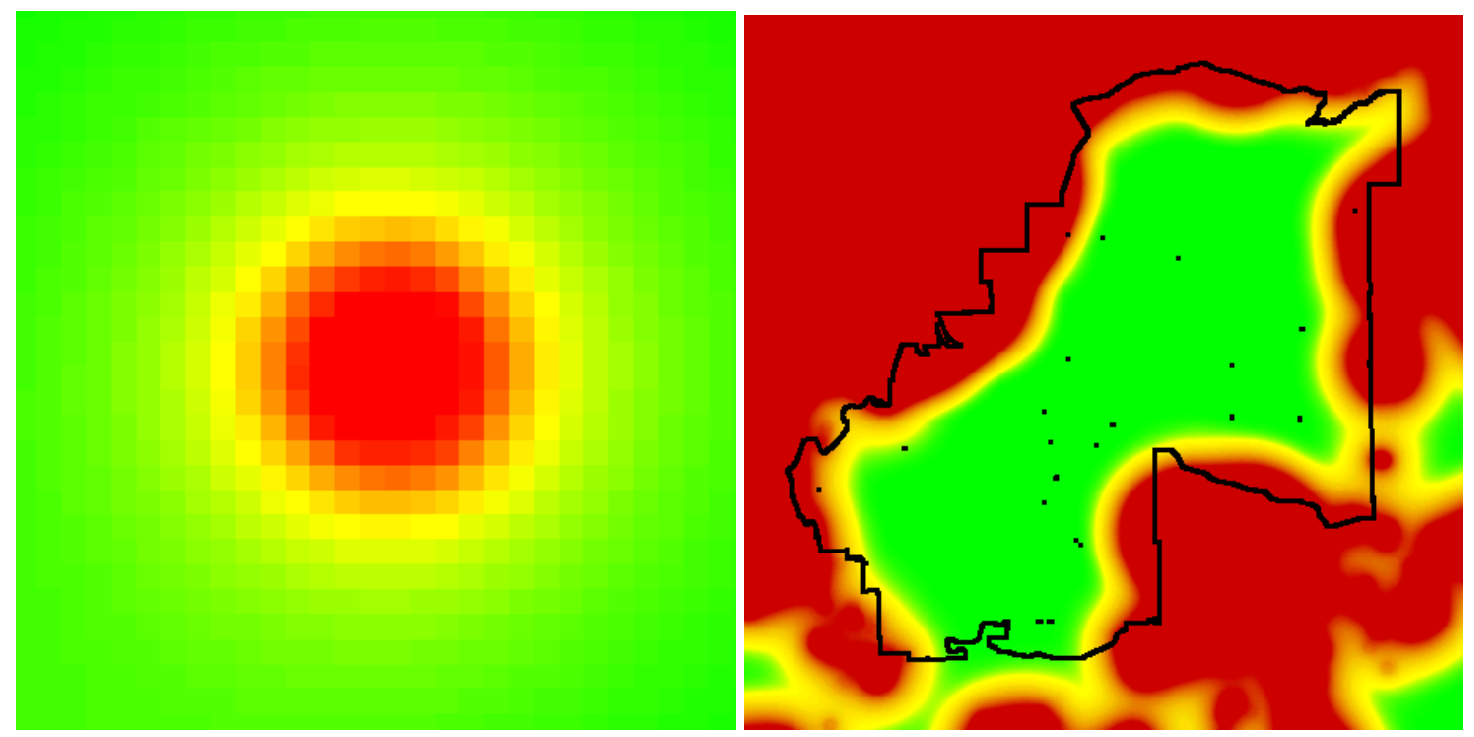

Figure 15. Probability of complaint by a single receptor.

The probability of complaint was calculated as 100 percent for the closest areas and is colored red. The probability drops to 50 percent in the yellow area and nearly o percent at the corners of the map. We therefore have a map that identifies where, in the area, a given noise can be located to minimize the probability of complaint by the one receptor. Consider a second receptor/residence and you can visualize multiple bulls-eye patterns that can overlap. Now consider an entire region with many residential receptors. The right-most map in Figure 15 shows an outline of Fort Benning overlaid on a probability of complaint map for a noise level equivalent to artillery firing.

LEAMtom software analysis models have been developed for noise, dust/smoke, and night lights. Software implementation was completed within GRASS (Goran 1989) running on a Linux computer. The resulting programs, developed using the $\mathrm{C}$ programming language, are called r.decay, r.decay.noise, and r.decay.dust.

\subsubsection{Comparison with Other Models}

LEAMtom analyses provide a very different analysis service than products such as Bnoise (Little et al. 1981) and SARNAM (Pater et al. 1999). These noise analysis models begin with locations of training and testing noise and generate noise-level contours that can be overlaid on the surrounding areas to identify potential land use incompatibilities. These models are very mature and accommodate details such as wind, air column temperature, land elevation, land cover, and directionality of noise sources. They are excellent for answering the question of how historic, current, or pro- 
posed training and testing noise impacts surrounding land uses. The LEAMtom models address a very different question, which is how projected urban patterns 20 to 50 years into the future will affect the opportunities to locate noise and dust/smoke generating training and/or testing.

\subsubsection{Caveats}

There are many assumptions associated with the LEAMtom analyses:

- A basic assumption of the entire mLEAM approach is that the landuse most incompatible with military training and testing is residential. Therefore, LEAMram generates attractiveness maps to residential development, which is used by LEAMluc to project future residential patterns. LEAMtom analyses assume that the regional residential patterns are, of course, correct.

- LEAMtom analyses do not take into account annual or seasonal wind directionalities. Noise is not significantly affected by wind and dust/smoke, though affected by wind speed, is not affected by wind direction.

- LEAMtom does not consider the affects of landuse, land cover, or land elevation on the propagation of sound, dust, or noise.

Generally, these assumptions allow for faster computation of a computeintensive algorithm, but still allow for good rank-ordering of alternative proposed regional plans. 


\section{Application to Fort Benning}

To successfully determine the extent of urban development around Fort Benning, data from various sources were obtained and integrated for analysis using the mLEAM suite of models. This integration is key to defining trends in urban development and using these trends to forecast future growth.

Researchers used the capabilities of mLEAM to conduct an evaluation of current land use around Fort Benning to assess the impacts of certain "exogenous" factors' impacts on installation mission operations. The analysis used data readily available from national sources, and offers a relative measure of land use changes around the immediate perimeter of Fort Benning. It provides a consistent visual data analysis of land use change trends that can help installation staff analysts evaluate possible issues or concerns when advising local regional planners and making potential future mission decisions. For example, an installation with rapid growth in the land surrounding its perimeter may have current (or future) constraints for a specific type of unit's missions.

\subsection{Comparison with Other Models}

While other analysis tools used to predict the impact of actual or planned training/ testing are readily available, they provide inadequate support for analyzing installation suitability for unknown future activities. While they are good at answering the question, "If a training range is placed here, what is the pattern of the impact on the surrounding area?", they are less useful for answering the question "Where can I consider placing a training range to minimize the impact on the surrounding area?" Instead of running an analysis of the impact of an actual or planned activity, the need here is to analyze the impact of regional residential areas with respect to the collective tolerance of the residents to an activity that will need to occur somewhere on the installation.

\subsection{Community Identified Scenarios}

The following scenarios were the result of input provided by the local attendees of a community land use planning charrette held at Fort Benning in November 2005. Attendees were asked to outline their knowledge of, and/or concerns about the effects of current, planned or hypothetical ef- 
forts within the surrounding communities that could potentially alter current land use. These efforts included improvements to current or the development of future infrastructure, changes in zoning ordinances or any human activity that could otherwise alter the landscape in favor of development. Each of these scenarios represents a unique set of potential regional planning inputs as outlined by the participants of this event.

\subsubsection{Interstate 14 around Fort Benning Scenario}

This scenario examined the effect that a new interstate skirting Fort Benning to the south would have on patterns of residential development. Figure 16 shows Interstate 14 (I-14), the proposed designation for a new freeway corridor running between Natchez, MS and Augusta, GA. Negotiations are currently underway in Congress to extend I-14 west to Austin, TX, and east to Myrtle Beach, SC, thus creating a "Gulf Coast Strategic Highway." Under this scenario, to connect properly with the nearby Interstates, I-14 would continue west from Natchez to Austin Texas. I-14 would extend east into South Carolina, where it would connect with I-20. This proposed interstate is important to Fort Benning because, if the project is implemented, it will cross the state line between Alabama and Georgia at or near Columbus, with the potential to affect regional transportation times and the residential attractiveness of areas in the region, which before has shown marginal potential for urban growth.

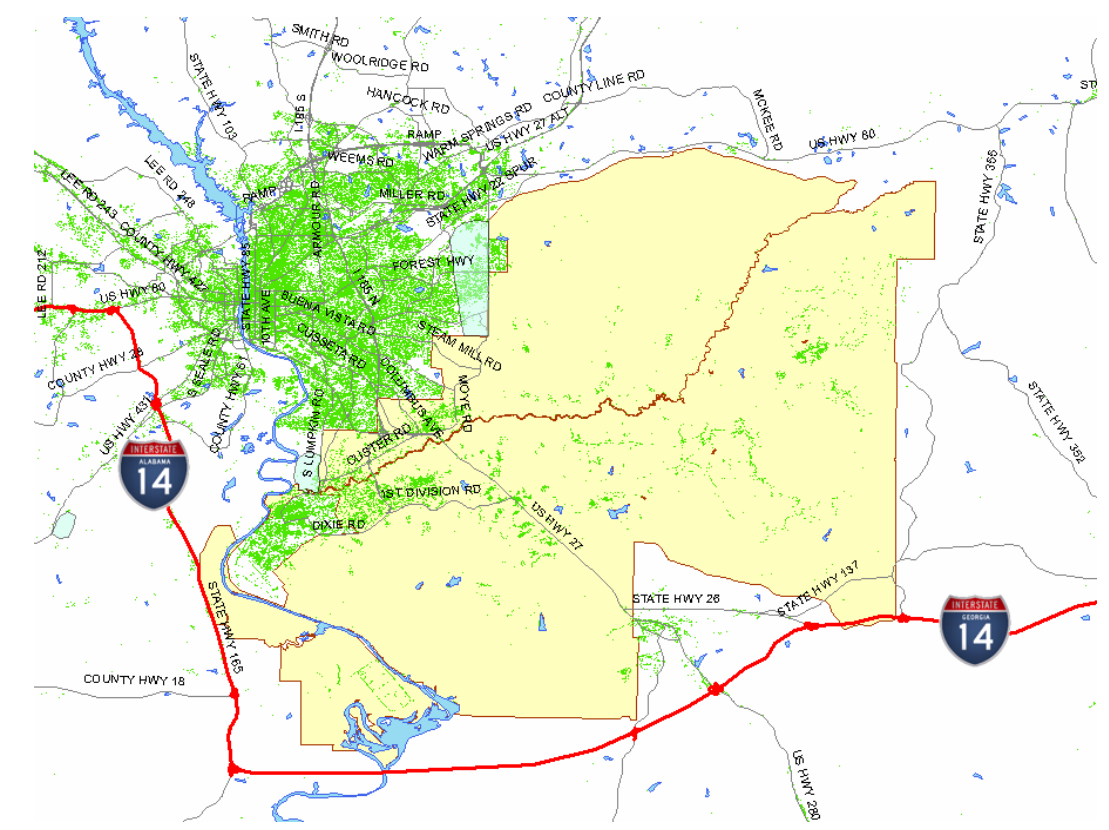

Figure 16. I14_around scenario showing Interstate 14 as it may look in the future skirting Fort Benning. 


\subsubsection{Interstate 14 through Fort Benning Scenario}

This scenario is similar to the previous simulation in that it examines the affect of I-14 on the region surrounding Fort Benning. For this simulation however, the route for the proposed interstate has been altered (Figure 17). Instead it follows existing US80 and its bypass of Columbus, it would then turn south on I-185, and southeast on US27-280/Georgia 1, traveling directly through the Fort Benning military reservation. I-14 would then split east along Georgia 26 at Cusseta, and continue to meet I-75 in the vicinity of Perry.

\subsubsection{Expansion of US431 Scenario}

The expansion and improvement of US431 could have an impact on regional growth west of Fort Benning. We modeled the effect of this in the scenario outlined in Figure 18.

\subsubsection{US431, State Highway 165 Connector Scenario}

This scenario examines the regional effect of a proposed connector road between US431 and Alabama State highway 165 near the western boundary of Fort Benning. Both these highways run in a north-south direction on this side of the installation in Alabama. Figure 19 shows a very rough estimate of where this connector could be located.

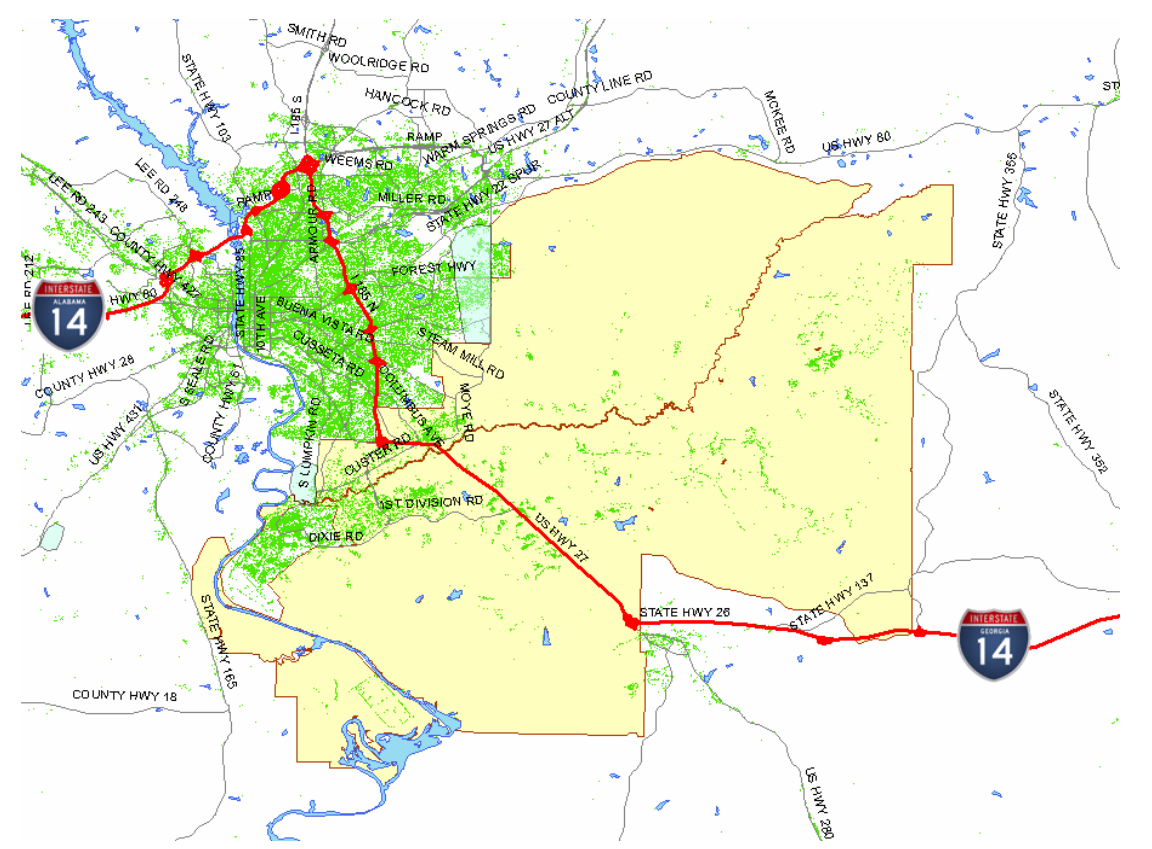

Figure 17. I14_thru scenario shows Interstate 14 running through the installation. 


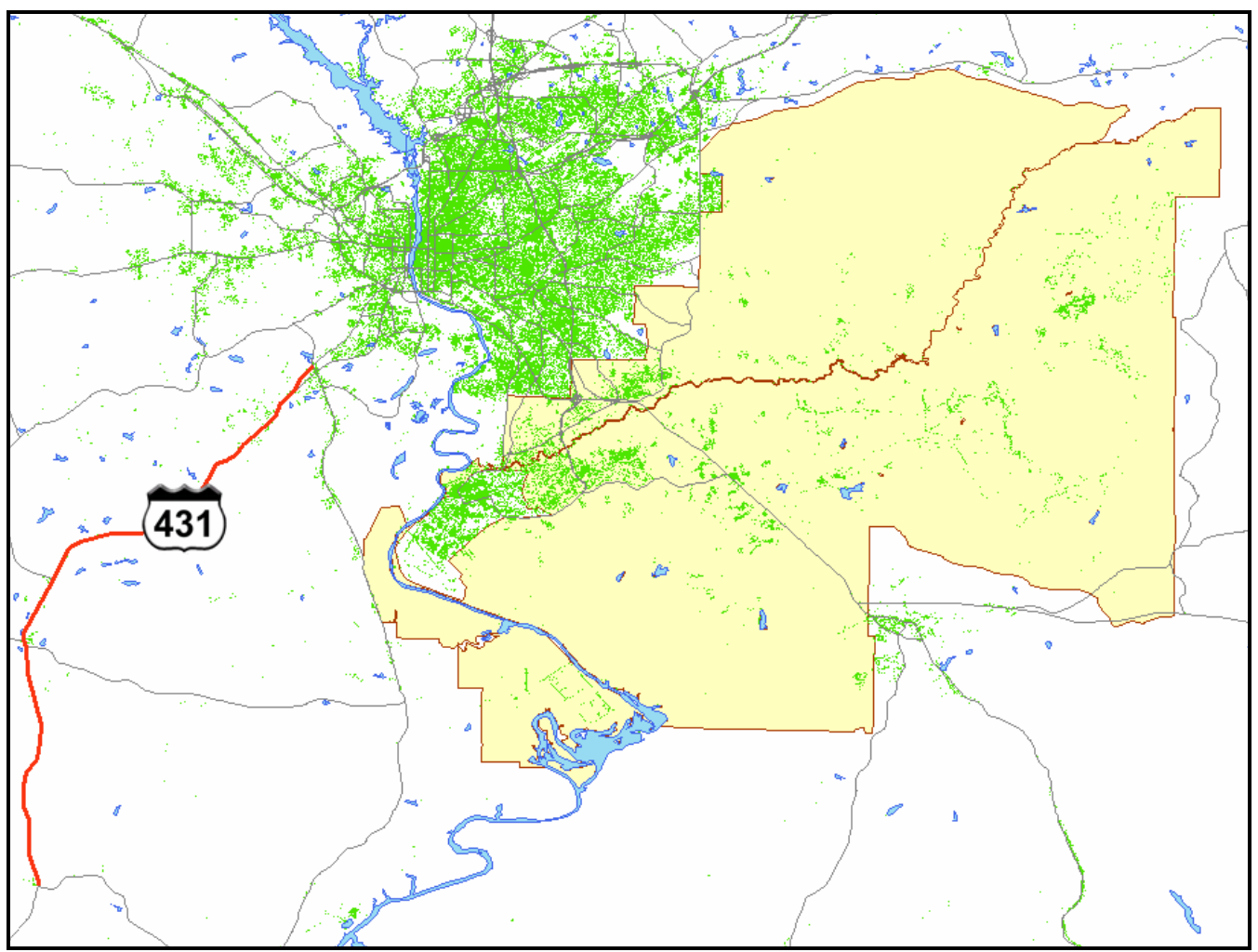

Figure 18. US431 scenario models effects from improvement of this U.S. highway

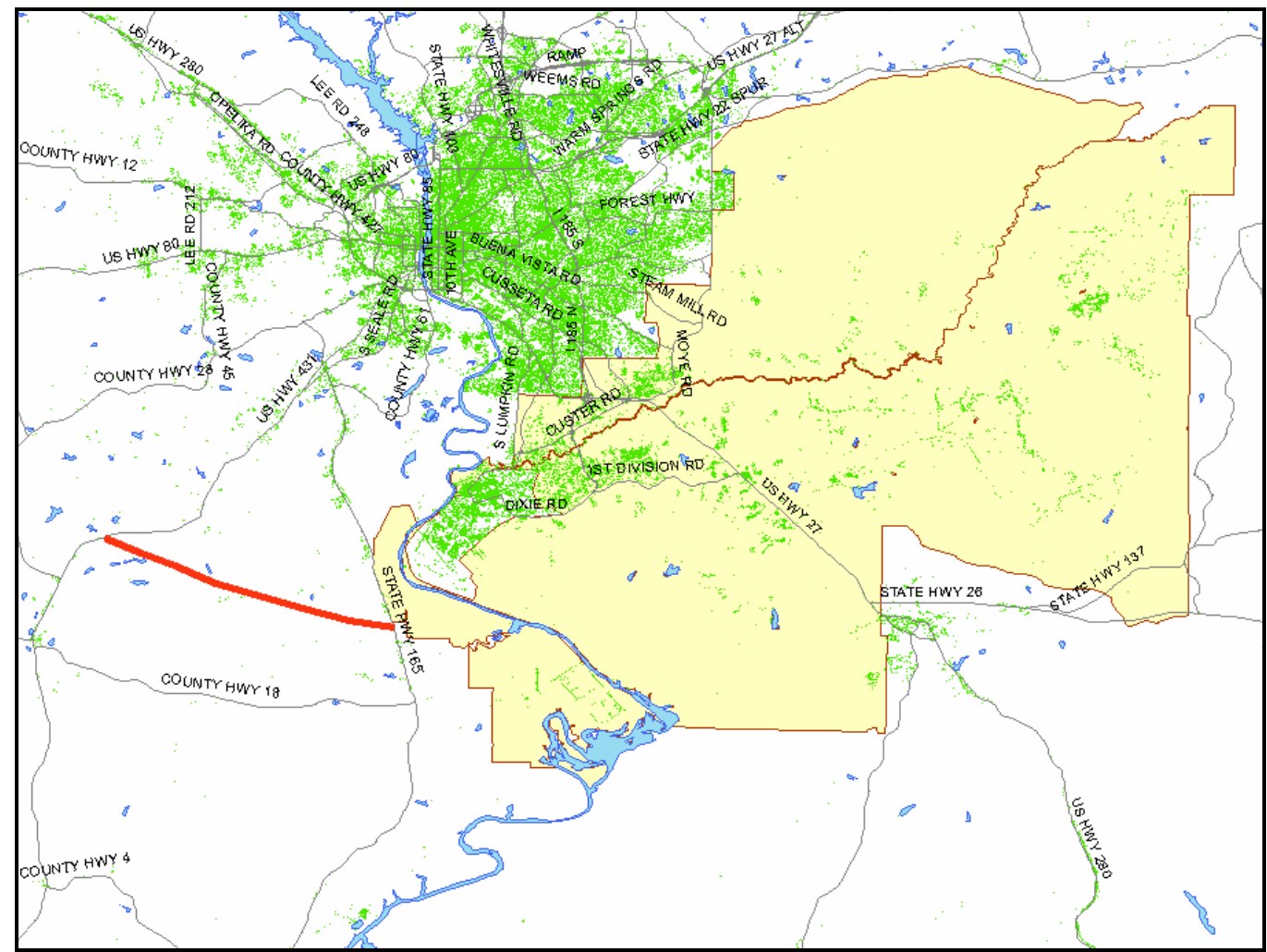

Figure 19. US431_SR165 scenario examines effects of a connector between these two major roads. 


\subsubsection{No-Development Buffer Scenario}

A no-development buffer was simulated for the next scenario. Such a buffer could be established in any number of possible ways. For instance, private land owners and Non-Government Organizations (NGOs) like The Nature Conservancy may have an interest in preserving areas of native forest and wetlands in southern Chattahoochee County to the south of Fort Benning, or in Muscogee and Talbot counties to the north. Land purchases (where feasible) or conservation agreements between Fort Benning and these stakeholders could provide Army Compatible Use Buffer (ACUB) zones along the installation perimeter where development would be excluded (Figure 20). No military training activities could be performed within these buffers, but development from the nearby cities of Columbus, Cusseta, and other surrounding communities would also be restricted.

Note that the areas indicated in the following map used to simulate these no development areas were arbitrarily selected by the participants in the charrette held at Fort Benning and by the modeling team. At this time, there are no indications that such agreements between the Army and local stakeholders are pending. This simulation was intended only as a "what if?" and should not be construed as any kind of regional planning action, proposed or otherwise.

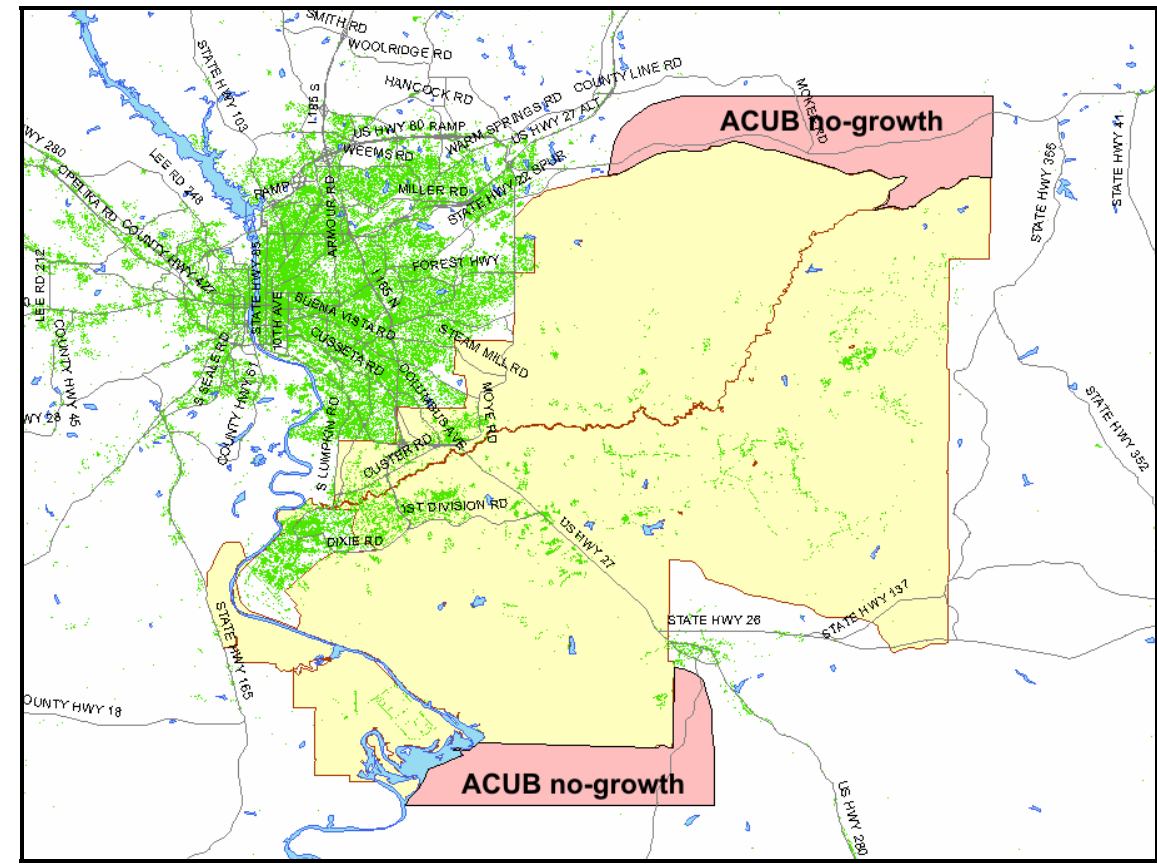

Figure 20. No-development buffer scenario looks at fictitious no-growth areas. 


\subsubsection{New Sewer and Water Utility Lines Scenario}

This scenario considers the consequences of new water and sewer infrastructure running from Columbus to Cusseta. These lines are presently under construction and parallel US27, running through the middle of Fort Benning. Another proposed set of sewer and water lines to accommodate the anticipated growth in Chattahoochee and Muscogee counties run along the east side of the installation. Figure 21 outlines the areas of influence for this new infrastructure.

\subsubsection{New Tourism and Industry Scenario}

The new tourism and industry scenario (Figure 22) examines the effect of two industrial parks and a newly constructed marina and Army museum on the western edge of the installation. Installation personnel are concerned that the possible result of these new commercial centers (the influx of permanent resident population, and seasonal and intermittent increase in tourism) may influence training decisions made on Fort Benning.

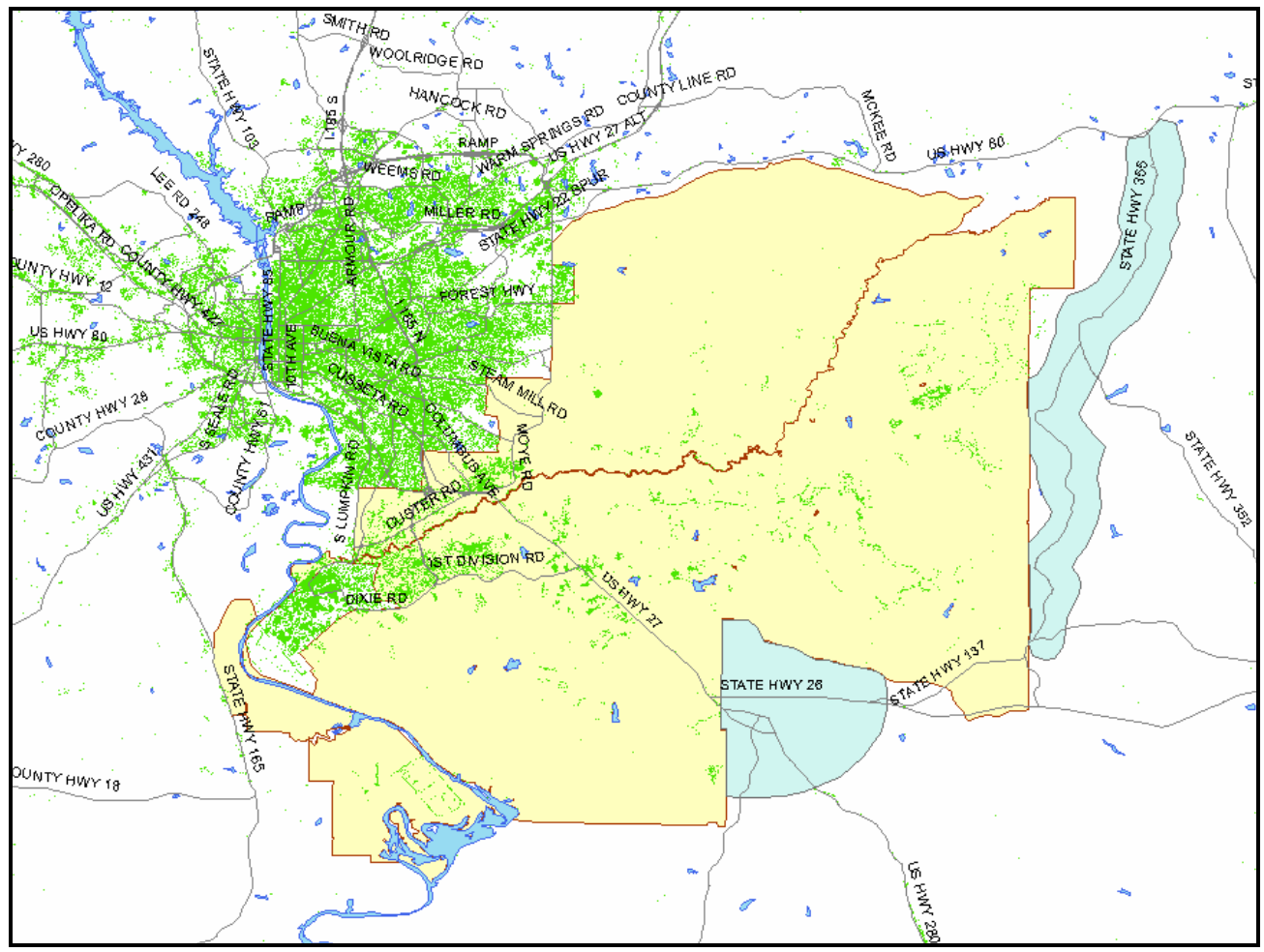

Figure 21. new_utilities scenario; Blue areas indicate where water and sewer lines have been laid in anticipation of growth south and east of Fort Benning. 


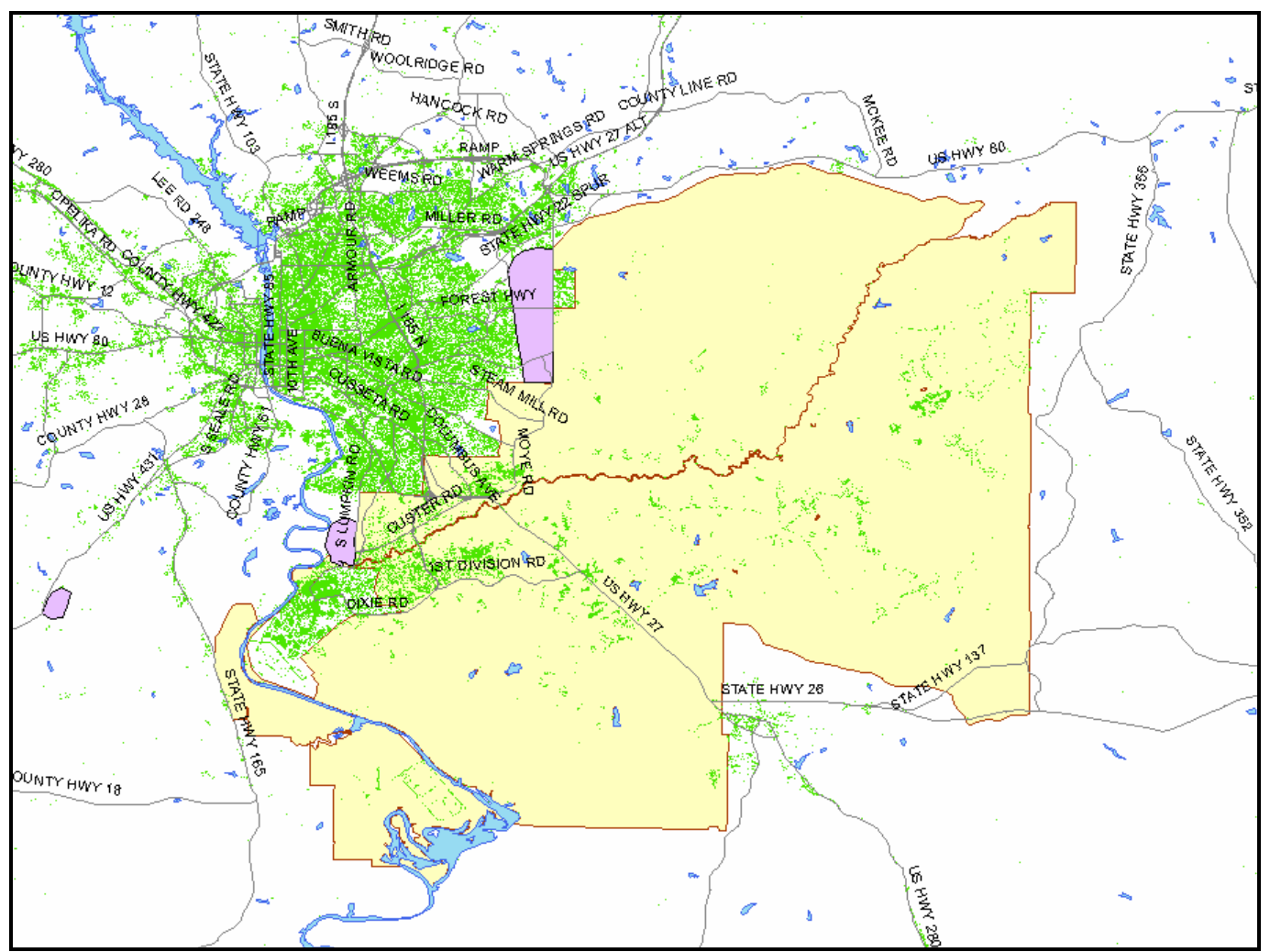

Figure 22. New industry scenario models effects of new industrial and tourism areas (shown in purple).

\subsection{LEAMram Analyses}

The data available for Fort Benning and the region surrounding the installation used in this project were:

- Fort Benning boundary map

- National Land Cover Data (NLCD) 1992

- Digital Elevation Maps (DEMs)

- U.S. Census Bureau Tiger data: Georgia and Alabama Roads GIS layers

- Highways, and Interstates

- Natural Areas, wetlands, and Federal, state and local government property (no-growth areas).

The focus of this research was to integrate these data sources into a model and generate a scientifically justifiable set of maps showing how land use changes may occur over the next two and a half decades. In a series of development contracts, ERDC-CERL and its partner, the University of Illinois LEAM laboratory have developed a procedure to use these maps as input data to derive new land cover maps representing future land uses. This procedure was used to generate map coverages for Fort Benning and the surrounding counties in Georgia and Alabama. This region served as 
the study area for this project. This effort resulted in a set of spatially explicit graphics that show an increasingly intense land usage on the perimeter of the installation, and how that land usage is likely to affect the activities of Army training and testing in the future.

\subsection{Base Scenario}

Using the method described in the previous section, researchers ran a number of different scenarios when looking at attractiveness to urban growth. The first was the base scenario, which predicts where future growth is likely to occur given no changes to roads, highways, or designation of no-growth areas. The only no-growth areas considered were those known to exist in the study area today (swamps, water, parks, Fort Benning itself, etc.).

Figure 23 shows the residential attractiveness map for the base scenario. (Note that these residential attractiveness maps are not predictions of where growth will occur, simply a visual indication of the area's relative attractiveness to residential development.)

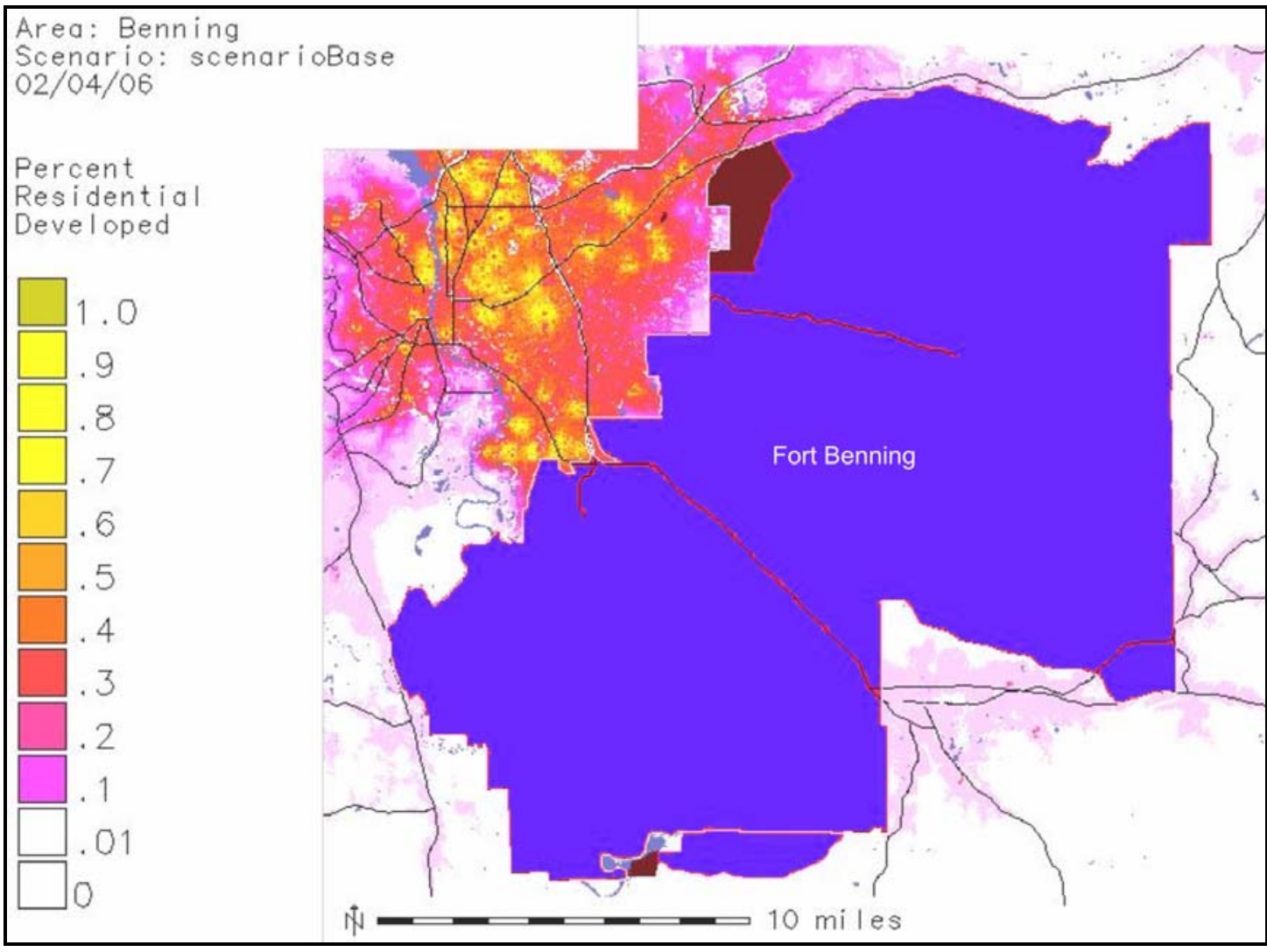

Figure 23. Residential Attractiveness map for Base Scenario. 
This residential attractiveness map represents the residential attractiveness for the area at the beginning of the study period. The scale on the left uses a rainbow color table to represent the percentage of similar lands that were developed into a residential land use as indicated in the NLCD map used in the analysis. For example, in the image, 80 percent of all yellow cells (value of about 0.8 ) were residential, 10 percent of all pink (value of about 0.1 ) were residential, and so on. The assumption is that future development is more likely to occur in areas that have a higher probability of already being developed.

The Base Scenario is the simulation to which all of the alternative/proposed regional plan scenarios were compared. It served as a baseline to evaluate the results of the changes in residential attractiveness and the ensuing impacts to training land availability. These scenarios were developed from input provided by the attendees of the charrette held at Fort Benning in November 2005. Each scenario represents a unique set of potential regional planning inputs and is described below.

\subsection{LEAMluc Analyses}

The LEAMram residential attractiveness maps were processed by the LEAMluc model with the request to increase the total urban residential by 1 percent over each of 50 growth steps. Figure 24 shows the results of the base scenario (no change in roads, highways, or regional no-growth areas). Fort Benning itself is colored pink with original residential in light green and commercial in dark green. The rightmost image shows, in red, locations of new residential development. Figure 25 shows the same results, but zooms into the northern edge of the installation. Black lines depict state and Federal highways to help provide some reference.

Note that the probability of new residential areas in Figures 24 and 25 tracks the residential attractiveness map provided as input to LEAMluc (Figure 23). Also, the clumpiness, which represents the formation of new neighborhoods, increases with increased original attractiveness.

LEAMluc analyses were conducted for each regional planning scenario to generate projected residential patterns to be analyzed with LEAMtom. 


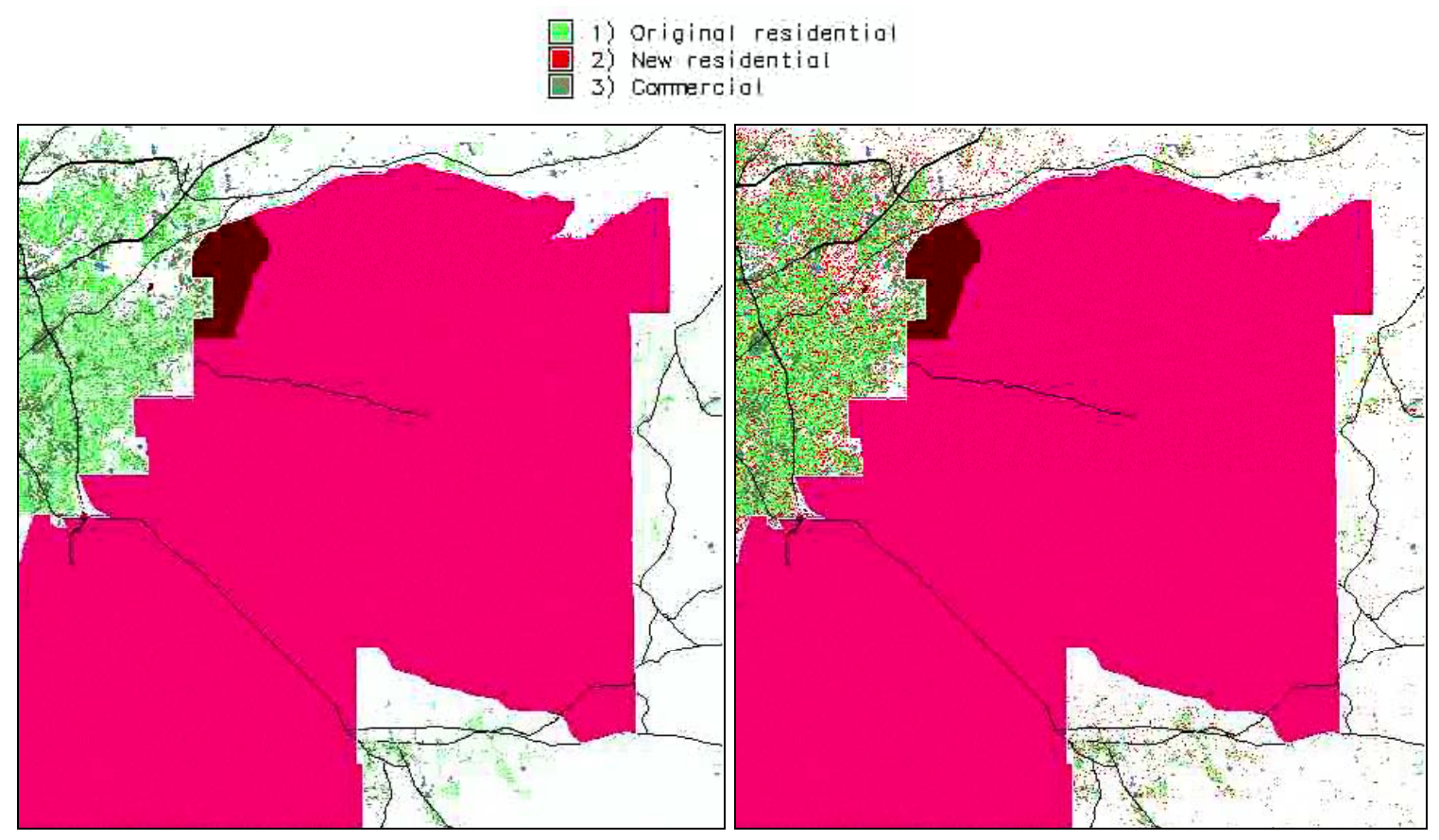

Figure 24. Projected urban residential growth near Fort Benning (before to left; after to right).

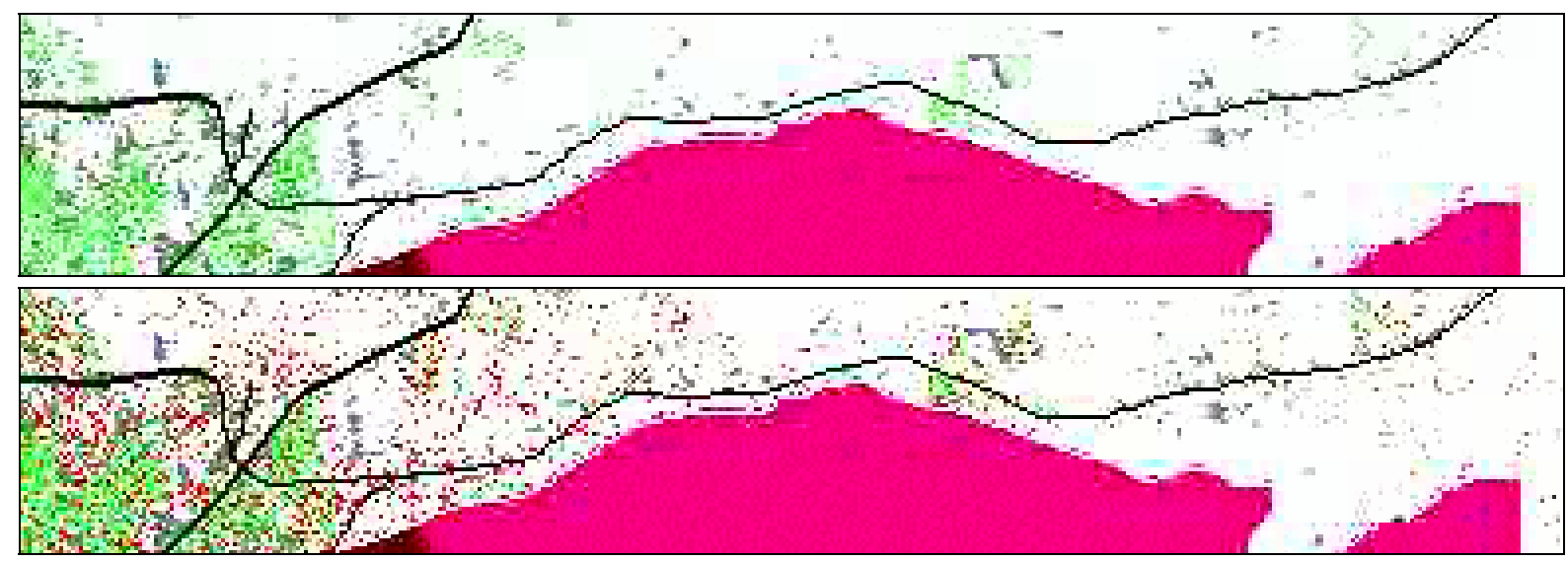

Figure 25. Detail of projected urban residential growth near north edge of Fort Benning (before at top; after at bottom).

\subsection{LEAMtom Analyses}

The LEAM land use change analyses have predicted how proposed regional plans might result in future land use patterns, which can now be used to identify training and testing location opportunities within those projected patterns. This is done by virtually placing a training/testing event everywhere in the study area and predicting the probability of community complaints in response to the event. The modeling process simulates the urban residential growth patterns initially discerned from the USGS NLCD. Using the LEAMluc urban growth model, new land cover data maps are projected out to the year 2030. 
Using these maps, LEAMtom creates a new map representing a contour of the predicted number of complaints in raster format, based on forecast patterns of development. The result is a red-amber-green map showing the probability of community complaint in response to the training/testing event. Each of the colored rings of the annoyance tolerance contour represents a gross calculation of the increasing number of complaints being generated from an Army training exercise on Fort Benning. Figure 26 shows an example of a pair of such maps, predicting the number of complaints regarding the noise associated with artillery training. The pair of maps above represent the number of noise complaints for an artillery training exercise BEFORE and AFTER growth. This event would generate noise measured at $80 \mathrm{~dB}$ at a range of 600 meters. Notice that a significant portion of land deemed "safe" for artillery training purposes exists beyond the boundary of the installation.

These are the large green areas extending beyond the boundary to the south. These contours do not represent lands that should be used for training purposes, but rather lands that could be used if they were available. (LEAMtom does not consider the installation boundary when assessing "safe" areas on which the Army can train, therefore the entire study area is open to its interpretation.) There is little to no development here and few neighbors to potentially be bothered by training activities. It should be noted that this "safe" area shrinks as the scenario runs to completion, so that by the final time step, sufficient development has occurred to eliminate some of this land as potential training land (areas in purple).

Scenario: LEAMbase Time: Wed Mar 15 17:10 CST 2006

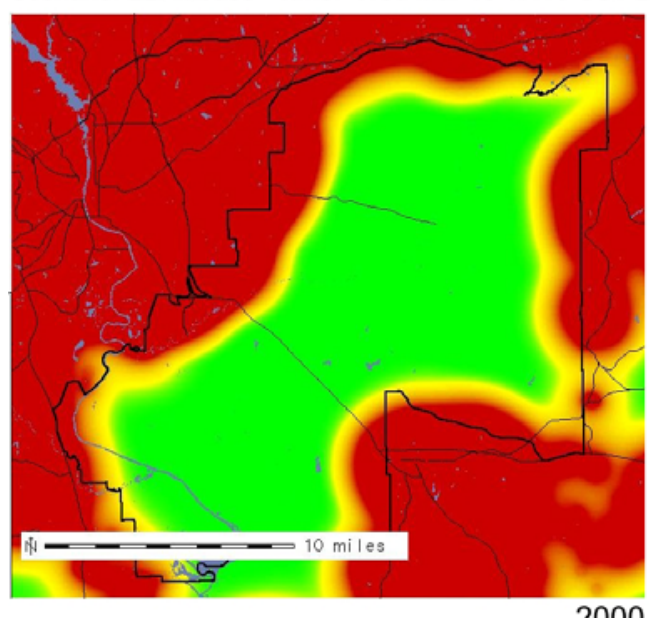

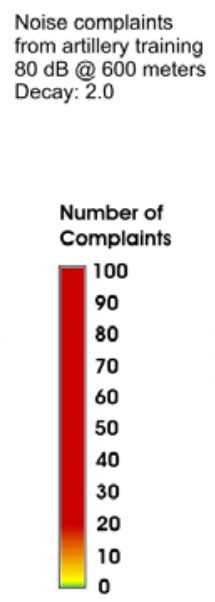

from artillery training

dB @ 600 mete

Number of

Complain

80

60

40

20

0

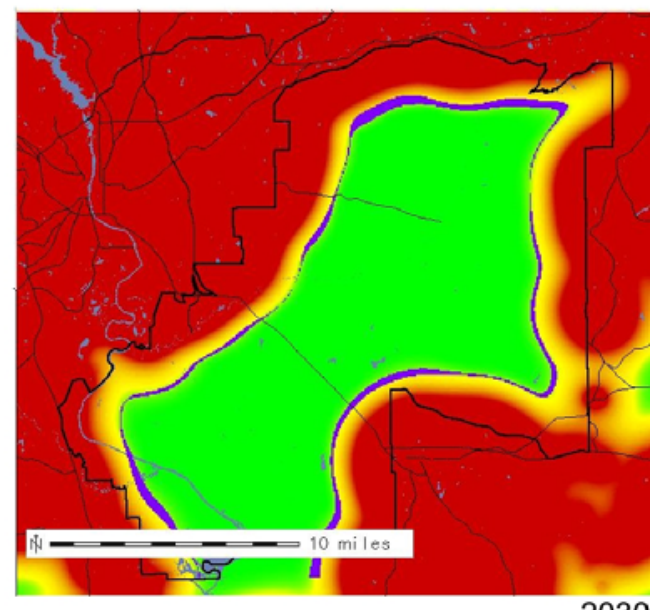


LEAMtom analyses are based on mathematical models that decay noise, dust, and light while taking into account measurements of the level of the associated human annoyance. For example, knowing the level of a noise, its decay over space, and its location allows us to generate a map of the level of noise across the landscape. Relating these levels to measurements of human annoyance in response to the noise allows us to convert the noise map to a probability of complaint map. Combining this map with maps of the projected urban patterns results in a community probability of complaint for the given location and volume of the noise source. Recalculating for every location in the study area we get a final map of the probability of community complaint for the given activity anywhere in the study area. This Fort Benning analysis considered the following potential activities:

- artillery training

- tracked vehicle training

- an aircraft similar to the $\mathrm{C}-130$ training at an altitude of 2000 meters

- helicopter training with the Bell_J_2A at an altitude of 300 meters

- an F-22 Raptor training at an altitude of 4500 meters

- dust generated by tracked vehicle training

- night training requiring dark nights.

However, LEAMtom is flexible-it can be adapted to analyze the potential number of complaints for other and new weapon systems, given some rudimentary data on noise patterns and rates of decay.

The first five of the current analyses address the tolerance for noise associated with military training by the surrounding residential areas. Every residential location is associated with concentric rings of complaint probability. Training at more distant areas are therefore associated with an increasingly lower number of complaints. Our question, therefore is, "Where, within Fort Benning, can these training activities be carried out after development has occurred with respect to the regional planning scenarios modeled by LEAMluc?" Each location on the map is then given a probability of complaint associated with every other residential area across the entire map, and these values are combined to give an overall probability of complaint. In the following set of maps, a given event of military training in the green areas is projected to generate fewer than two complaints; in the yellow areas, about 10 complaints; and in the red areas, 20 or more complaints. 
Scenario: LEAMbase Time: Wed Mar 15 16:33 CST 2006
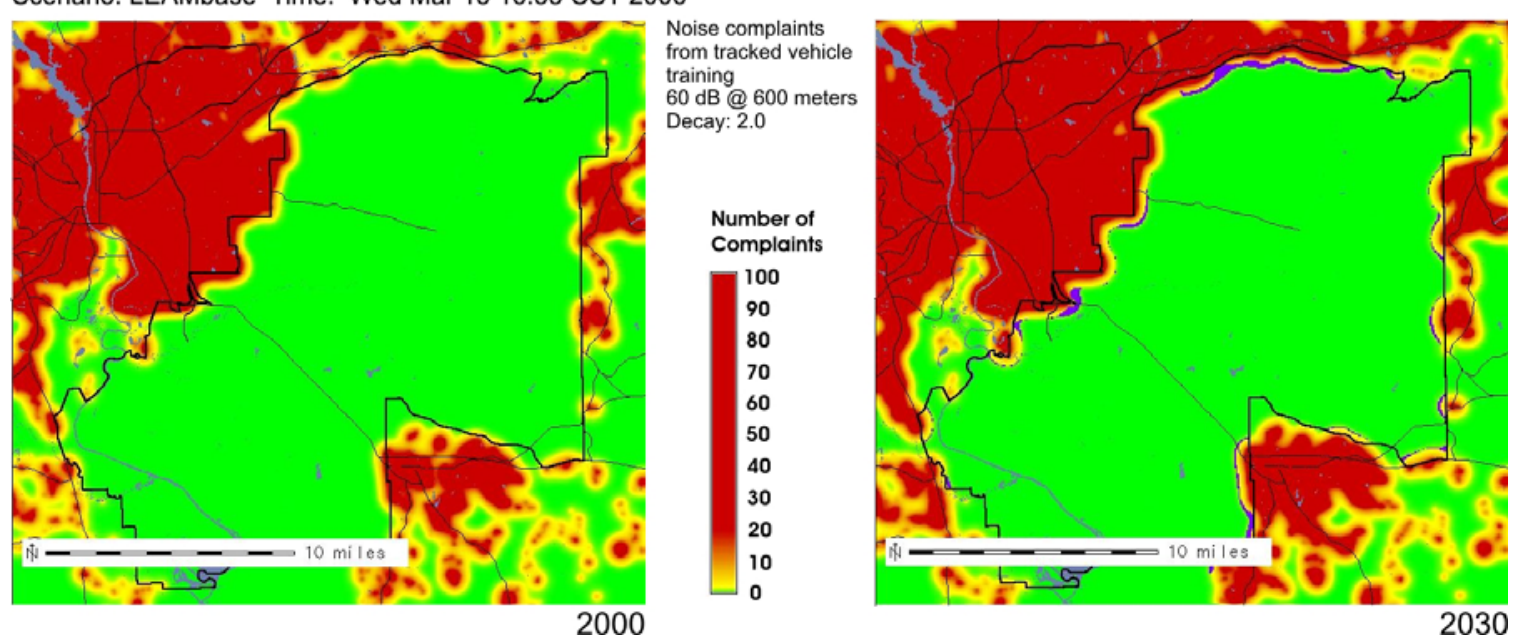

Figure 27. Potential complaints from tracked vehicle training

The training potential for the year 2000 was considered first, followed by the training potential associated with each urban projection in the year 2030 in response to each regional planning proposal. Note the small areas in purple shown in the maps on the right. These represent the real estate lost to training due to the increased probability that activities will result in civilian complaints when the 2030 map is compared to the current map.

The maps shown in Figure 27 were generated by LEAMtom and show the number of complaints from surrounding residential areas BEFORE and AFTER growth in response to a tracked vehicle training exercise generating noise measured as:60 dB@600 meters.

Figure 28 shows the complaint probability from surrounding residential areas BEFORE and AFTER growth, in response to a $\mathrm{C}-130$ at an altitude of 2000 meters generating noise measured as: $99 \mathrm{~dB} @ 92$ meters.

The maps in Figure 29 show the complaint probability from surrounding residential areas AFTER GROWTH in response to a Bell Jet Ranger helicopter at an altitude of 300 meters generating noise measured as: $100 \mathrm{~dB}$ @ 30 meters.

LEAMtom can predict the number of complaints from an Air Force F-22 Raptor flying at an altitude of 4572 meters (Figure 30). This aircraft can generate a noise measured as $114 \mathrm{~dB}$ at 152 meters. This is a significant amount of disturbance and even at this altitude, the land with a low probability of complaint shrinks accordingly by the time the simulation runs to completion. 
Scenario: LEAMbase Time: Wed Mar 15 17:11 CST 2006

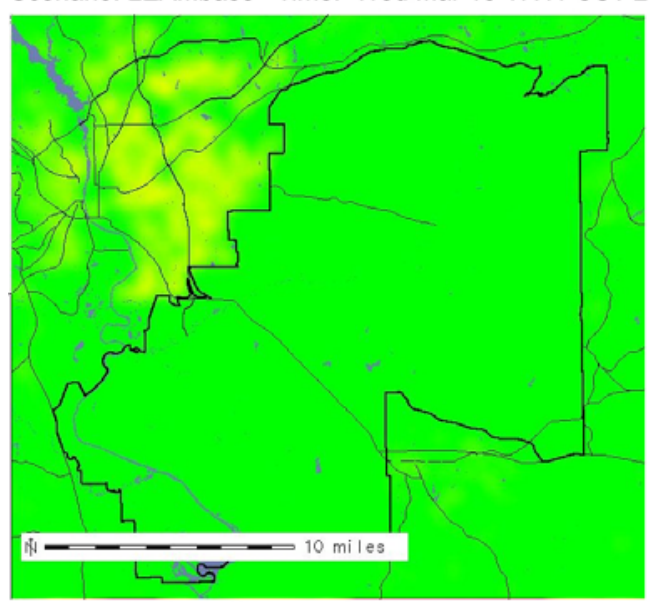

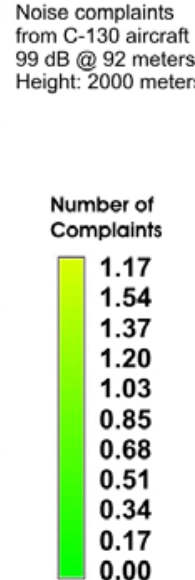

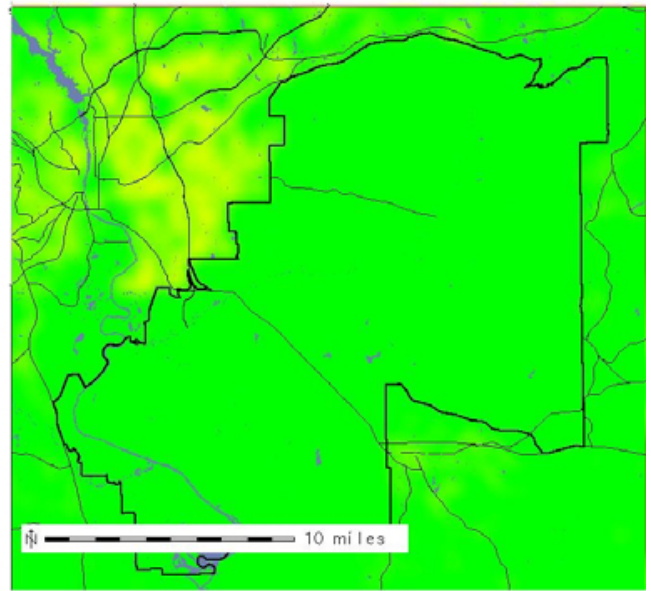

2030

Figure 28. Potential complaints from C-130 aircraft.

Scenario: LEAMbase Time: Wed Mar 15 17:11 CST 2006
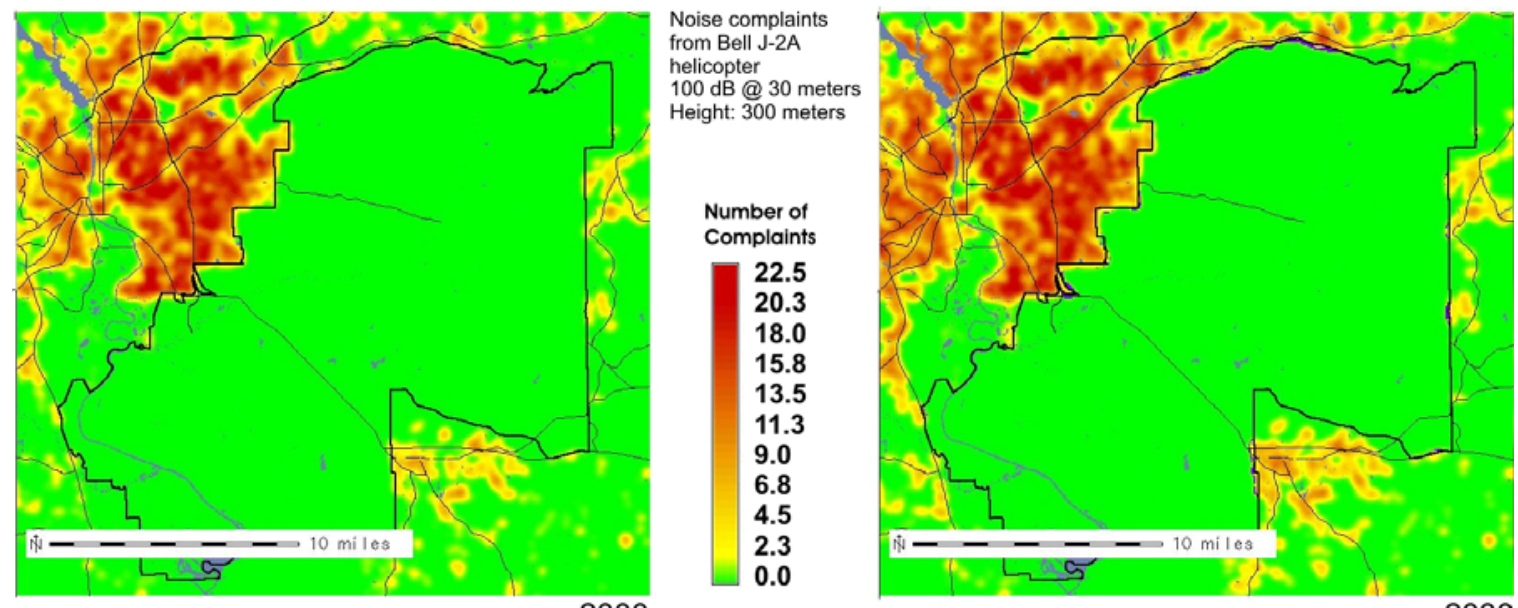

Figure 29. Potential complaints from a helicopter training exercise.

Scenario: LEAMbase Time: Wed Mar 15 17:11 CST 2006
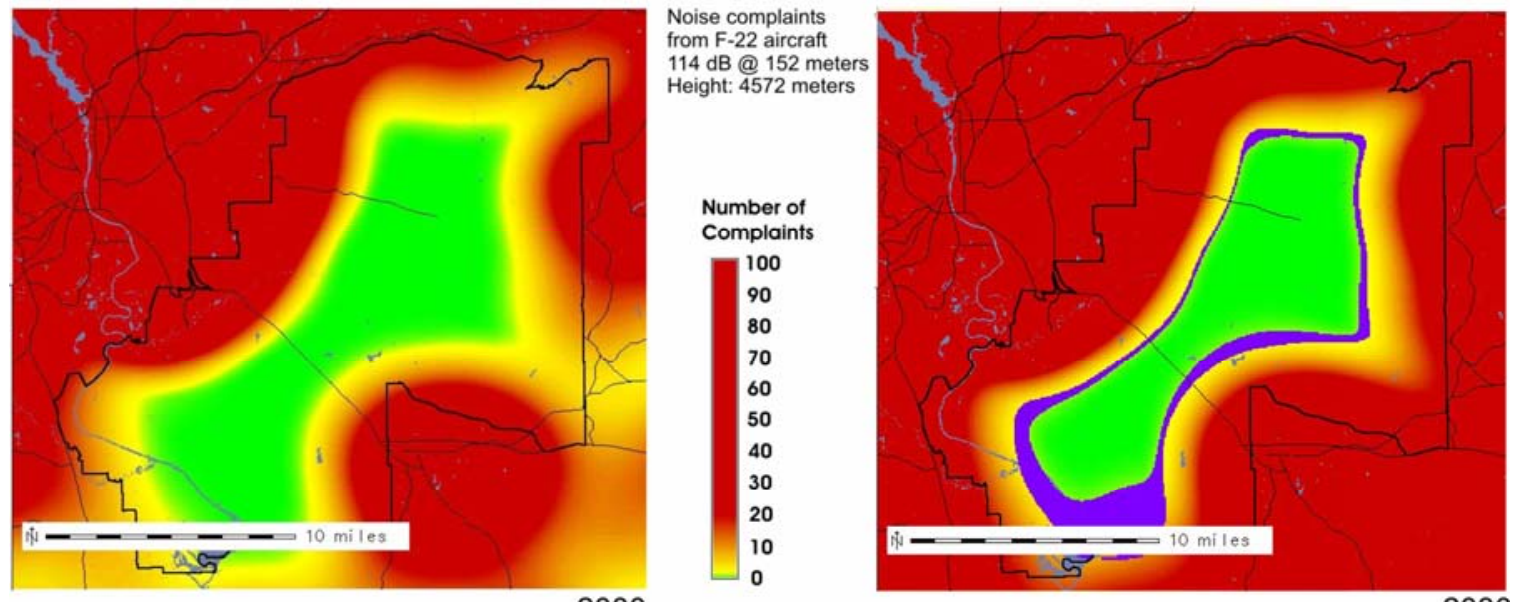

Figure 30. Potential noise complaints from an F-22 training above Fort Benning. 
In addition to complaints about noise, LEAMtom can also predict the number of complaints resulting from the dust generated by tracked vehicle training (Figure 31). Currently, dust is modeled at a release rate of 10 grams per second, and carried on the wind at 5 meters per second.

Where the first six LEAMtom analyses listed above examine the probability of civilian complaints due to the Army's effect on the community, the seventh looks at the effect the surrounding communities have on the Army and its capacity to conduct night training. The ability to own the nighttime battlefield with night vision goggles can be greatly compromised with the bright city lights associated with residential and commercial areas. The sky glow associated with these lights, high humidity, and low cloud decks can render large areas unsuitable for night training.

LEAMtom can predict where this is likely to be a problem by simulating the night sky glow associated with civilian light pollution (Figure 32). To generate artificial sky-glow maps, each residential and commercial location is allowed to brighten the sky at every other location in the area. Combining all of the sky-glow calculations at every location as a result of the surrounding urban areas yields a brightness index.

These maps show the relative potential for night training exercises BEFORE and AFTER growth in response residential lights reflecting off clouds along with high atmospheric humidity. Note the somewhat decreased areas of blackness in the map on the right (future training opportunities) vs. the map on the left (current training opportunities). It is within these areas of darkness that the military can effectively conduct nighttime training activities without interference from residential light pollution.

An examination of the group of maps in Figure 33 reveals the differences in probability of complaint against a tracked vehicle training exercise for all the simulated scenarios. The maps displayed below represent the last time step in each simulation, or what the region might look like in terms of the number of complaints in the year 2030. Note that visually, all the maps for this training event look identical at this resolution. It is only with a fine-scale analysis that differences can be detected between the images. For this reason, we chose not to include the final time step maps for the other training exercises here. The next section of this report summarizes a more in-depth analysis of these training exercises for each of the simulations performed. 
Scenario: LEAMbase Time: Wed Mar 15 17:11 CST 2006
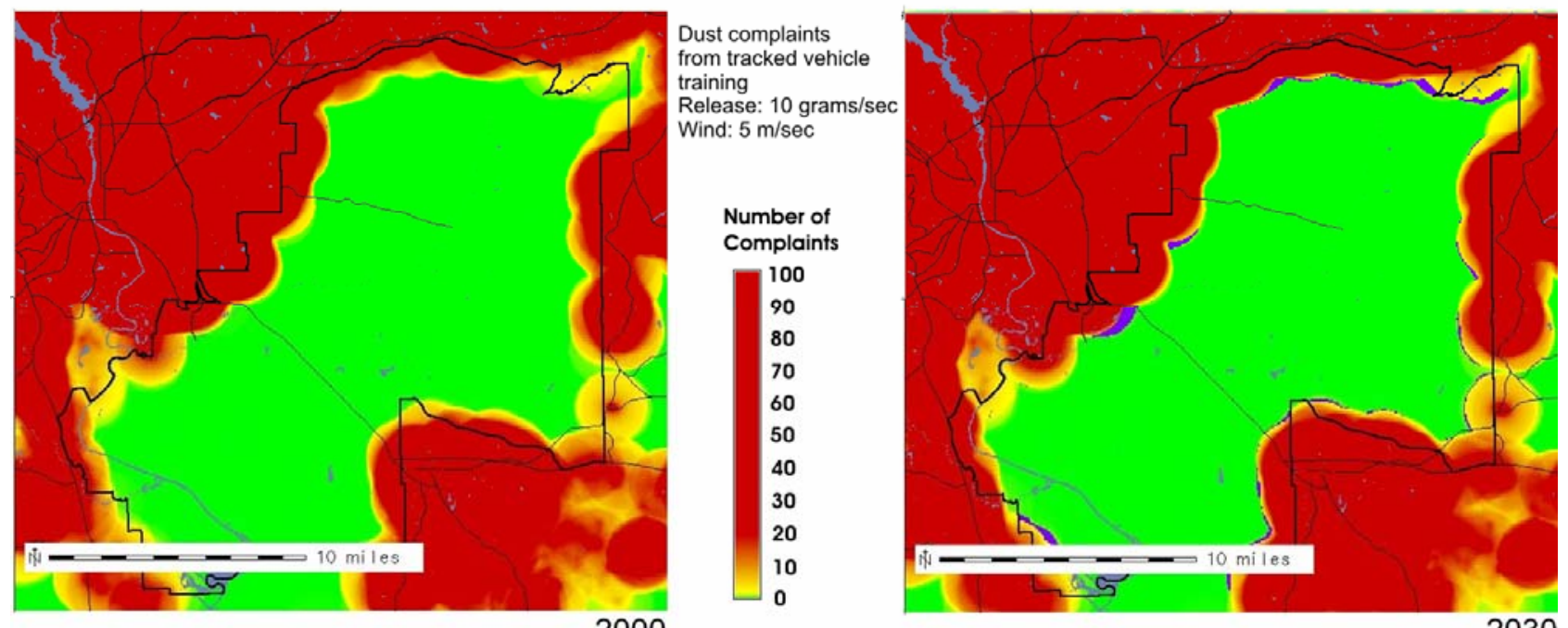

2000

Figure 31. Potential number of dust complaints from tracked vehicles.

Scenario: LEAMbase Time: Wed Mar 15 17:11 CST 2006
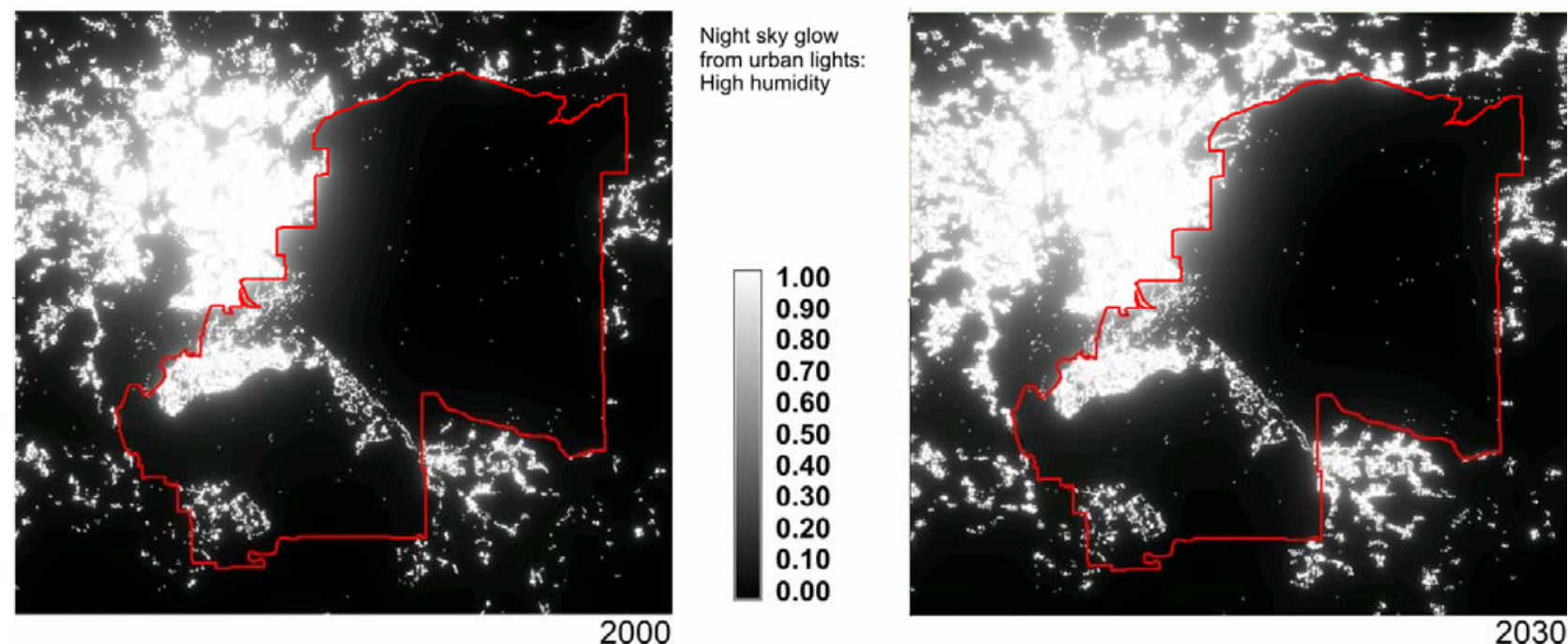

Figure 32. Night training opportunities; black cells are areas of low light pollution compatible with Army night vision goggle training.

\subsection{Analysis of the Scenarios}

An analysis of the maps resulting from each scenario was performed to see how future growth might affect Fort Benning. And while it is not possible to predict exactly those locations that will become urbanized, it is feasible to predict the locations most attractive to urbanization. Further, if we know how much land is expected to be urbanized by 2030, then we can expect that the LEAMluc model will forecast a similar degree of growth. The question then becomes, "How attractive is the land near Benning to development? And how will this attractiveness translate to training area loss due to land use conflicts?" 

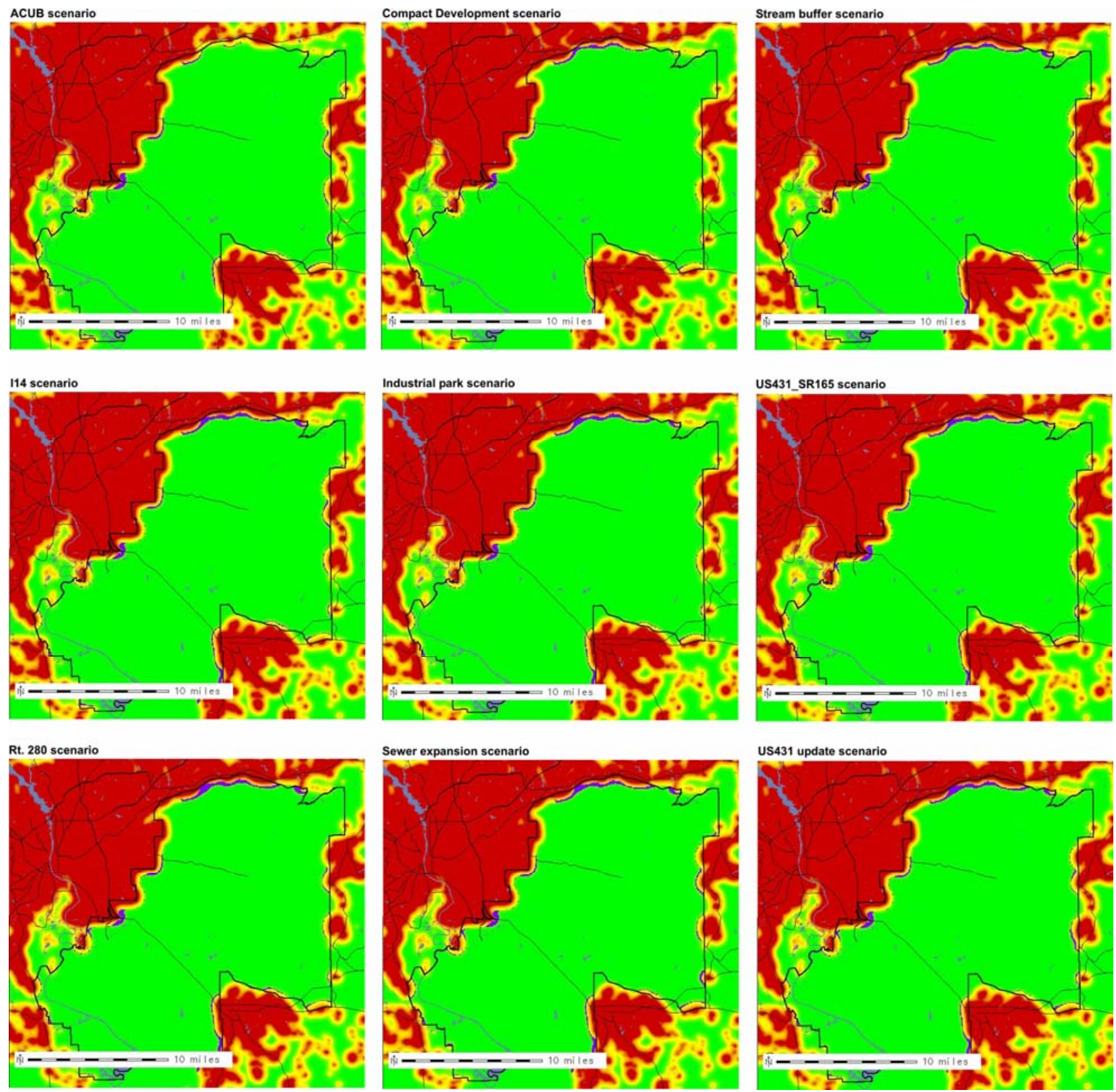

Figure 33. Comparison of 2030 maps for all modeled scenarios.

Table 2 lists the percent and number of hectares of the entire installation available for each training disturbance by scenario. Table 3 lists the potential loss of lands used for training within the boundaries of Fort Benning (in hectares and percent of potential land available) by training disturbance and land use scenario. 
Table 2. Analysis of training land available by training disturbance and scenario.

\begin{tabular}{|c|c|c|c|c|c|c|c|c|c|}
\hline & Scenario & ACUB & $\begin{array}{l}\text { I14_ } \\
\text { around }\end{array}$ & $\begin{array}{l}\text { I14_ } \\
\text { thru }\end{array}$ & $\begin{array}{l}\text { new_ } \\
\text { industry }\end{array}$ & $\begin{array}{c}\text { new_ } \\
\text { utilities }\end{array}$ & $\begin{array}{c}\text { Scenario } \\
\text { Base }\end{array}$ & US431 & $\begin{array}{r}\text { US431 } \\
\text { _SR165 }\end{array}$ \\
\hline $\begin{array}{c}\text { Training } \\
\text { Disturbance }\end{array}$ & $\begin{array}{c}\% \\
\text { Fort Benning } \\
\text { available } \\
(2000)\end{array}$ & \multicolumn{8}{|c|}{ Percent of entire installation available for training (2030) } \\
\hline 757_2000 & $99.9 \%$ & $99.8 \%$ & $99.8 \%$ & $99.8 \%$ & $99.7 \%$ & $99.8 \%$ & $99.8 \%$ & $99.8 \%$ & $99.8 \%$ \\
\hline Artillery Training & $58.4 \%$ & $52.3 \%$ & $48.3 \%$ & $48.7 \%$ & $48.2 \%$ & $48.4 \%$ & $48.7 \%$ & $48.7 \%$ & $48.8 \%$ \\
\hline Bell_J_2A & $99.3 \%$ & $98.8 \%$ & $98.8 \%$ & $98.8 \%$ & $98.6 \%$ & $98.7 \%$ & $98.7 \%$ & $98.7 \%$ & $98.7 \%$ \\
\hline C130_2000 & $100.0 \%$ & $100.0 \%$ & $100.0 \%$ & $100.0 \%$ & $100.0 \%$ & $100.0 \%$ & $100.0 \%$ & $100.0 \%$ & $100.0 \%$ \\
\hline F22_15000 & $34.2 \%$ & $27.7 \%$ & $25.0 \%$ & $25.4 \%$ & $24.8 \%$ & $24.7 \%$ & $25.3 \%$ & $25.3 \%$ & $25.4 \%$ \\
\hline $\begin{array}{l}\text { Tracked Vehicle } \\
\text { Dust }\end{array}$ & $76.1 \%$ & $71.4 \%$ & $67.4 \%$ & $67.6 \%$ & $67.5 \%$ & $67.5 \%$ & $67.6 \%$ & $67.7 \%$ & $67.7 \%$ \\
\hline $\begin{array}{l}\text { Tracked Vehicle } \\
\text { Training }\end{array}$ & $94.4 \%$ & $91.6 \%$ & $88.8 \%$ & $88.9 \%$ & $88.7 \%$ & $88.8 \%$ & $89.0 \%$ & $89.0 \%$ & $89.0 \%$ \\
\hline & Scenario & ACUB & $\begin{array}{l}114_{-} \\
\text {around }\end{array}$ & $\begin{array}{l}\text { I14_ } \\
\text { thru }\end{array}$ & $\begin{array}{l}\text { new_ } \\
\text { industry }\end{array}$ & $\begin{array}{l}\text { new }_{-} \\
\text {utilities }\end{array}$ & $\begin{array}{l}\text { Scenario } \\
\text { Base }\end{array}$ & US431 & $\begin{array}{l}\text { US431 } \\
\text { SR165 }\end{array}$ \\
\hline $\begin{array}{l}\text { Training } \\
\text { Disturbance }\end{array}$ & $\begin{array}{l}\text { Training land } \\
\text { available } \\
(2000)\end{array}$ & \multicolumn{8}{|c|}{ Number of hectares available for training (2030) } \\
\hline 757_2000 & 73,774 & 73,665 & 73,668 & 73,671 & 73,657 & 73,665 & 73,663 & 73,663 & 73,664 \\
\hline Artillery Training & 43,151 & 38,650 & 35,693 & 35,992 & 35,611 & 35,718 & 35,938 & 35,966 & 36,016 \\
\hline Bell_J_2A & 73,357 & 72,978 & 72,923 & 72,935 & 72,832 & 72,901 & 72,905 & 72,905 & 72,916 \\
\hline C130_2000 & 73,844 & 73,831 & 73,832 & 73,833 & 73,831 & 73,831 & 73,831 & 73,831 & 73,831 \\
\hline F22_15000 & 25,235 & 20,447 & 18,493 & 18,769 & 18,314 & 18,240 & 18,672 & 18,691 & 18,729 \\
\hline $\begin{array}{l}\text { Tracked } \\
\text { Vehicle Dust }\end{array}$ & 56,209 & 52,721 & 49,746 & 49,908 & 49,878 & 49,840 & 49,949 & 49,973 & 50,027 \\
\hline $\begin{array}{l}\text { Tracked } \\
\text { Vehicle Training }\end{array}$ & 69,715 & 67,641 & 65,563 & 65,671 & 65,527 & 65,597 & 65,699 & 65,722 & 65,758 \\
\hline
\end{tabular}


Table 3. Analysis of potential losses of training lands on Fort Benning by 2030.

\begin{tabular}{|l|l|l|l|l|l|l|l|l|l|l|}
\hline Scenario & \multicolumn{1}{|c|}{ ACUB } & $\begin{array}{c}\text { I14_ } \\
\text { around }\end{array}$ & I14_thru & $\begin{array}{c}\text { new_ } \\
\text { industry }\end{array}$ & $\begin{array}{c}\text { new_ } \\
\text { utilities }\end{array}$ & $\begin{array}{c}\text { Scenario } \\
\text { Base }\end{array}$ & HS431 & $\begin{array}{c}\text { US431_ } \\
\text { SR165 }\end{array}$ \\
\hline Training Disturbance & \multicolumn{7}{|c|}{ UStares lost to training by 2030 } \\
\hline $757 \_2000$ & 109.44 & 106.38 & 103.14 & 117 & 109.17 & 111.6 & 111.6 & 109.98 \\
\hline ArtilleryTraining & 4500.8 & 7458.57 & 7158.9 & 7540.38 & 7433.46 & 7213.14 & 7184.8 & 7135.38 \\
\hline Bell_J_2A & 379.62 & 434.7 & 422.46 & 525.78 & 456.03 & 452.7 & 452.7 & 441.9 \\
\hline C130_2000 & 12.96 & 12.51 & 11.61 & 13.23 & 12.87 & 13.05 & 13.41 & 13.05 \\
\hline F22_15000 & 4788.1 & 6741.81 & 6465.6 & 6920.82 & 6994.53 & 6562.8 & 6544.2 & 6506.1 \\
\hline $\begin{array}{l}\text { Tracked } \\
\text { Vehicle_Dust }\end{array}$ & 3487.3 & 6463.08 & 6300.3 & 6330.51 & 6368.58 & 6259.23 & 6235.7 & 6181.47 \\
\hline $\begin{array}{l}\text { Tracked } \\
\text { Vehicle_Training }\end{array}$ & 2074 & 4151.34 & 4044.1 & 4187.34 & 4117.77 & 4015.98 & 3992.5 & 3956.4 \\
\hline
\end{tabular}

\begin{tabular}{|c|c|c|c|c|c|c|c|c|}
\hline Scenario & ACUB & $\begin{array}{l}\text { I14_ } \\
\text { around }\end{array}$ & I14_thru & $\begin{array}{l}\text { new_ } \\
\text { industry }\end{array}$ & $\begin{array}{l}\text { new_ } \\
\text { utilities }\end{array}$ & $\begin{array}{l}\text { Scenario } \\
\text { Base }\end{array}$ & US431 & $\begin{array}{l}\text { US431_ } \\
\text { SR165 }\end{array}$ \\
\hline & \multicolumn{8}{|c|}{ Potential training area lost by 2030 (\%) } \\
\hline 757_2000 & $0.3 \%$ & $0.3 \%$ & $0.3 \%$ & $0.3 \%$ & $0.3 \%$ & $0.3 \%$ & $0.3 \%$ & $0.3 \%$ \\
\hline ArtilleryTraining & $6.2 \%$ & $10.2 \%$ & $9.8 \%$ & $10.3 \%$ & $10.2 \%$ & $9.9 \%$ & $9.8 \%$ & $9.8 \%$ \\
\hline Bell_J_2A & $0.5 \%$ & $0.6 \%$ & $0.6 \%$ & $0.7 \%$ & $0.6 \%$ & $0.6 \%$ & $0.6 \%$ & $0.6 \%$ \\
\hline C130_2000 & $0.1 \%$ & $0.1 \%$ & $0.1 \%$ & $0.1 \%$ & $0.1 \%$ & $0.1 \%$ & $0.1 \%$ & $0.1 \%$ \\
\hline F22_15000 & $9.1 \%$ & $12.8 \%$ & $12.3 \%$ & $13.1 \%$ & $13.3 \%$ & $12.4 \%$ & $12.4 \%$ & $12.3 \%$ \\
\hline $\begin{array}{l}\text { Tracked } \\
\text { Vehicle_Dust }\end{array}$ & $5.2 \%$ & $9.6 \%$ & $9.3 \%$ & $9.4 \%$ & $9.4 \%$ & $9.3 \%$ & $9.2 \%$ & $9.1 \%$ \\
\hline $\begin{array}{l}\text { Tracked } \\
\text { Vehicle_Training }\end{array}$ & $2.8 \%$ & $5.6 \%$ & $5.5 \%$ & $5.7 \%$ & $5.6 \%$ & $5.5 \%$ & $5.4 \%$ & $5.4 \%$ \\
\hline
\end{tabular}

From these figures we can determine that:

- For all training disturbances we modeled, urban growth near Fort Benning will negatively affect usable training land availability in the future.

- The most significant losses were for training with the new F-22 aircraft. Although this aircraft does not currently fly at Fort Benning, this is an example of the new technologies and future weapon systems that could potentially be deployed at this installation. This plane represents the cutting edge of defense technology, but its lethality comes at a price. The design of the F-22 causes high noise levels not associated with other aircraft in the U.S. inventory. This noise translates to potential complaints on the ground, even when the F-22 flies at an altitude of 15,000 meters. Model output suggests that the zone of low complaint 
probability within the installation boundary could shrink by as much as 13.3 percent by the year 2030 .

- The only scenario that showed significant differences from the others that were modeled was the ACUB scenario.

- The Base Scenario (where no additional inputs were supplied to the model) showed 2.7 percent greater loss of o-complaint artillery training area than the ACUB scenario in which large tracts of land adjacent to the installation perimeter were set aside as zones of no-growth.

- This trend was similar in the results all the other modeled training disturbances.

- The expansion of US431 scenario, the 431-165 connector scenario and the I14 through thru Benning scenario were all similar to the base scenario for tracked vehicle training, artillery training, and F-22 training.

- For all the scenarios tested, the potential training land for $\mathrm{C}-130$ and Bell J-2A helicopter was the least impacted.

The results of this analysis show that the trend of increased growth surrounding the Fort Benning Military Reservation will continue into the future, and that land directly beyond the installation boundary is at the greatest risk for urbanization.

\subsection{Discussion of Annoyance Tolerance Contours}

Where it is possible to know the past, current, or even future location of military training and testing, it is possible to apply existing analyses and models to predict the impact of that training on surrounding natural and developed areas. However, because of anticipated (but as of yet unknown) changes in training doctrine, weapon systems, and stationing of troops, it becomes impossible to predict the impact of future training. Instead, we have turned to predicting where training (on or off the installation) could occur so as to best mitigate potential conflicts before they arise. The simulations presented in this report, though not real, are realistic and showcase current abilities to understand, predict, and visualize the impact of urban growth on future training and testing opportunities.

Properly calibrated, this approach will be useful for predicting future training and testing area opportunities not only with respect to noise, but to dust, smoke, and light pollution as well. Calibration will be approached in two ways:

1. With respect to current knowledge of the physical transmission of noise, dust, smoke, and light, such analyses can provide insights into 
the strength of a training annoyance, and this information must be connected to the human psychology of annoyance. Continued research should involve looking at building tables of annoyance levels and decay rates based on the annoyance itself, the local attenuating factors (environmental and structural), and human psychology.

2. Calibration can be accomplished through interviews with people that have experienced the annoyances. Information gathered through interviews will help to correlate levels of annoyance with particular times of the day or year and establish useful working coefficients. This information would help refine these annoyance tolerance contours, making them more flexible and more useful to the trainers at Fort Benning.

\subsection{Internet Presentation of Results}

Scripts guiding the LEAMram, LEAMluc, and LEAMtom analyses automatically package results that are posted on a web site hosted at:

http://earth.cecer.army.mil/FF

Figure 34 shows the initial page. The table at the right lists currently available locations and titles of associated scenarios and dates the scenarios were run. Clicking on "scenarioBase" for "Benning" gives results like those shown in Figure 35. This page provides information about the analysis that was run, and provides links to images and movies that capture mLEAM outputs.

The images and movies may be accessed by clicking on the green dots associated with viewing areas (far left column) and results (top row). The LEAMram image results are available under the column entitled "Residential Attract" and "Residential Attract Differences." The second column lists the current scenario for comparison with the base scenario (which, in this particular case, is comparing the scenario with itself). An mpeg movie is available under "Residential Movie," which is captures results of the LEAMluc analysis. The rest of the columns are images that capture the LEAMtom results (presented in the previous section of this document).

Once the input maps are developed to capture the essence of an alternative scenario involving possible changes to the road/highway map or the nogrowth (zoning) map, the GIS technician can start the entire mLEAM analysis using a single script, which invokes from 1 to many hours of computer processing that results in the automatic posting of results through the described web interface. 


\begin{tabular}{|c|c|c|c|}
\hline \multirow{2}{*}{$\begin{array}{l}\text { To the right are working and preliminary results from testing the effect of alternative regional plans on the } \\
\text { opportunities for military training decades into the future. }\end{array}$} & Locations & Scenarios & Date Run \\
\hline & Atterbury & $\begin{array}{l}\text { scenarioBase } \\
\text { scenario } 2\end{array}$ & $\begin{array}{l}11 / 21 / 2005 \\
11 / 15 / 2005\end{array}$ \\
\hline \multirow{2}{*}{$\begin{array}{l}\text { All analyses are GIS based. The steps are as follows: } \\
\text { 1. Prepare from national (and optionally local) GIS data sources a set of raster maps } \\
\text { 2. Process these maps with LEAMram, the LEAM residential attractiveness model. This generates: } \\
\text { ○ Residential attractiveness map } \\
\text { ○ Inputs for the next step } \\
\text { 3. Process the results with LEAMluc, the LEAM land use change model. The results: } \\
\text { ○ Time-series maps (displayable as short movies) of urban development } \\
\text { - Inputs for the next step } \\
\text { 4. Process the LEAMluc results with LEAMtom, the LEAM training opportunities model to identify future } \\
\text { training and testing opportunities. }\end{array}$} & Belvoir & scenarioBase & $11 / 21 / 2005$ \\
\hline & Benning & \begin{tabular}{|l} 
scenarioBase \\
I14 around \\
I14 thru \\
US431 \\
US431 SR165 \\
new utilities \\
new industry \\
\end{tabular} & \begin{tabular}{|l}
$2 / 15 / 2006$ \\
$2 / 14 / 2006$ \\
$2 / 14 / 2006$ \\
$2 / 14 / 2006$ \\
$2 / 14 / 2006$ \\
$2 / 14 / 2006$ \\
$2 / 21 / 2006$ \\
\end{tabular} \\
\hline Locations are matched with user defined scenarios that involve modifying the inputs to capture such things as: & BenningLEAM & \begin{tabular}{|l|} 
scenarioBase \\
CompactDev \\
Il4 \\
IndPark \\
leamBase \\
RT280 \\
SewerExp \\
StreamBuf \\
US431 SR165 \\
US431 update \\
\end{tabular} & \begin{tabular}{|l|}
$3 / 15 / 2006$ \\
$3 / 15 / 2006$ \\
$3 / 15 / 2006$ \\
$3 / 15 / 2006$ \\
$3 / 15 / 2006$ \\
$3 / 15 / 2006$ \\
$3 / 15 / 2006$ \\
$3 / 15 / 2006$ \\
$3 / 15 / 2006$ \\
$3 / 15 / 2006$ \\
\end{tabular} \\
\hline \multirow{3}{*}{$\begin{array}{l}\text { LEAM is a modeling software suite and process developed by the Dept. of Urban and Regional Planning at the } \\
\text { University of Illinois Urbana-Champaign and the Construction Engineering Research Laboratory (CERL), part of the } \\
\text { Army Corps' Engineer Research and Development Center (ERDC). }\end{array}$} & Bliss & scenarioBase & $11 / 21 / 2005$ \\
\hline & Bragg & scenarioBase & $11 / 21 / 2005$ \\
\hline & Carson & scenarioBase & $11 / 21 / 2005$ \\
\hline \multirow{3}{*}{$\begin{array}{l}\text { LEAM development was funded by } \\
\text { funding. }\end{array}$} & Eglin & scenarioBase & $5 / 16 / 2006$ \\
\hline & Eustis & scenarioBase & $11 / 21 / 2005$ \\
\hline & Gordon & scenarioBase & $11 / 21 / 2005$ \\
\hline \multirow{2}{*}{$\begin{array}{l}\text { LEAM is part of the Sustainability, Encroachment, and Room to Maneuver (SERM) research program, which is part of } \\
\text { the Fort Future R\&D effort. }\end{array}$} & Jackson & scenarioBase & $11 / 21 / 2005$ \\
\hline & Knox & $\mid \frac{\text { scenarioBase }}{1 . . .-1 .}$ & $\|_{7 / 1 / \text { inne }}^{11 / 21 / 2005}$ \\
\hline
\end{tabular}

Figure 34. Introduction page to mLEAM results.

\section{BORT FURU1: है:}

Location: Benning

Scenario: scenarioBase

Date: Wed Feb 22 16:51:10 CST 2006

Operator: Jim Westervelt

Analysis of the impacts of proposed regional planning and projected population growth on future training and testing opportunities.

Based on the MLEAM simulation modeling and analysis tools, part of Fort Future.

\section{Urban Growth Analysis Model Results}

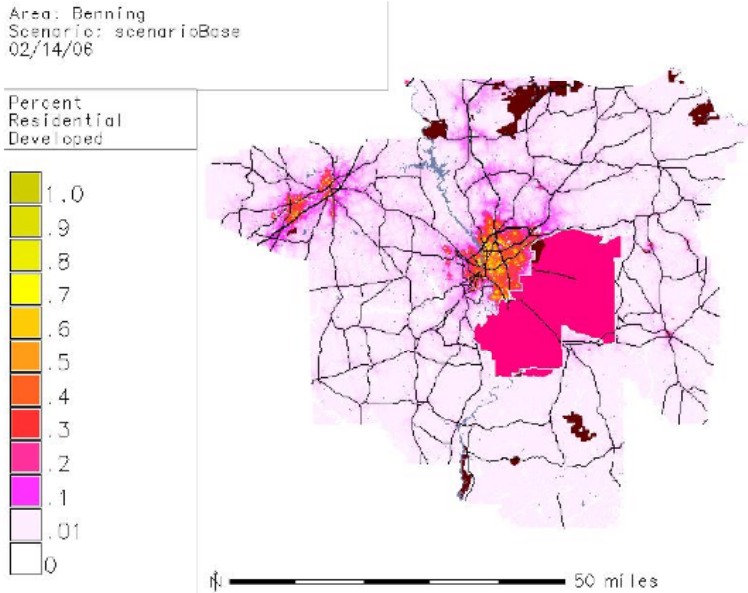

Available Results (click on the $\mathrm{for}$ images)

\begin{tabular}{|c|c|c|c|c|c|c|c|c|c|c|c|c|c|}
\hline Area & $\begin{array}{c}\text { Residential } \\
\text { Attract }\end{array}$ & \begin{tabular}{|c|} 
Residential \\
Attract \\
Difference
\end{tabular} & $\begin{array}{c}\text { Residential } \\
\text { Movie }\end{array}$ & Time & \begin{tabular}{|c|} 
Tracked \\
Vehicle \\
Training \\
Dust \\
\end{tabular} & \begin{tabular}{|c|} 
Tracked \\
Vehicle \\
Training \\
Noise \\
\end{tabular} & \begin{tabular}{|c|} 
Artillery \\
Training \\
Noise
\end{tabular} & \begin{tabular}{|c|} 
C-130 \\
Aircraft \\
Noise \\
\end{tabular} & \begin{tabular}{|c|} 
F-22 \\
Aircraft \\
Noise
\end{tabular} & \begin{tabular}{|c|} 
Bell J-2A \\
Helicopter \\
Noise
\end{tabular} & \begin{tabular}{|c|} 
Boeing \\
757 \\
Noise
\end{tabular} & \begin{tabular}{|c|} 
Night \\
Light - \\
High \\
Humidity
\end{tabular} & \begin{tabular}{|c|} 
Night \\
Light - \\
Low \\
Humidity
\end{tabular} \\
\hline Benning & & & & Now & 0 & 0 & 0 & $C$ & 0 & & & & 3 \\
\hline & & & & Future & & & 0 & 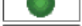 & & & & & \\
\hline East & & & & \begin{tabular}{|l|} 
Now \\
\end{tabular} & 0 & 0 & 0 & 0 & 0 & 0 & 0 & $\bar{C}$ & 0 \\
\hline
\end{tabular}

Figure 35. Benning "scenarioBase" results. 
The analysis process also generates a large set of temporary maps that can be useful for further analysis. Table 4 contains a partial list of these maps.

Table 4. Temporary maps that can be useful for further analysis.

\begin{tabular}{|c|c|}
\hline Name & Description \\
\hline \multicolumn{2}{|l|}{ LEAMram input maps } \\
\hline boundary & Study area boundary \\
\hline dem & Digital elevation model (elevation) \\
\hline interstates & Limited access highways \\
\hline landcover & National Land Cover Data \\
\hline noGrowth & Areas where no residential growth is possible \\
\hline otherroads & All roads other than limited access highways \\
\hline \multicolumn{2}{|l|}{ LEAMram output maps } \\
\hline cities_att & Attractiveness of each cell to the nearest cities \\
\hline cities_prob & Probability of residential based on cities_att \\
\hline cross & Locations of road crossover from otherroads to interstates \\
\hline developable & Areas that can potentially develop to residential \\
\hline forest_att & Attractiveness of each cell to forested areas \\
\hline forest_prob & Probability of residential based on forest_att \\
\hline hwyBuff & Buffer of non-development around limited access highways \\
\hline intersect_att & Attractiveness of each cell based on distance to intersections \\
\hline intersection & Location of major intersections \\
\hline intersect_prob & Probability of residential based on intersect_att \\
\hline intersectTimeRoad & Driving time to nearest intersection \\
\hline intTravelSpeed30 & Travel speed for interstates at 30-meter resolution \\
\hline intTravelTime30 & Travel time for interstates at 30-meter resolution \\
\hline landTravelSpeed30 & Travel time off-road at 30-meter resolution \\
\hline largeCity & Location of large cities \\
\hline largeCityTime & Driving time to nearest large city \\
\hline largeCityTimeRoad & Driving time to nearest large city across roads \\
\hline mediumCity & Location of medium cities \\
\hline mediumCityTime & Driving time to nearest medium city \\
\hline mediumCityTimeRoad & Driving time to nearest medium city across roads \\
\hline neighbor_att & Attractiveness based on proximity to neighbors \\
\hline neighbor_prob & Probability of residential based on neighbor_att \\
\hline othTraveISpeed30 & Travel speed for otherroads at 30-meter resolution \\
\hline othTravelTime30 & Travel time for otherroads at 30-meter resolution \\
\hline overlandTravelSpeed90 & Overland travel speeds at 90-meter resolution \\
\hline overlandTravelTime90 & Overland travel times at 90-meter resolution \\
\hline ramp_att & Attractiveness based on proximity to interstates \\
\hline ramp_prob & Probability of residential based on ramp_att \\
\hline rampTimeRoad & Driving time to ramps across roads \\
\hline residential_att & Combined attractiveness of other *_att maps \\
\hline residential_prob & $\begin{array}{l}\text { Probability of currently being developed } \\
\text { Primary input map to LEAMluc }\end{array}$ \\
\hline
\end{tabular}




\begin{tabular}{|c|c|}
\hline Name & Description \\
\hline road_att & Attractiveness based on proximity to interstates \\
\hline road_prob & Probability of residential based on ramp_att \\
\hline slope_att & Attractiveness based on slope \\
\hline slope_prob & Probability of residential based on slope_att \\
\hline smallCity & Location of small cities \\
\hline smallCityTime & Driving time to nearest small city \\
\hline smallCityTimeRoad & Driving time to nearest small city across roads \\
\hline staterd_att & Attractiveness based on proximity to state roads \\
\hline staterd_prob & Probability of residential based on staterd_att \\
\hline stateTimeRoad & Driving time to stateroads across roads \\
\hline water_att & Attractiveness based on proximity to water \\
\hline water_prob & Probability of residential based on water_att \\
\hline xLargeCity & Location of largest cities \\
\hline xLargeCityTime & Driving time to nearest largest city \\
\hline xLargeCityTimeRoad & Driving time to nearest largest city across roads \\
\hline \multicolumn{2}{|l|}{ LEAMluc output maps } \\
\hline change & Map identifying the step at which each cell changed \\
\hline summary & Final new residential development map \\
\hline \multicolumn{2}{|c|}{ LEAMtom complaint probability result maps } \\
\hline 757_2000_begin & \multirow{2}{*}{$\begin{array}{l}\text { Probability of complaint from a } 757 \text { jet aircraft at } 2000 \text { meters before } \\
\text { and after new residential development. }\end{array}$} \\
\hline 757_2000_end & \\
\hline ArtilleryTraining_begin & \multirow{2}{*}{$\begin{array}{l}\text { Probability of complaint from artillery training before and after new } \\
\text { residential development. }\end{array}$} \\
\hline ArtilleryTraining_end & \\
\hline Bell_J_2A_begin & \multirow{2}{*}{$\begin{array}{l}\text { Probability of complaint from a helicopter before and after new resi- } \\
\text { dential development. }\end{array}$} \\
\hline Bell_J_2A_end & \\
\hline C130_2000_begin & \multirow{2}{*}{$\begin{array}{l}\text { Probability of complaint from a C130 jet aircraft at } 2000 \text { meters before } \\
\text { and after new residential development. }\end{array}$} \\
\hline C130_2000_end & \\
\hline F22_15000_begin & \multirow{2}{*}{$\begin{array}{l}\text { Probability of complaint from a F22 jet aircraft at } 15,000 \text { meters be- } \\
\text { fore and after new residential development. }\end{array}$} \\
\hline F22_15000_end & \\
\hline NightLightHigh_begin & \multirow{4}{*}{$\begin{array}{l}\text { Relative light from cities before and after new residential development } \\
\text { for low and high humidity levels }\end{array}$} \\
\hline NightLightHigh_end & \\
\hline NightLightLow_begin & \\
\hline NightLightLow_end & \\
\hline TrackedVehicleDust_begin & \multirow{2}{*}{$\begin{array}{l}\text { Probability of complaint from dust generated by tracked vehicles be- } \\
\text { fore and after new residential development. }\end{array}$} \\
\hline TrackedVehicleDust_end & \\
\hline TrackedVehicleTraining_begin & \multirow{2}{*}{$\begin{array}{l}\text { Probability of noise complaint from tracked vehicle training before and } \\
\text { after new residential development. }\end{array}$} \\
\hline TrackedVehicleTraining_end & \\
\hline
\end{tabular}




\section{Conclusions and Recommendations}

\subsection{Conclusions}

This work has developed a tool to quickly and cost-effectively define the present state of development surrounding Fort Benning. Simple GIS map layers were used in an analysis of land use and urban growth in the region. These GIS layers then formed the input to the LEAMtom model to predict annoyance contours around Fort Benning into the future.

Current land use maps, present and future highway system plans, and municipal zoning information all contributed to forecast residential and commercial development, and to identify areas within the installation boundary with a potential to receive an increased number complaints about military training activities at a given future point in time.

This tool can help provide Army installations with options to proactively mitigate conflicts between the Army and the growing civilian community surrounding this installation.

\subsection{Recommendations}

It is recommended that additional work be done to refine the annoyance tolerance contours for Fort Benning. Properly calibrated, this approach will be useful for predicting future training and testing area opportunities not only with respect to noise, but to dust, smoke, and light pollution. Continued research should build tables of annoyance levels and decay rates based on each annoyance, local attenuating factors (environmental and structural), and human psychology. This work may be accomplished through personal interviews with people that have experienced the annoyances to correlate levels of annoyance with particular times of the day or year. 


\section{References}

Court, A. T. (1939). "Hedonic Price Indexes with Automotive Examples.” The Dynamics of Automobile Demand. New York: General Motors Corporation, pp 99-117.

Cowardin, L. M., V. Carter, F. C. Golet, and E. T. LaRoe. (1979). Classification of Wetlands and Deepwater Habitats of the United States. Washington, DC: U.S. Department of the Interior, Fish and Wildlife Service.

Deal, B., and Z. Sun. (2005). "A Spatially Explicit Urban Simulation Model: The Land-use Evolution and impact Assessment Model (LEAM).” Regional Development, Infrastructure, and Adaptation to Climate Variability and Change. M. Ruth (ed.), New York: Springer.

Deal, Brian M., Donald F. Fournier, Diane M. Timlin, and Elisabeth M. Jenicek. (October 2002). ERDC/CERL TR-02-27/ADA409139, An Assessment of Encroachment Mitigation Techniques for Army Lands. Champaign, IL: Engineer Research and Development Center, Construction Engineering Research Laboratory (ERDCCERL).

Haas, C. G. (1922). Sale Prices as a Basis for Farm Land Appraisal. Technical Bulletin 9. St. Paul, MN: University of Minnesota.

Hosmer, D. W., and S. Lemeshow. (1989). Applied Logistic Regression. New York, NY: Wiley.

Kelly, P. M., and J. M. White. (1993). "Preprocessing Remotely Sensed Data for Efficient Analysis and Classification." Applications of Artificial Intelligence 1993: Knowledge-Based Systems in Aerospace and Industry. Proceedings of SPIE. vol 1993, pp 24-30.

Goran, W. D. (January 1989). “Testing Guidelines for GRASS Ports and Drivers.” Automatic Data Processing (ADP) Report N-89/22/ADA221176. Testing Guidelines for GRASS Ports and Drivers. Champaign, IL: Construction Engineering Research Laboratory (CERL).

Little, Violet I., LLP, and David L. Effland. (1981). "BNOISE 3.2 Computer Program Description and Program Listing.” Blast Noise Prediction: Volume II. p 256.

Lozar, R, William D. Meyer, Joel D. Schlagel, Robert H. Melton, Bruce A. MacAllister, Joseph S. Rank, Daniel P. MacDonald, Paul T. Cedfeldt, and Patricia M. Kirby. (April 2005). Characterizing Land Use Change Trends Around the Perimeter of Military Installations. Champaign, IL: Engineer Research and Development Center (ERDC) TR-05-4.

Pater, L. W., Pamela Woof, Diane Rhoads, and Michael White. (May 1999). Getting Started Guide for the Small Arms Range Noise Assessment Model (SARNAM). CERL ADP Report 99/48/ADA364860. Champaign, IL: Construction Engineering Research Laboratory (CERL). 
Saaty, Rozann. (1996). "The Analytic Hierarchy Process and Utility Theory: Ratio Scales and Interval Scales." Proceedings of the Fourth International Symposium on the Analytic Hierarchy Process. Burnaby, BC, Canada: Simon Frasier University. July 12-15, pp 22-27.

Schkade, D., and J. Payne. (1993). "Where Do the Numbers Come from? How People Respond to Contingent Valuation Questions." Contingent Valuation: A Critical Assessment (J. Hausman, ed.). Amsterdam, Holland.

Sirmans, G. Stacy, David A. Macpherson, and Emily N. Zietz. (2005). "Composition of Hedonic Pricing Models.” J ournal of Real Estate Literature. Vol 13, No. 1, pp 3-43.

Timlin, Diane M., Douglas M. Johnston, and Brian M. Deal. (January 2002). ERDC/CERL TR-02-4/ADA408249. Guidelines for Developing Historic Urban Growth Series for Military Installation Risk Assessment. Champaign, IL: CERL.

U.S. Environmental Protection Agency (USEPA). (September 2000). EPA/60o/Roo/o98, Projecting Land-Use Change: A Summary of Models for Assessing the Effects of Community Growth and Change on Land-Use Patterns. Cincinnati, OH: USEPA Office of Research and Development, National Exposure Research Laboratory. p 260.

Vogelmann, J. E., T. Sohl, and S. M. Howard. (1998a). "Regional Characterization of Land Cover Using Multiple Sources of Data.” Photogrammetric Engineering \& Remote Sensing. Vol 64, No. 1, pp. 45-47.

Vogelmann, J. E., Sohl, T., Campbell, P. V., and Shaw, D. M. (1998b). "Regional Land Cover Characterization Using Landsat Thematic Mapper Data and Ancillary Data Sources." Environmental Monitoring and Assessment. Vol 51, pp 415-428.

Wallace, H. A. (October 1926). "Comparative Farmland Values in Iowa.” J ournal of Land and Public Utility Economics. No. 2, pp 385-92.

Westervelt James D., and Bruce A. MacAllister. (2006). ERDC/CERL TR-o6-DRAFT. LEAM Rapid Analysis of the Attractiveness of Land to Residential Developers." Champaign, IL: CERL.

Westervelt James D., and Joseph Rank. (2006). ERDC/CERL TR-o6-DRAFT. LEAMram $^{\mathrm{TM}}$ : Land use Evolution and impact Assessment Model. Champaign, IL: CERL. 


\section{Acronyms and Abbreviations}

\begin{tabular}{|c|c|}
\hline$\underline{\text { Term }}$ & Spellout \\
\hline ACUB & Army Compatible Use Buffer \\
\hline ADP & automatic data processing \\
\hline ANSI & American National Standards Institute \\
\hline BLM & Bureau of Land Management \\
\hline CERL & Construction Engineering Research Laboratory \\
\hline DBOS & Directorate of Base Operation Support \\
\hline EPA & Environmental Protection Agency \\
\hline ERDC & Engineer Research and Development Center \\
\hline ERDC-CERL & $\begin{array}{l}\text { Engineer Research and Development Center, Construction Engineering Research } \\
\text { Laboratory }\end{array}$ \\
\hline ES & Electrical System \\
\hline ESRI & Environmental Systems Research Institute, Inc. \\
\hline ESTCP & Environmental Security Technology Certification Program \\
\hline GIS & geographic information system \\
\hline GRASS & Geographic Resources Analysis Support System \\
\hline LEAM & Landuse Evolution Assessment Model \\
\hline MRLC & Multi-Resolution Land Characteristics Consortium \\
\hline NALC & North American Landscape Characterization (NALC) \\
\hline NASA & National Aeronautics and Space Administration \\
\hline NLCD & National Land Use Data \\
\hline NOAA & National Oceanic and Atmospheric Administration \\
\hline NSN & National Supply Number \\
\hline OMB & Office of Management and Budget \\
\hline $\mathrm{RF}$ & Radio Frequency \\
\hline SERDP & Strategic Environmental Research and Development Program \\
\hline $\mathrm{SI}$ & Systeme Internationale \\
\hline SPIE & Security Professionals Information Exchange \\
\hline TM & Thermal Mapper \\
\hline TR & Technical Report \\
\hline URL & Universal Resource Locator \\
\hline USEPA & U.S. Environmental Protection Agency \\
\hline USFS & U.S. Forestry Service \\
\hline USGS & U.S. Geological Survey \\
\hline WWW & World Wide Web \\
\hline
\end{tabular}




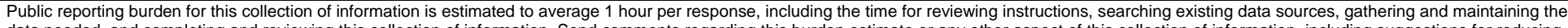

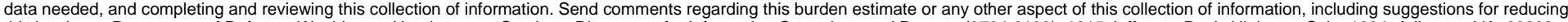

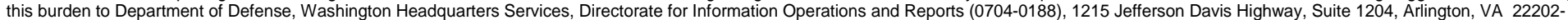

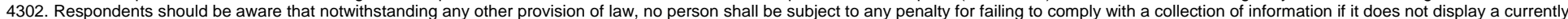
valid OMB control number. PLEASE DO NOT RETURN YOUR FORM TO THE ABOVE ADDRESS.
1. REPORT DATE (DD-MM-YYYY)
2. REPORT TYPE
3. DATES COVERED (From - To)

30-09-2006 Final

4. TITLE AND SUBTITLE

Quick Prediction of Future Training/Testing Opportunities Using mLEAM

5a. CONTRACT NUMBER

5b. GRANT NUMBER

5c. PROGRAM ELEMENT NUMBER

\section{AUTHOR(S)}

James Westervelt and Bruce MacAllister

\section{5d. PROJECT NUMBER}

SERDP

5e. TASK NUMBER

SI-1257

5f. WORK UNIT NUMBER

\section{PERFORMING ORGANIZATION NAME(S) AND ADDRESS(ES)}

U.S. Army Engineer Research and Development Center (ERDC)

Construction Engineering Research Laboratory (CERL)

8. PERFORMING ORGANIZATION REPORT NUMBER

PO Box 9005,

ERDC/CERL TR-06-27

Champaign, IL 61826-9005

\section{SPONSORING I MONITORING AGENCY NAME(S) AND ADDRESS(ES)}

Program Manager, Sustainable SERDP \& ESTCP

10. SPONSOR/MONITOR'S ACRONYM(S)

901 North Stuart Street

SERDP

Suite 303

Arlington, VA 22203

11. SPONSOR/MONITOR'S REPORT NUMBER(S)

\section{DISTRIBUTION I AVAILABILITY STATEMENT}

Approved for public release; distribution is unlimited.

\section{SUPPLEMENTARY NOTES}

\section{ABSTRACT}

Urban development around many installations threatens the ability to provide realistic military training to the soldiers of the U.S. Army and adequate testing for future weapon systems. Regional planning can alter the patterns of future development around installations. The Engineer Research and Development Center, Construction Engineering Research Laboratory (ERDC-CERL) has developed the military Landuse Evolution Assessment Model (mLEAM) suite of software tools to allow for the rapid and inexpensive testing of the impact of alternative regional plans on the future training and testing opportunities of nearby installations. This report describes the mLEAM approach and documents the application of mLEAM to the counties surrounding Fort Benning, GA to provide Fort Benning with options to proactively mitigate conflicts between the Army and the growing civilian community surrounding the installation.

\begin{tabular}{llll}
\hline $\begin{array}{l}\text { 15. SUBJECT TERMS } \\
\text { mLEAM } \\
\text { simulation modeling }\end{array}$ & $\begin{array}{l}\text { SERDP } \\
\text { Ft. Benning, GA }\end{array}$ & $\begin{array}{l}\text { encroachment } \\
\text { landuse planning }\end{array}$ & $\begin{array}{l}\text { training lands } \\
\text { urbanization }\end{array}$ \\
\hline
\end{tabular}

\begin{tabular}{|l|l|c|c|c|c}
\hline \multicolumn{2}{|l|}{ 16. SECURITY CLASSIFICATION OF: } & $\begin{array}{c}\text { 17. LIMITATION } \\
\text { OF ABSTRACT }\end{array}$ & $\begin{array}{c}\text { 18. NUMBER } \\
\text { OF PAGES }\end{array}$ & SAR \\
\cline { 1 - 2 } $\begin{array}{c}\text { a. REPORT } \\
\text { Unclassified }\end{array}$ & $\begin{array}{c}\text { b. ABSTRACT } \\
\text { Unclassified }\end{array}$ & $\begin{array}{c}\text { c. THIS PAGE } \\
\text { Unclassified }\end{array}$ & SAR & 68 & \\
\hline
\end{tabular}

